\title{
PLASMODIUM PURINE METABOLISM AND ITS INHIBITION BY NUCLEOSIDE AND NUCLEOTIDE ANALOGUES
}

\author{
Thomas Cheviet, ${ }^{1}$ Isabelle Lefebvre-Tournier, ${ }^{1}$ Sharon Wein, ${ }^{2}$ Suzanne Peyrottes ${ }^{1 *}$ \\ ${ }^{1}$ Institut des Biomolécules Max Mousseron (IBMM), UMR 5247 UM-CNRS-ENSCM, Univ. Montpellier, \\ Equipe Nucléosides \& Effecteurs Phosphorylés, Place E. Bataillon, cc 1704, 34095 Montpellier, France \\ ${ }^{2}$ Dynamique des Interactions Membranaires Normales et Pathologiques (DIMNP), UMR 5235 UM- \\ CNRS, Univ. Montpellier, Place E. Bataillon, 34095 Montpellier, France
}

\begin{abstract}
Malaria still affects around 200 million people and is responsible for more than 400,000 deaths per year, mostly children in subequatorial areas. This disease is caused by parasites of the Plasmodium genus. Only a few WHO-recommended treatments are available to prevent or cure plasmodial infections, but genetic mutations in the causal parasites have led to onset of resistance against all commercial antimalarial drugs. New drugs and targets are being investigated to cope with this emerging problem, including enzymes belonging to the main metabolic pathways, while nucleoside and nucleotide analogues are also a promising class of potential drugs. This review highlights the main metabolic pathways targeted for the development of potential antiplasmodial therapies based on nucleos(t)ide analogues, as well as the different series of purine-containing nucleoside and nucleotide derivatives designed to inhibit Plasmodium falciparum purine metabolism.
\end{abstract}




\section{INTRODUCTION}

WHO, in 2018, reported more than 435,000 deaths associated with malaria, and at least 219 million people — mostly children — are still affected by this disease in 91 countries located in Africa and Asia. ${ }^{1}$ The disease, which represents an endemic in tropical areas, is caused by protozoal parasites of the Plasmodium genus in the Apicomplexa phylum. Among the six human Plasmodium species (P. falciparum, P. vivax, $P$. malariae, P. ovale curtisi, P. ovale wallikeri ${ }^{2,3}$ and P. knowlesi originally known to cause simian malaria), P. falciparum is the most widespread and lethal. The parasite is transmitted to humans by female mosquitos of the Anopheles genus (Figure 1). Plasmodium begins its development cycle in humans by multiplication in hepatocytes. After 10-12 days, the parasites are released in the blood and invade the erythrocytes (asexual multiplication). This intraerythrocytic phase constitutes the symptomatic phase of the disease, with massive destruction of erythrocytes and sometimes adherence to blood vessels of large organs like the brain, thus restricting the blood flow with serious consequences. A small proportion of the blood stages develop into sexual forms (so-called gametocytes) that are ingested by a feeding mosquito, therefore completing the cycle. Parasites of the $P$. vivax and $P$. ovale species can persist for years as dormant stages in the liver (so-called hypnozoites) and can cause relapses. 


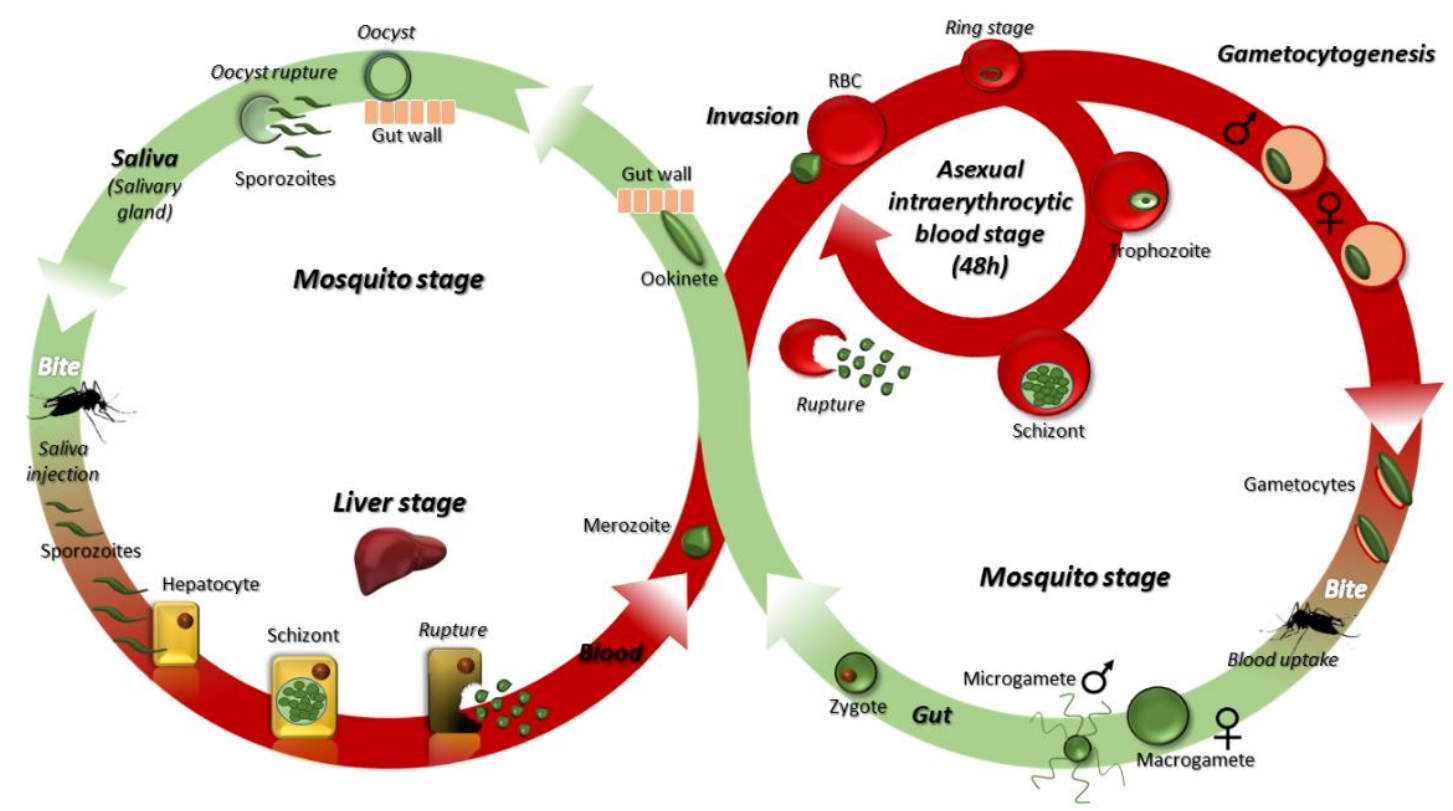

Figure 1 : Plasmodium falciparum life-cycle

Since the historical use of quinine 400 years ago, particularly as of the late $19^{\text {th }}$ century, several treatments of synthetic or natural origins have been developed (Figure 2) and have been successfully used to cure malarial diseases in infected human hosts. The various classes of antimalarial drugs belong to a few families according to their chemical structures, such as: aryl amino alcohols (quinine, mefloquine, halofantrine, etc.); 4-aminoquinolines (chloroquine, amodiaquine, piperaquine, etc.); 8-aminoquinolines (primaquine, tafenoquine), antifolates (proguanyl, pyrimethamine, sulfadoxine, dapsone, etc.); naphthoquinones (atovaquone); peroxides and sesquiterpene derivatives (artemisinin, artesunate, artemether, etc.); antimicrobials (tetracycline, azithromycin, fluoroquinolones, etc.). In addition to chemotherapy, an efficient vaccine would be a desirable tool to control and eventually eradicate malaria, but such a vaccine has yet to be validated despite clinical assays. ${ }^{4,5}$ 


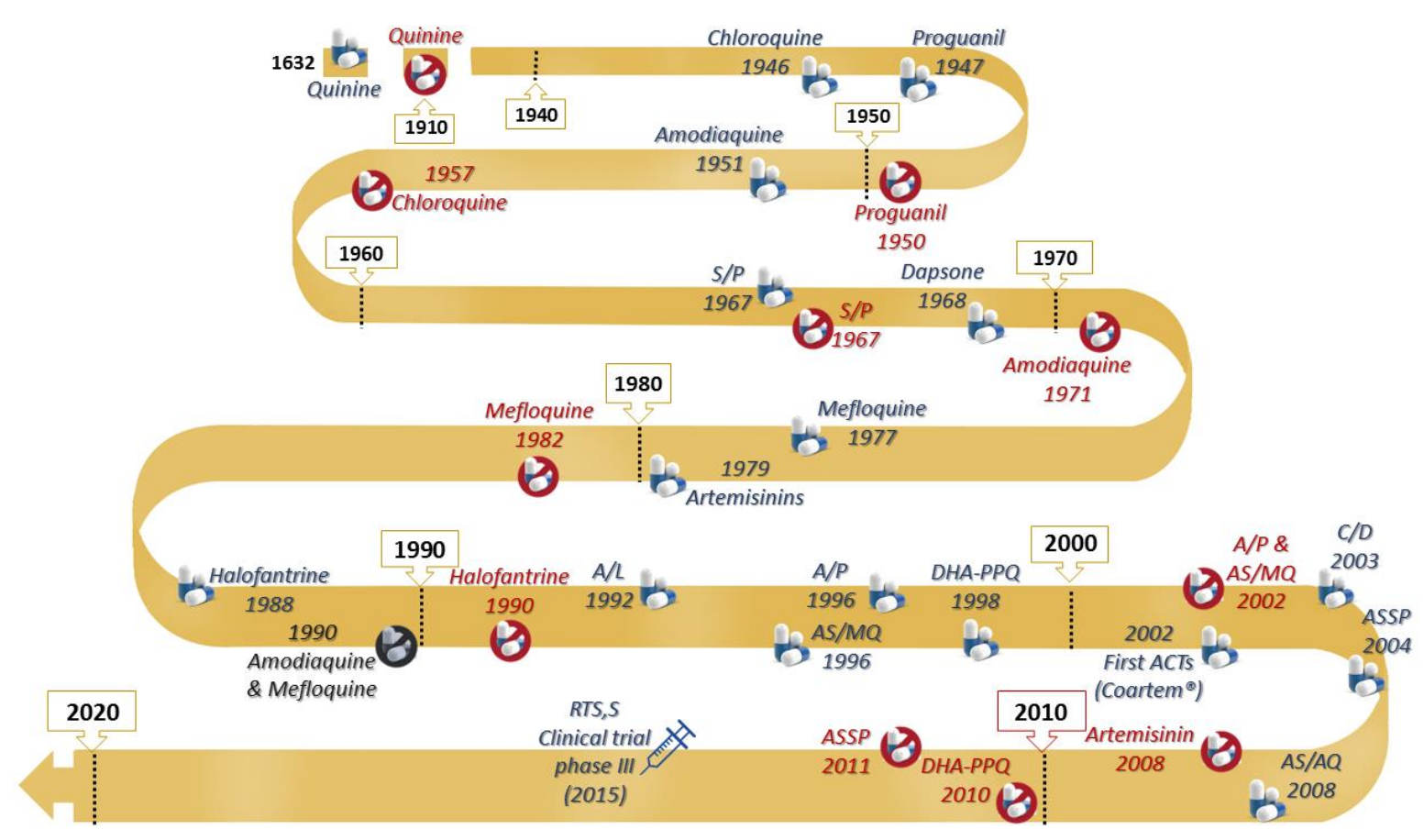

Figure 2: Timeline of main antimalarials and occurring resistance

Blue pills: first used as antimalarial; red circles: first reported resistance; black circles: no longer marketed AS/AQ, artesunate/amodiaquine; DHA-PPQ, dihydroartemisinin-piperaquine; A/P, atovaquone/proguanil; A/L, artemether/lumefantrine; ASSP, artesunate sufadoxine pyrimethamine; S/P, sulfadoxine/pyrimethamine; AS/MQ, arestunate/mefloquine; $\mathrm{ACTs}$, artemisinin combination therapies; and $\mathrm{C} / \mathrm{D}$, chlorproguanil/dapsone.

Mutations in the parasite genome have appeared over the last century, inducing fast spreading resistance against all commercial drugs (Figure 2). To address these issues, and in the absence of an available efficient vaccine, new drugs with original modes of action are crucial as resistance to front-line antimalarial drugs (essentially artemisinin-based combination therapies, ACTs) is spreading in Southeast Asia. A number of collaborative drug discovery programs have thus been initiated worldwide and a few drug candidates are currently under clinical development or have recently been approved for clinical use. Among them, most of the new drugs correspond to compounds that are structurally related to previously used drugs or artemisinin-based combinations, and some molecules with a novel mechanism of action 
have been proposed. To our knowledge, none of them belong to the nucleos(t)ide analogue family, targeting proteins involved in purine or pyrimidine metabolism, except DSM265 (currently in phase IIa

clinical trials). ${ }^{6}$ The latter is a selective inhibitor of Plasmodium dihydroorotate dehydrogenase (PfDHODH), which plays a central role within the de novo pyrimidine pathway. However, target mutations were found in patient's parasites (already observed in earlier in vitro studies) and concerned a few patients with recurrence at day 28 after receiving a single oral dose of DSM265. Once again, this data highlights the need to use combination therapies.

Herein, we will focus on nucleobase, nucleoside and nucleotide analogues, which so far have been reported to target and inhibit proteins involved in the purine salvage pathway of Plasmodium falciparum. This family of derivatives is of special interest as they can mimic the endogenous substrates of these proteins, so the design of analogues and their study may result in a new class of antimalarial drugs. In addition, as Plasmodium falciparum relies solely on the de novo pathway for pyrimidine nucleotide biosynthesis and on the salvage pathway for purine nucleotides, both metabolic processes appear to be attractive chemotherapeutic targets. The development of these analogues as inhibitors of plasmodial purine metabolism is relatively recent and somehow associated with the discovery of the antiviral and antitumoral potential of such compounds. The main nucleic acid biosynthesis pathways of Plasmodium will be described as well as the wide collection of analogues targeting the corresponding proteins.

\section{I/ NUCLEIC ACID METABOLISM IN PLASMODIUM FALCIPARUM}

Mammalian cells are able to synthesize nucleic acids from small molecules through the de novo pathway but requiring 6 ATP equivalents for the synthesis of IMP from ribose-5-phosphate and a dozen steps. In contrast, the salvage pathway is based on the recycling of related metabolites, which is less 
energy-demanding (a single step from hypoxanthine to IMP and 1 ATP equivalent is required for phosphoribosylpyrophosphate formation). The human host has both pathways to produce purine and pyrimidine nucleotides, whereas protozoan parasites such as Plasmodium only possess the salvage pathway for purine containing derivatives and de novo synthesis of pyrimidine derivatives. The latter are therefore essential for parasite growth, which requires a huge amount of purine and pyrimidine nucleoside triphosphates for its nucleic acid biosynthesis. A few reviews have provided detailed accounts of purine and pyrimidine pathways as chemotherapeutic targets. ${ }^{7-9}$

\section{1) Pyrimidine Metabolism}

Protozoan parasites rely solely on the de novo pathway to produce their pyrimidine derivatives, and they are not very capable of salvaging pyrimidines from erythrocytes. Briefly, Pf pyrimidine biosynthesis involves six enzymatic steps (Figure 3) as in the human host producing a central metabolite, i.e. uridine-5'-monophosphate (UMP), which is then used as precursor for all pyrimidine nucleotides (dUMP, dCTP, dTTP, UTP and CTP) required for DNA/RNA biosynthesis. The related enzymes can be divided in two groups of monofunctional and multifunctional proteins, i.e. the first and last three, respectively. Little attention has been focused on carbamoyl phosphate synthetase (CPS II) and aspartate transcarbamoylase (ATC), whereas $P f$ dihydroorotase (DHOase) has received much attention. The latter has been characterized and found to share many properties with mammalian proteins. ${ }^{10}$ The three following enzymes, i.e. orotate phosphoribosyltransferase (OPRT), dihydroorotate hydrogenase (DHODH) and dihydroorotase (DHOase), are considered as key enzymes to target the human parasite, and DHODH is one of the most widely studied. ${ }^{11,12}$ Their 3D crystal structures have been solved, their characteristics have been studied in detail and compared to their human counterpart. 
This review is not intended to provide a detailed account of these proteins and their inhibitors, but these data may be gleaned from the literature ${ }^{7,13}$

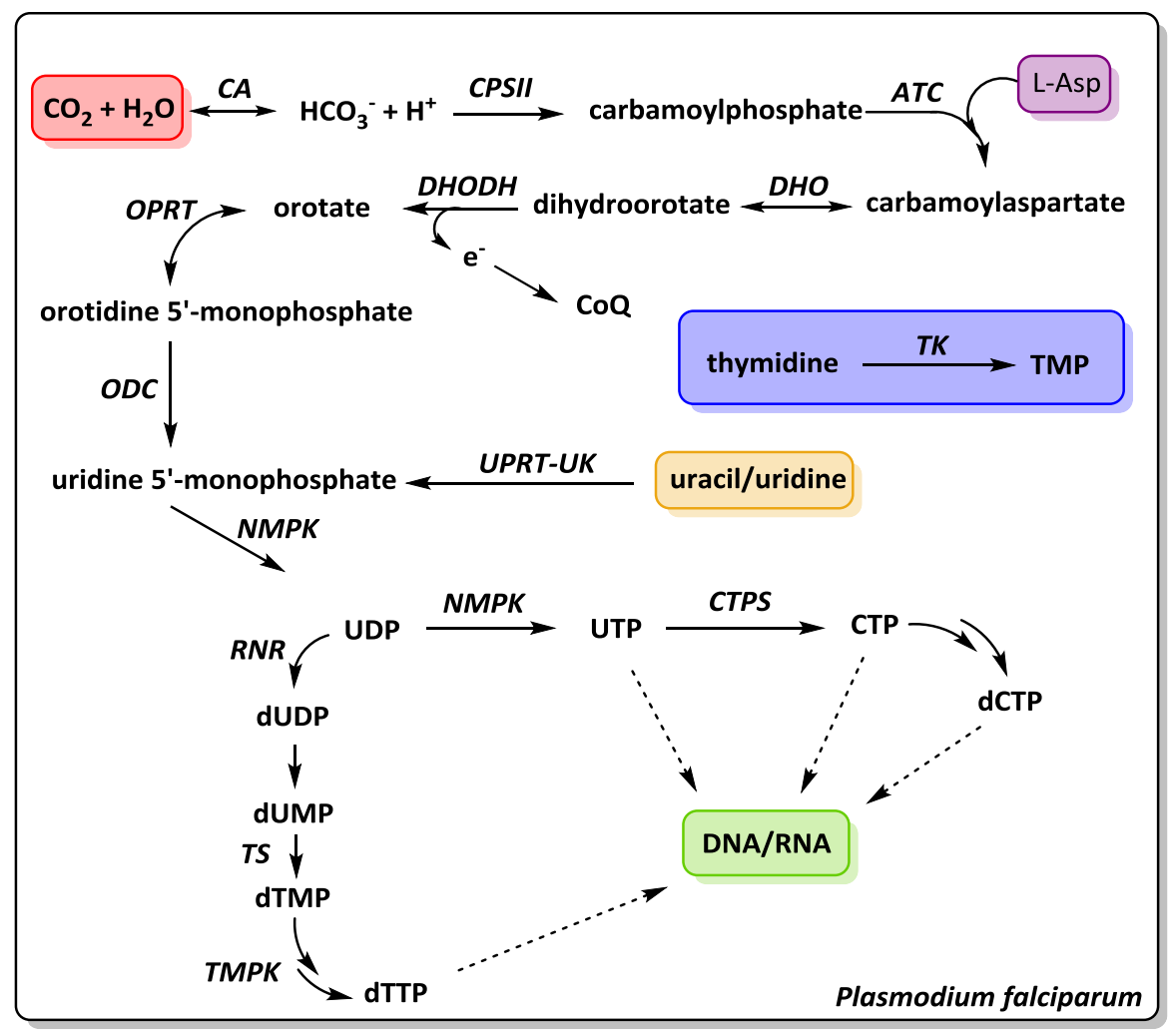

Figure 3 : Pf pyrimidine metabolism

Enzymes: CPSII, carbamoyl phosphate synthetase II; CA, carbonic anhydrase; ATC, aspartate transcarbamoylase; DHO, dihydroorotase; DHODH, dihydroorotate dehydrogenase; OPRTase, orotate phosphoribosyl transferase;

ODC, orotidine 5'-monophosphate decarboxylase; NMPK, nucleoside monophosphate kinase; RNR, ribonucleotide reductase; TS, thymidylate synthase; TMPK, thymidylate monophosphate kinase; CTPS, cytosine 5'-triphosphate synthetase; TK, thymidine kinase; UPRT, uracile phosphoribosyl transferase; and UK, uridine kinase.

Metabolites: UDP, uridine-5' -diphosphate; UTP, uridine-5' -triphosphate; dUDP, 2'-deoxyuridine-5' -diphosphate; dUMP, 2'-deoxyuridine-5'-monophosphate; CTP, cytidine-5'-triphosphate; dTMP, 2'-deoxythymidine-5'monophosphate; dTTP, 2'-deoxythymidine-5'-triphosphate; dCTP, 2'-deoxycytidine-5'-triphosphate; and CoQ, co-enzyme Q. 


\section{2/ Purine Metabolism}

Plasmodium species are purine auxotroph parasites that depend exclusively on purine materials derived from erythrocytes. Furthermore, as the Plasmodium genome has an extremely high adenine content (over $80 \%$ AT content), the parasite requires a considerable amount of adenine nucleotides (dATP and ATP) to maintain its high replication rate. Erythrocytes are unable to perform de novo purine synthesis alone, so the corresponding nucleobases and nucleosides are taken up from the plasma by the erythrocytes and then by the parasites. ${ }^{14,15}$ Purine import from the host cell is mediated by membrane transporters such as equilibrative nucleoside transporters (ENTs, Figure 5), $P f$ ENT1 is the main one from the four transporters (Pf ENT1-4) reported to date and supplying the purine salvage pathway. ${ }^{15,16}$ Although the transport of purine and pyrimidine derivatives in mammalian cells is well-documented, ${ }^{17,18}$ few studies have been performed on the parasite transporters in the last decade and mainly concerned $P f$ ENT1. Further investigations are thus required for rational design of purine transport inhibitors as antimalarial drugs.

A few of the enzymes involved in $P f$ purine metabolism have attracted special attention, namely purine phosphoribosyl transferases (PRT), adenosine deaminases (ADA) and purine nucleoside phosphorylases (PNP). Phosphoribosyl transferases induce the ribophosphorylation of purine bases in a single step and are present in many parasites, as well as in mammalian cells. In Plasmodium, hypoxanthine-guanine-xanthine-phosphoribosyl transferase (HGXPRT) converts hypoxanthine, guanine and xanthine into inosine-5'-monophosphate (IMP), guanosine-5'-monophosphate (GMP) and xanthosine-5'-monophosphate (XMP), respectively (Figure 6). Purine nucleoside phosphorylases degrade nucleosides into their corresponding nucleobases and sugar counterparts (Figure 7). Adenosine deaminases convert the exocyclic amino group of purine nucleos(t)ides into their oxo-derivatives (Figure 8). Moreover, HGXPRT, ADA and PNP enzymes are highly expressed and key players in purine 
metabolism, but other enzymes are also involved, such as guanosine-5' -monophosphate synthase (GMPS), adenylosuccinate synthetase (AdSS), adenosine-5' -monophosphate deaminase (AMPDA) and inosine-5' monophosphate dehydrogenase (IMPDH).

This metabolism is remarkable because of the few enzymes involved even though it has a crucial role in parasite survival. In addition, these enzymes are also present in the metabolic pathway of other plasmodial parasites and may have a high degree of similarity. As example $P v$ ENT1 shares $\sim 75 \%$ amino acid sequence identity with PfENT1. However, differences between $P$. vivax and $P$. falciparum were reported and resulted in modifications of the $3 \mathrm{D}$ protein structure and/or conformation. ${ }^{19}$ As example, structural differences between $P v$ and $P f$ ADA have been highlighted by computational studies and crystal structure analysis, and mainly concern the ligand recognition domain. ${ }^{20}$

The parasite salvages adenosine from the erythrocytes and the combined action of ADA and PNP successively leads to the formation of inosine and hypoxanthine (Figure 4). As very little adenosine is available from the erythrocyte (due to the activity of erythrocytic adenosine kinases), the parasite essentially relies on hypoxanthine, which is also salvaged from the host. The key purine metabolism precursor is consequently hypoxanthine, and therefore malarial cultures are often enriched with this nucleobase, which serves as a nutrient to promote parasite growth. Hypoxanthine is then converted into IMP by HGXPRT (Figure 4). IMP is thus the nucleotidic precursor of all other purine nucleotides required for nucleic acid biosynthesis, especially adenosine 5'-monophosphate (AMP). As $P f$ does not have the genes coding for nucleoside kinases ${ }^{21,22}$ (AMP synthesis directly from adenosine), there is no other alternative to obtain AMP, and IMP is the sole adenosine 5'-monophosphate metabolite available. To a lesser extent, it has been shown that by using high concentrations of adenosine in $P f$ cultures, AMP synthesized by RBC could induce erythrocytic AMP uptake into the parasite. ${ }^{22}$ IMP is also transformed into XMP via IMPDH and then into GMP via GMPS. GMP is also produced via a second pathway 
involving guanosine and guanine uptake, with the latter being PNP and HGXPRT substrates, respectively. Similarly, XMP is produced through HGXPRT activity following xanthine uptake. ${ }^{7}$

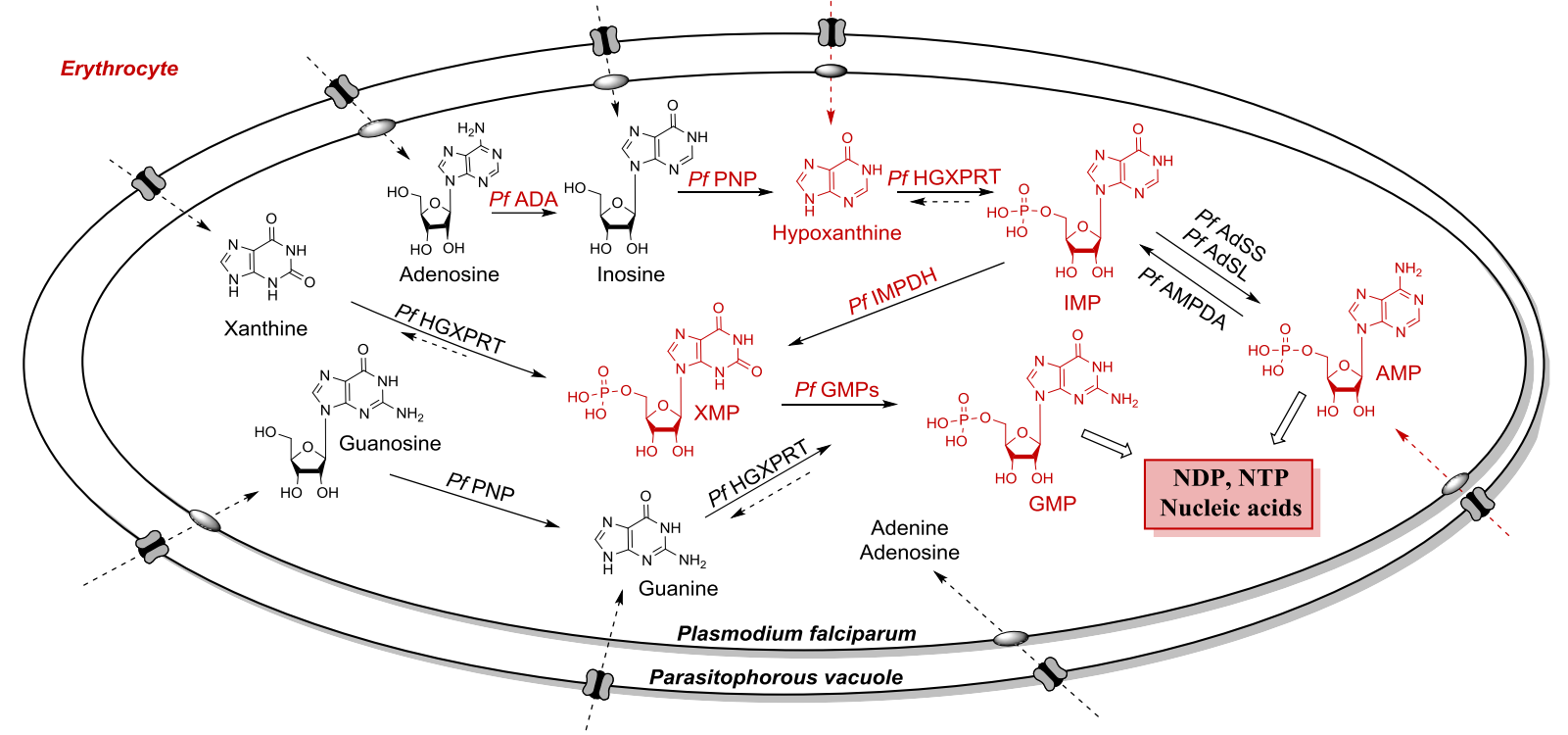

Figure 4: Representative scheme of $P f$ purine metabolism

In red: main path or nucleic acids synthesis in $P f$

Metabolites: IMP, inosine-5'-monophosphate; XMP, xanthosine-5' -monophosphate; AMP, adenosine-5'monophosphate; NDP, nucleoside diphosphate; and NTP, nucleoside triphosphate.

Enzymes: HGXPRT, hypoxanthine-guanine-xanthine-phosphoribosyl transferase; ADA, adenosine deaminase; PNP, purine nucleoside phosphorylase; GMPs, guanosine-5'-mono-phosphate synthase; IMPDH, inosine-5'monophosphate dehydrogenase; AMPDA, adenosine-5' -monophosphate deaminase; AdSS, adenylosuccinate synthase; and AdSL, adenylosuccinate lyase.

Transporters: ENT, equilibrative nucleoside transporter, notably Pf ENT1-4. PVM channel are represented at the parasitophorus vacuole membrane.

To date, the main strategy developed to inhibit Plasmodium falciparum growth involved targeting PNP and ADA $P f$ enzymes, because of their importance in the hypoxanthine pathway in the parasite. 


\section{Uptake of purine bases and nucleosides into the parasite}

a. Erythrocyte transport pathways

As for many human cells, mature erythrocytes have a profusion of transport systems (transporters and channels) located at the plasma membrane and responsible for the uptake of ions, hexoses, amino acids and other nutrients (Figure 5). Human nucleoside transporters (hNTs) thus include various transport system families, such as hENT1 and hENT2 (both equilibrative nucleoside transporters and responsible for purine and pyrimidine uptake, with nucleosides being the preferred substrates) ${ }^{18}, \mathrm{hFNT1}$ (facilitated nucleobase transporter, which transports hypoxanthine and adenine) and hCNTs (concentrative ioncoupled nucleoside transporters). ${ }^{16,14}$ It has been demonstrated that hENT1 and hFNT1 are the most important source of purine-containing derivatives in $P f$-infected RBC, while parasite-induced new permeability pathways (NPP, an alteration in membrane permeability) has also been mentioned. ${ }^{23,14}$ NPP are designed to facilitate the uptake of low molecular weight metabolites required for the parasite growth, such as sugar, sugar-alcohols, polyamine, nucleosides, nucleobases, ions, amino-acids ${ }^{24}$, etc. ${ }^{25,26}$

\section{b. Parasite transporters}

Four equilibrative nucleoside transporters (Pf ENT1-4) have been identified to date (Figure 5) - but they have yet to be fully characterized - and are expressed during the intraerythrocytic stage of the Plasmodium life cycle. ${ }^{202}$ According to genetic studies, $P f$ ENT1 has only $17 \%$ identical sequence homology with hENT1 and only shares 15 to $22 \%$ identical amino acid sequence with other parasite ENT transporters, and all four share only $2 \%$ similarity between them. ${ }^{16}$

Among them, $P f$ ENT1 (also called $P f$ NT1) is mainly responsible for the import of most purine nucleosides and nucleobases inside the parasite. Its characteristics (affinity and substrate specificity) have been the focus of some debate with regard to the model used for transport studies and the effects of purine metabolism upon import. ${ }^{27}$ In 2008, Quashie et al. ${ }^{15}$ suggested that hypoxanthine and purine nucleoside 
uptake was mediated by a high-affinity and broad-specificity transporter, i.e. $P f$ NT1 (located at the parasite plasma membrane ${ }^{28}$ ), and the existence of another high-affinity transporter and two low-affinity systems. Downie and co-workers proposed an alternative model, taking into account the fact that highaffinity proteins of purine metabolism readily transform $P f$ ENT substrates into nucleotides. ${ }^{27}$ They thus reported a fast, equilibrative and low-affinity mechanism for $P f \mathrm{NT} 1 .{ }^{29} P f$ ENT1 is a proton-dependent transporter ${ }^{30}$ accepting inosine, hypoxanthine, guanine, adenosine and guanosine as substrates, but with higher affinities for hypoxanthine and adenosine $\left(\mathrm{K}_{\mathrm{i}} 300-700 \mu \mathrm{M}\right.$ range) ${ }^{31}$ They are reported to be 11 transmembrane helix segment proteins, with intracellular $\mathrm{N}$-ter and extracellular $\mathrm{C}$-ter, which is the common structure for all protozoan and mammalian ENT1. Helices are mostly linked by short hydrophobic connectors, except for two large loops (one extracellular and one intracellular). ${ }^{32}$ As its human homologue, $P f$ ENT1 may also accept pyrimidine nucleosides as substrate. ${ }^{33}$

$P f$ ENT2 and ENT3 have received much less attention. ${ }^{16} P f$ ENT2 was shown to be located at the parasitic endoplasmic reticulum membrane and thus may not be involved in purine uptake. ${ }^{34} \mathrm{Pf}$ ENT3 has yet to be localized or shown to be involved in purine or pyrimidine transport.

Frame et al. have shown that $P f$ ENT4 is a low-affinity (in the millimolar range) purine transporter able to transport both nucleosides and bases such as adenine, adenosine and 2'-deoxyadenosine with low affinity ${ }^{35} P f$ ENT4 does not transport AMP or hypoxanthine (the main metabolite in the purine pathway), thus presenting a different substrate profile from that of $P f$ ENT1.

Like $P f, P v$ parasites also present four equilibrative nucleoside transporters. $P v$ ENT1 shares an almost identical amino acid sequence with $P f$ ENT1, although small differences have been observed with variable affinities of both transporters for the same substrate. ${ }^{36}$ The substrate and inhibitor specificity of P. berghei ENT1 has been reported recently. ${ }^{37}$ 


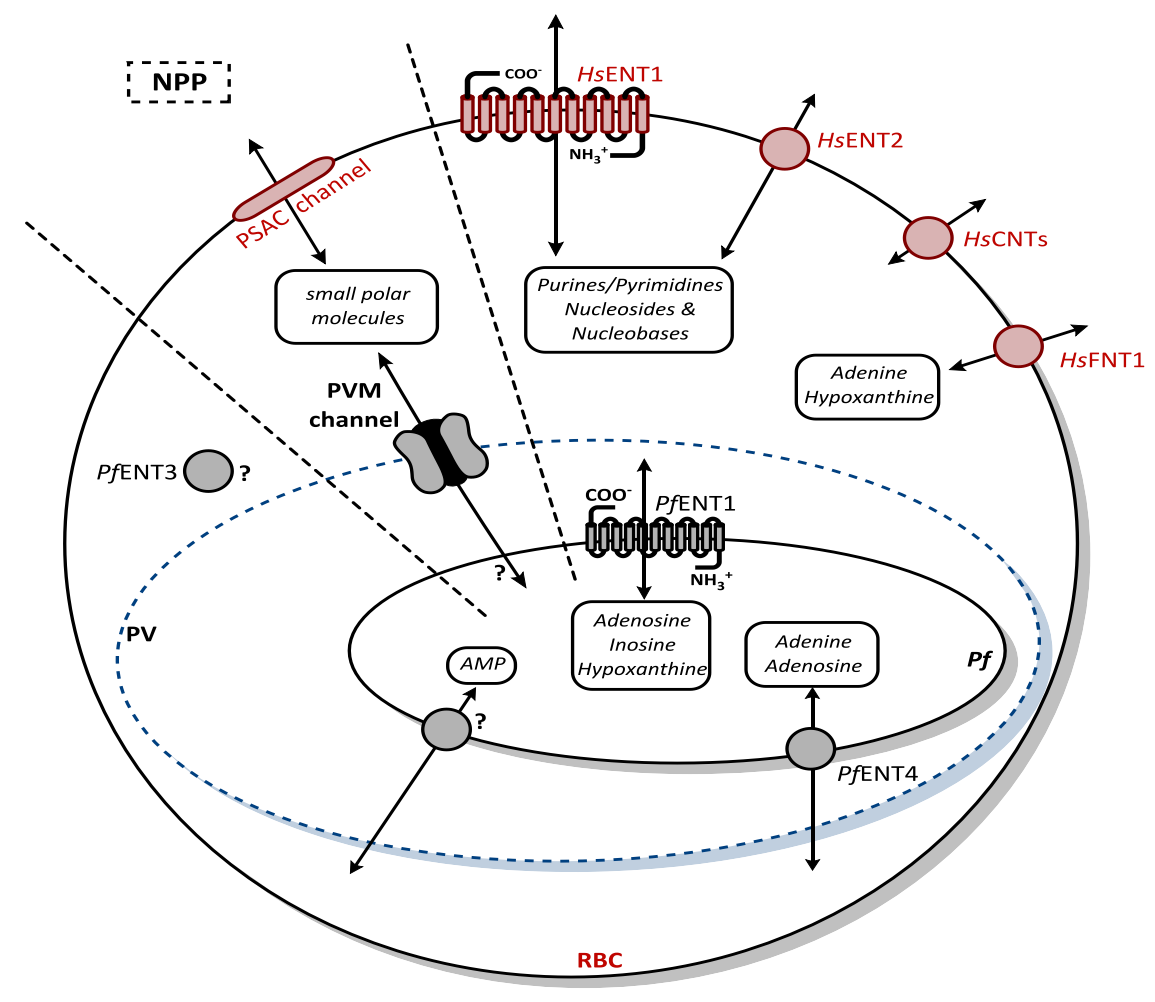

Figure 5: Main transporters involved in the uptake of purines and derivatives into RBC and the parasite.

PfENT3 is not yet localized; "?” sign, unknown transporters.

\section{HGXPRT}

HGXPRT is the most targeted purine metabolism enzyme in P. falciparum due to its major and multiple implications in the metabolism of this parasite (Figure 4). The crucial role of HGXPRT in purine metabolism has also been observed in $P . v i v a x .{ }^{38}$ Indeed, it provides the sole PRT activity for three substrates, i.e. converting hypoxanthine, xanthine and guanine into the corresponding nucleoside 5'monophosphates (IMP, GMP and XMP). Briefly, HG(X)PRT facilitates transfer of the phosphoribosyl moiety from $P$ Rib- $P P$ (alpha-D-5-phopshoribosyl-1-pyrophosphate) to 6-oxopurines in the presence of divalent metal ions, i.e. usually $\mathrm{Mg}^{2+}$ in vivo (Figure 6). Reyes et al. reported a detailed enzymatic 
characterization of Pf HGXPRT, demonstrating that phosphoribosyl transferases are the most important enzymes in purine metabolism. ${ }^{39}$

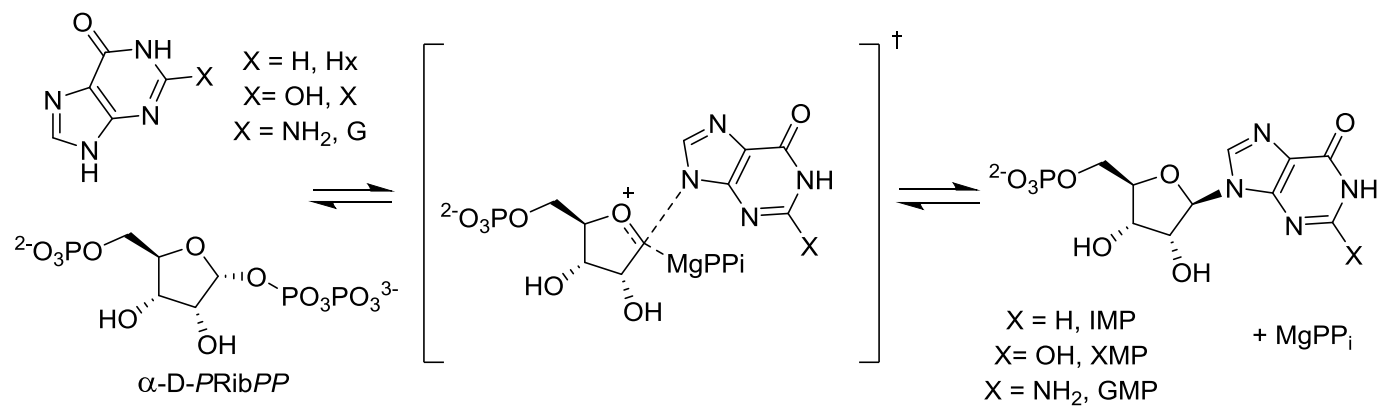

Figure 6: Mechanism and transition state of the 6-oxopurinephosphoribosyltransferase catalyzed reaction

Hx, hypoxanthine; X, xanthine; G, guanine; IMP, inosine 5'-monophosphate; XMP, xanthosine 5'monophosphate; GMP, guanosine 5'-monophosphate; $\alpha$-D-PRib- $P P, \alpha$-D-ribofuranose-5-phosphate-1diphosphate; and $\mathrm{PP}_{\mathrm{i}}$, pyrophosphate.

Few differences between the human and Pf HGXPRT were revealed by Keough et al. ${ }^{40}$ when comparing the specific activity (greater for human enzymes), kinetic parameters and substrate selectivity (the human enzyme does not accept xanthine as substrate, contrary to the parasite protein). Both enzymes are active as a homotetrameric form and share $44 \%$ sequence identity and $76 \%$ similarity. Superposition of their structures (in the presence of substrates of the catalytic reaction) generates a good root-meansquare deviation (rmsd) value (nearly 1,7 $\AA$ ). ${ }^{41}$ Considering these structural similarities between the two enzymes, the challenge is to selectively target and inhibit the parasite phosphoribosyl transferases so as to avoid any toxicity for human cells.

The crystal structures of the human 6-oxopurinephosphoribosyltransferase (Hs HGPRT) in the presence of nucleoside analogues have been often described. The human enzyme has three important binding sites 
hosting the nucleobase (through hydrogen bonds with residues), the 5'-phosphate (binding pocket is located between residues 137-141) and the pyrophosphate moiety (of Prib-PP or only $\mathrm{PP}_{\mathrm{i}}$ ).

In humans, $P$ Rib- $P P$ first binds to the metal ion and then the required nucleobase associates with the complex to form the intermediate. Then the pyrophosphate dissociates from the ribooxocarbenium complex and nucleoside 5 '-monophosphate is released from the enzyme catalytic site. ${ }^{42}$ The initial proposed mechanism for $P f \mathrm{HGXPRT}$ was slightly different and consisted of a ping-pong exchange, where $P$ Rib- $P P$ first binds to the enzyme, followed by $\mathrm{PP}_{\mathrm{i}}$ release and then nucleobase entry ${ }^{43}$. These results have been contested by the reported crystal structure of PfHGXPRT complexed with hypoxanthine. $\mathrm{PP}_{\mathrm{i}} \cdot \mathrm{Mg}^{2+}$ and a few immucillin transition state analogues. ${ }^{175}$ It has been shown that nucleobase binding is conditional to $P$ Rib- $P P$ entry, suggesting that $P f$ HGXPRT proceeds through a steady-state-ordered mechanism. ${ }^{176}$

\section{3. $P N P$}

PNP are also important enzymes present in both mammals and protozoan parasites. Like HGXPRT, PNP inhibition leads to death of the parasite by blocking the formation of hypoxanthine, a key metabolite of the $P f$ purine metabolism (Figure 4) ${ }^{46,47} P f \mathrm{PNP}$ is structurally different from the human protein (hexamer versus homotrimer and low sequence homology, $\sim 20 \%$ identity of the primary amino acid sequence) and exhibits different catalytic rates with inosine as substrate $\left(56 \mathrm{~s}^{-1}\right.$ for hPNP and $0.34 \mathrm{~s}^{-1}$ for $\left.P f \mathrm{PNP}\right){ }^{48-50}$

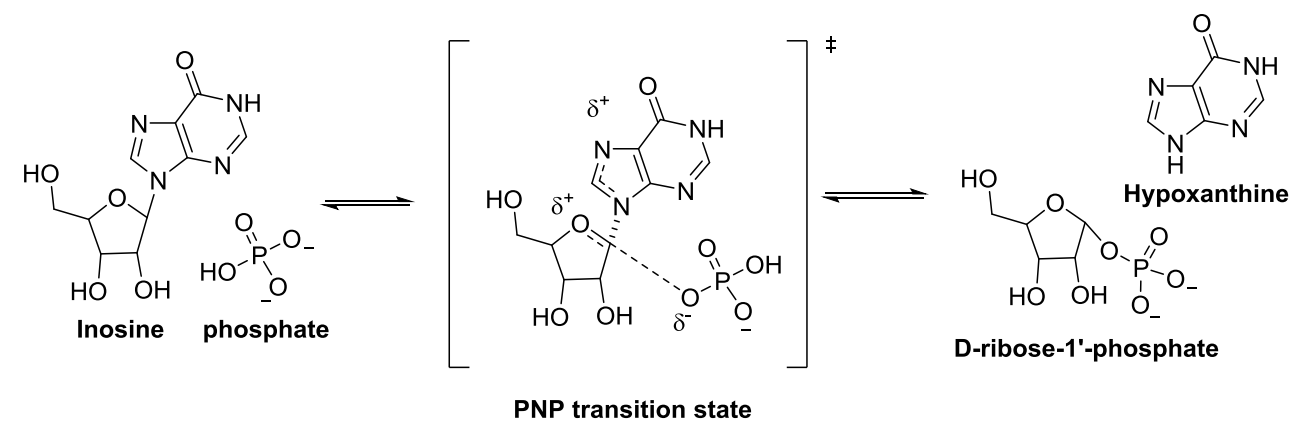




\section{Figure 7: Mechanism and transition state of the $P f$ purine nucleoside phosphorylase catalyzed reaction}

According to the mechanism proposed by Schramm et al. for both human and Pf PNPs ${ }^{51,52}$ the nucleoside and phosphate (as nucleophilic participant) first bind to the active site of the enzyme and the reaction transforms the inosine/enzyme complex (located on a single active site of the homotrimer), into a hypoxanthine/ribose/enzyme complex (Figure 7). Then the enzyme catalyzes cleavage of the glycosidic bond to release the ribose-1'-phosphorylated moiety, giving rise to a tight binding hypoxanthine/enzyme complex. The latter finally dissociates within the corresponding nucleobase and the D-ribose phosphorylated moiety. Both enzymes have similar transition states, with the active site environment being more constrained in the parasite enzyme than in the human one (on the basis of different interactions between the active site and substrate).

\section{4. $A D A$}

ADA is a zinc-dependent hydrolase that catalyzes the irreversible hydrolysis of adenosine into inosine, its corresponding 6-oxopurine derivative. The reaction is triggered by the deprotonation of a water molecule which then reacts with the substrate, giving rise to 6-amino-6-hydroxypurine as intermediate, which provides the corresponding oxopurine by releasing one ammonia molecule (Figure 8). ${ }^{53}$

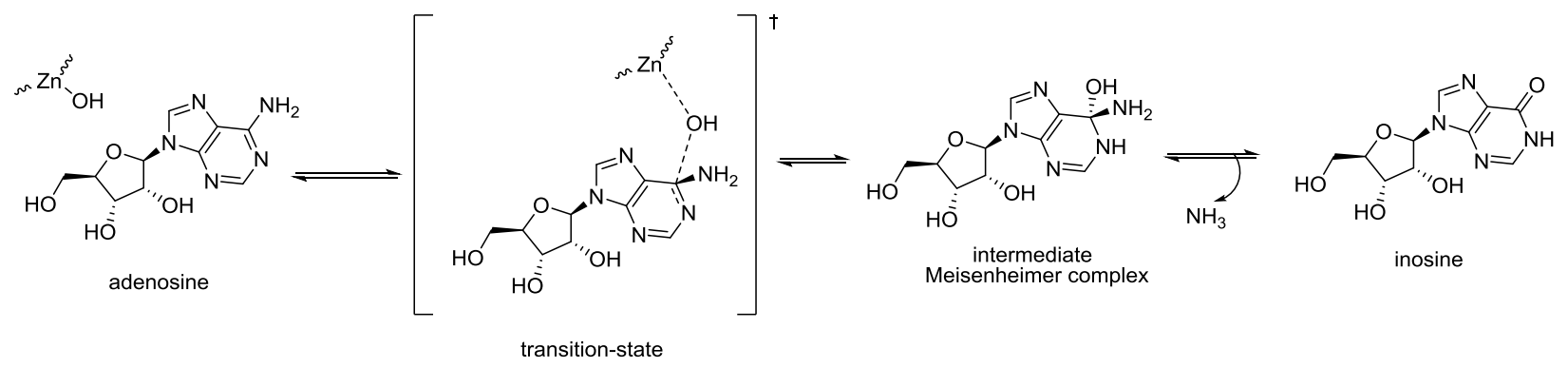

Figure 8: Mechanism and transition state of the $P f$ adenosine deaminase catalyzed reaction 
Human and $P f$ ADAs are functionally similar and have high sequence homology, but they differ slightly in terms of substrate specificity and catalytic turnover. Pf ADA thus accepts both adenosine and 5'-methylthioadenosine (MTA, a polyamine biosynthesis metabolite) as substrate, which is not the case for its human homologue. ${ }^{54}$

$P v$ ADA has been crystallized in a complex with three different ligands (adenosine, guanosine and 2'deoxycoformycin, i.e. a known human ADA inhibitor $)^{55}$. A parasite-specific conformation was observed, which closed the substrate binding site within a solvent-less cavity, whereas the human enzyme does not close its active site. This difference may explain the recognition of MTA, as the solvent-less cavity hosts the hydrophobic thiomethyl group. Amino-acid changes in the active sites of $P v$ and $P f$ ADAs have been highlighted via computational studies and comparison with a Pf ADA homology model. ${ }^{20}$

In addition, $P$. knowlesi growth (in infected primates) was found to be inhibited by 2'-deoxycoformycin, indicating that parasite survival was dependent on adenosine deaminase. ${ }^{56}$

In 2017, the $P f$ proteome was studied to identify commercial drugs which could target and inhibit $P f$ enzymes. Dipyridamole (a nitrogen heterocycle derivative used as blood vessel dilatator) was thus reported to be a PfADA inhibitor with an $\mathrm{IC}_{50}$ of $30 \mathrm{nM}^{57}$

\section{IMPDH}

Inosine 5'-monophosphate dehydrogenase catalyzes XMP formation from IMP through a covalent mechanism (Figure 9) and serves as an alternative/complementary pathway for providing GMP. As GMP synthesis mediated by HGXPRT is not substantial enough to provide the overall amount of GMP required for nucleic acid biosynthesis in the parasite, IMPDH inhibition could indirectly and partially block GMP formation from XMP. ${ }^{58,59} \mathrm{IMPDH}$ is a homotetramer protein. The active site is located at the C-terminal chain, whereas the cofactor $\left(\mathrm{NAD}^{+}\right)$binds at another site. ${ }^{60}$ Consequently, two classes of IMPDH 
inhibitors can be developed, i.e. one targeting the substrate binding site and the other targeting the cofactor binding loops via an uncompetitive mechanism (e.g. mycophenolic acid and phenyl-oxazole urea, respectively). ${ }^{61}$

Human and $P f$ IMPDH genome sequences shown only $48 \%$ of similar amino acid sequences and exhibit differences in the structure of the active site. ${ }^{60}$ That could possibly help to design selective inhibitors of the plasmodial enzyme.
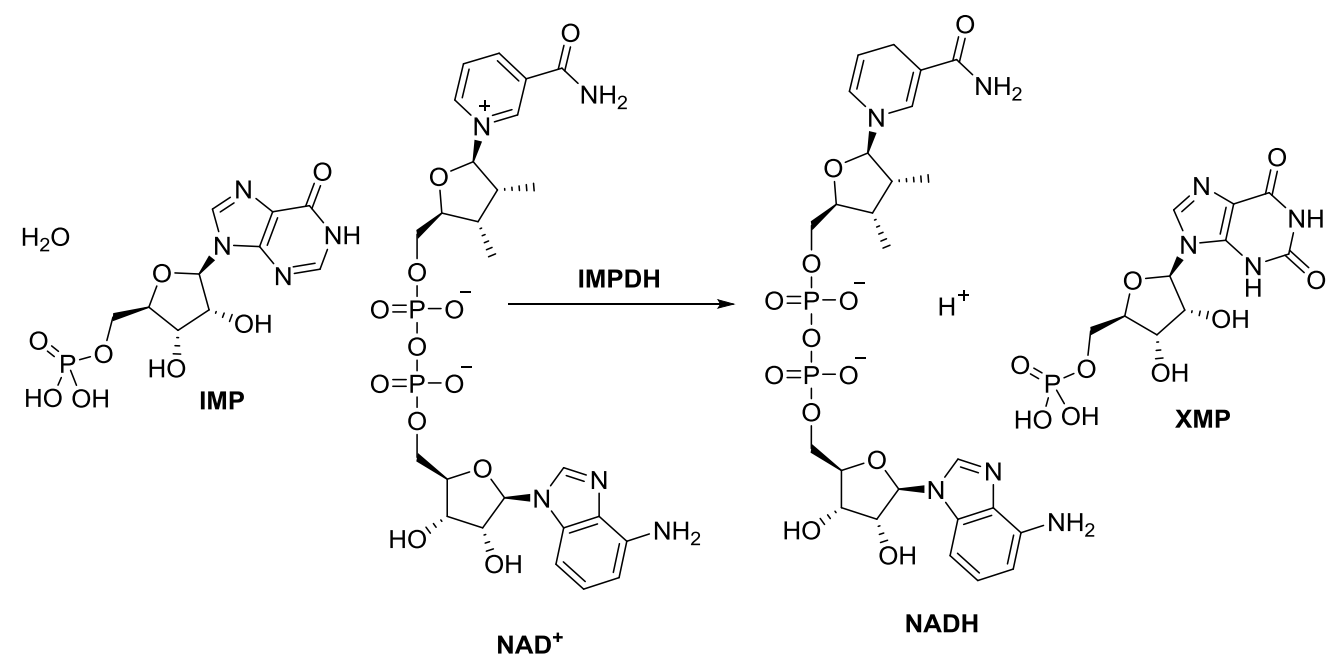

Figure 9: Pf inosine 5'-monophosphate deshydrogenase catalyzed reaction

\section{GMPS}

Pf GMP synthetase (belonging to the glutamine amidotransferase family) is a dimeric protein catalyzing the irreversible formation of GMP through XMP amination. GMP synthesis via HGXPRT is not enough to maintain optimal GMP levels in the parasite, ${ }^{62}$ thus blocking this enzyme may be a valuable approach to inhibit nucleic acid biosynthesis. $P f$ and human GMPS share $20-30 \%$ common chain sequence and both contain two domains, i.e. one catalyzing formation of the XMP-adenyl complex (ATPPase), and the other providing the required ammonia from glutamine hydrolysis (GATase, glutamine amidotransferase). The ammonia molecule is channeled to the other domain in order to generate the GMP product ${ }^{63}$ (Figure 10), 
which is a common amidotransferase reaction step (ping-pong mechanism) ${ }^{62}$ Both ATPPase and GATase sites can be targeted in competitive and uncompetitive ways, respectively. For instance, glutamine analogues, such as acivicin and 6-diazo-5-oxo-norleucine (use as antibiotics and known hGMPS inhibitors), are able to inactivate the enzyme by covalent modification of the GAT domain. ${ }^{62} P f$ GMPS also differs with regard to other plasmodial species associated with a single 20 amino-acid long sequence located in its GAT domain. ${ }^{63}$

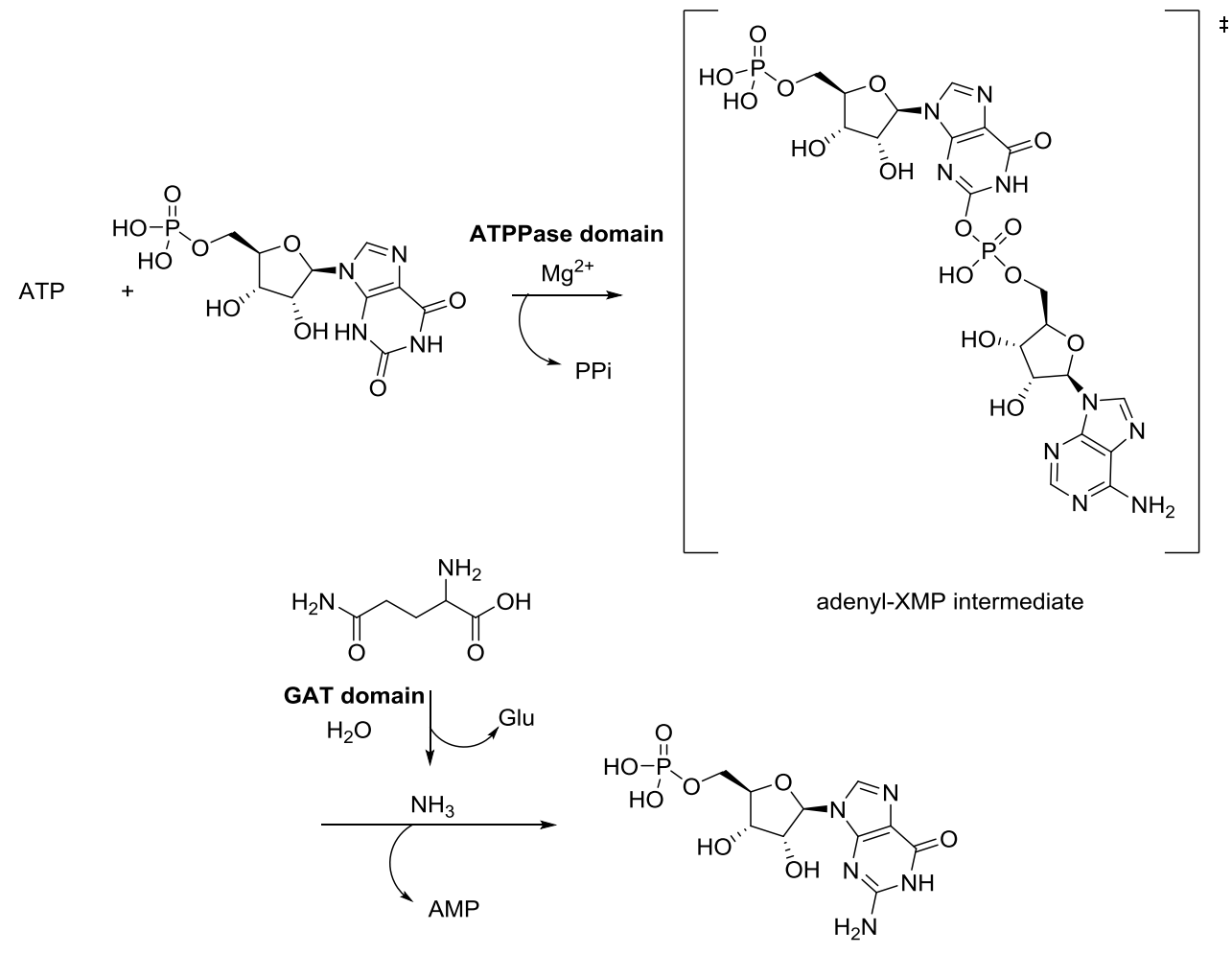

Figure 10: Formation of GMP from XMP, catalyzed by $P f$ GMPS from its GAT and ATPPase domains

\section{II/ TARGETING PURINE METABOLISM WITH NUCLEOS(T)IDE ANALOGUES}

Because of the importance of purine metabolism for plasmodial parasites, the inhibition of related enzymes has been considered since $1984 .{ }^{64}$ Nucleoside analogues are well-known inhibitors of the nucleic acids biosynthesis, so they may also be viewed as potential candidates for targeting of purine metabolism 
enzymes due to their structural similarities with their substrate. Series of purine-based heterocycles, nucleoside and nucleotide analogues have been studied with the aim of targeting these enzymes and related transporters. A few of them were designed on the basis of transition state studies. This part of the review concerns such compounds as inhibitors of transporters and/or enzymes involved in plasmodial purine metabolism.

\section{Purine-based Analogues}

In 2006, Keough et al. studied the effects of purine nucleobase skeleton modifications and the ability of these derivatives to bind to human and $P f$ HGXPRT, and the hypothetical discrimination between these two enzymes. ${ }^{65}$ By analogy with 6-mercaptopurines used in cancer chemotherapy ${ }^{66}$, the proposed mechanism of action consists of their conversion-mediated by 6-oxopurinePRTases-into their corresponding nucleoside 5'-monophosphate derivatives, thereafter incorporated into DNA or RNA and thus interfering with cell replication. Determination of the $K_{m}$ for these derivatives revealed that the presence of an exocyclic oxygen-containing group at position-2, and/or a chlorine atom at position-6, and/or the replacement of the carbon atom at position- 8 by a nitrogen allowed strong discrimination between human and $P f$ HGXPRT. In addition, these nucleobases are able to inhibit $P$. falciparum in vitro growth. The best $\mathrm{IC}_{50}$ values were $1.3 \mu \mathrm{M}$ and $6.6 \mu \mathrm{M}$ for 6-mercaptopurine and 8-azaguanine, respectively.

\section{Nucleoside analogues}

Since natural substrates of the targeted enzymes are mostly nucleosides and derivatives, the easiest and most promising way to selectively inhibit them is to design analogues. In the field of antiviral and antitumoral chemotherapy, the search for nucleoside analogues has led to the discovery of the active 
compounds which are nowadays used as drugs. Some of these derivatives were tested against the $P f$ purine salvage pathway, leading to the identification of lead compounds which served as a starting point for the synthesis of novel derivatives.

\section{a. Cordycepin}

Cordycepin (Table 1), an antibiotic and anti-tumoral nucleoside extracted from Cordyceps militari, was tested in vitro, by Trigg et al. in 1971 against $P$. knowlesi and in vivo in P. berghei-infected mice. ${ }^{67}$ Effects were noted on in vitro parasite growth at micromolar concentrations, but a full cure was not obtained in mice even at high concentration. The fact that nucleic acid biosynthesis in the parasite was affected suggested that the purine metabolism of the parasite was targeted.

b. Mizoribine and ribavirin derivatives

Mizoribine (Table 1) is an immunosuppressive drug that was isolated from Eupenicillium brefeldianum in Japan in 1971. It is clinically used for renal transplantation ${ }^{68}$ as well as an inhibitor of $H s$ IMPDH in leukemia and viral diseases. Its proposed mechanism of action involves IMPDH inhibition by the mizoribine-5'-monophosphate, thus limiting both XMP formation and GMP synthesis mediated by GMPS.${ }^{69}$ When tested as an antimalarial by Webster and Whaun in 1982, mizoribine appeared to be active

against drug-resistant $P f$ strains at $50 \mu \mathrm{M}^{70}$ Variations in the concentration of several purine-containing nucleosides and nucleotides in infected RBCs have been studied and a significant decrease was observed in the presence of mizoribine.

Recently, Raza et al. performed virtual screening of a library of ribavirin analogues (Table 1, a base modified nucleoside analogue known as a competitive inhibitor of human $\mathrm{IMPDH}^{71,72}$ ) using a 3Dhomology model of $P f \mathrm{IMPDH} .{ }^{60}$ Five promising ribavirin derivatives were identified as potential ligands, which should be able to selectively target the parasite enzyme by interacting with the active site (hydrogen 
bonds and hydrophobic pockets). To date, these molecules have not yet been tested in vitro against $P$. falciparum growth.

Table 1. Representative nucleoside analogues as potential purine metabolism inhibitors

\section{Cordycepin (3-deoxy-adenosine) ${ }^{67}$}<smiles>Nc1ncnc2c1ncn2C1OC(CO)C[C@H]1O</smiles>

Inhibitors of $\boldsymbol{P} \boldsymbol{f}$ IMPDH $^{60,70}$<smiles>NC(=O)c1ncn(C2O[C@H](CO)[C@@H](O)[C@H]2O)c1O</smiles><smiles>NC(=O)c1ncn(C2O[C@H](CO)[C@@H](O)[C@H]2O)n1</smiles>

Mizoribine (Bredinin) Ribavirin (Virazole)

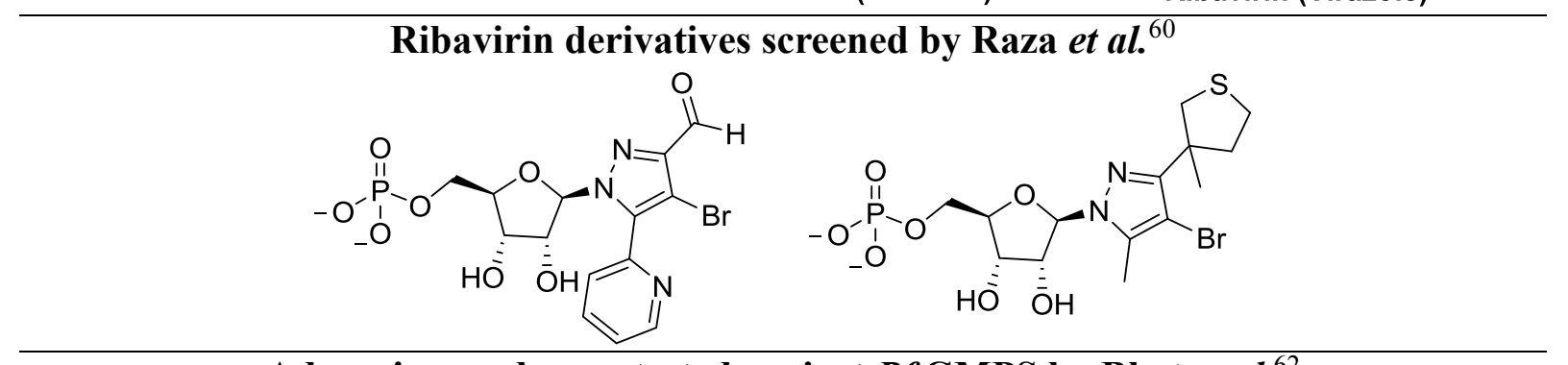

Adenosine analogues tested against $P f$ GMPS by Bhat et al. $^{62}$<smiles>C=C1O[C@@](CO)(n2cnc3c(N)ncnc32)[C@H](O)[C@@H]1O</smiles>

Decoyinine<smiles>Nc1ncnc2c1ncn2[C@@]1(CO)O[C@H](CO)[C@@H](O)[C@H]1O</smiles>

Psicofuranine

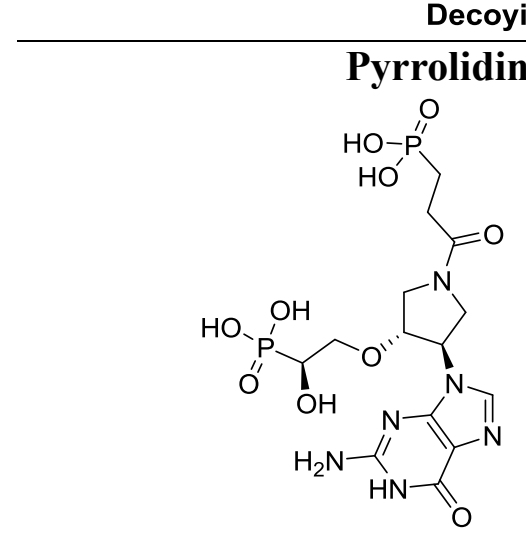

1

$\mathrm{K}_{\mathrm{i}} 8 \mathrm{nM}$ on $P V$ HGPRT $\mathrm{K}_{\mathrm{i}} 7 \mathrm{nM}$ on $P f$ HGXPRT $\mathrm{K}_{\mathrm{i}} 3 \mathrm{nM}$ on Hs HGPRT<smiles>O=C(CCP(=O)(O)O)N1CC(OCC(O)P(=O)(O)O)C(n2cnc3c(=O)[nH]cnc32)C1</smiles>

2

$\mathrm{K}_{\mathrm{i}} 6 \mathrm{nM}$ on $P V$ HGPRT $\mathrm{K}_{\mathrm{i}} 2 \mathrm{nM}$ on Pf HGXPRT $\mathrm{K}_{\mathrm{i}} 1.3 \mathrm{nM}$ on Hs HGPRT<smiles>Nc1nc2c(ncn2C2CCN(C(=O)CP(=O)(O)O)C2)c(=O)[nH]1</smiles>

3

$\mathrm{K}_{\mathrm{i}}$ 2,6 mM on Pv HGPRT $\mathrm{K}_{\mathrm{i}}$ 0.4 mM on Pf HGXPRT $\mathrm{K}_{\mathrm{i}} 73 \mathrm{mM}$ on Hs HGPRT 


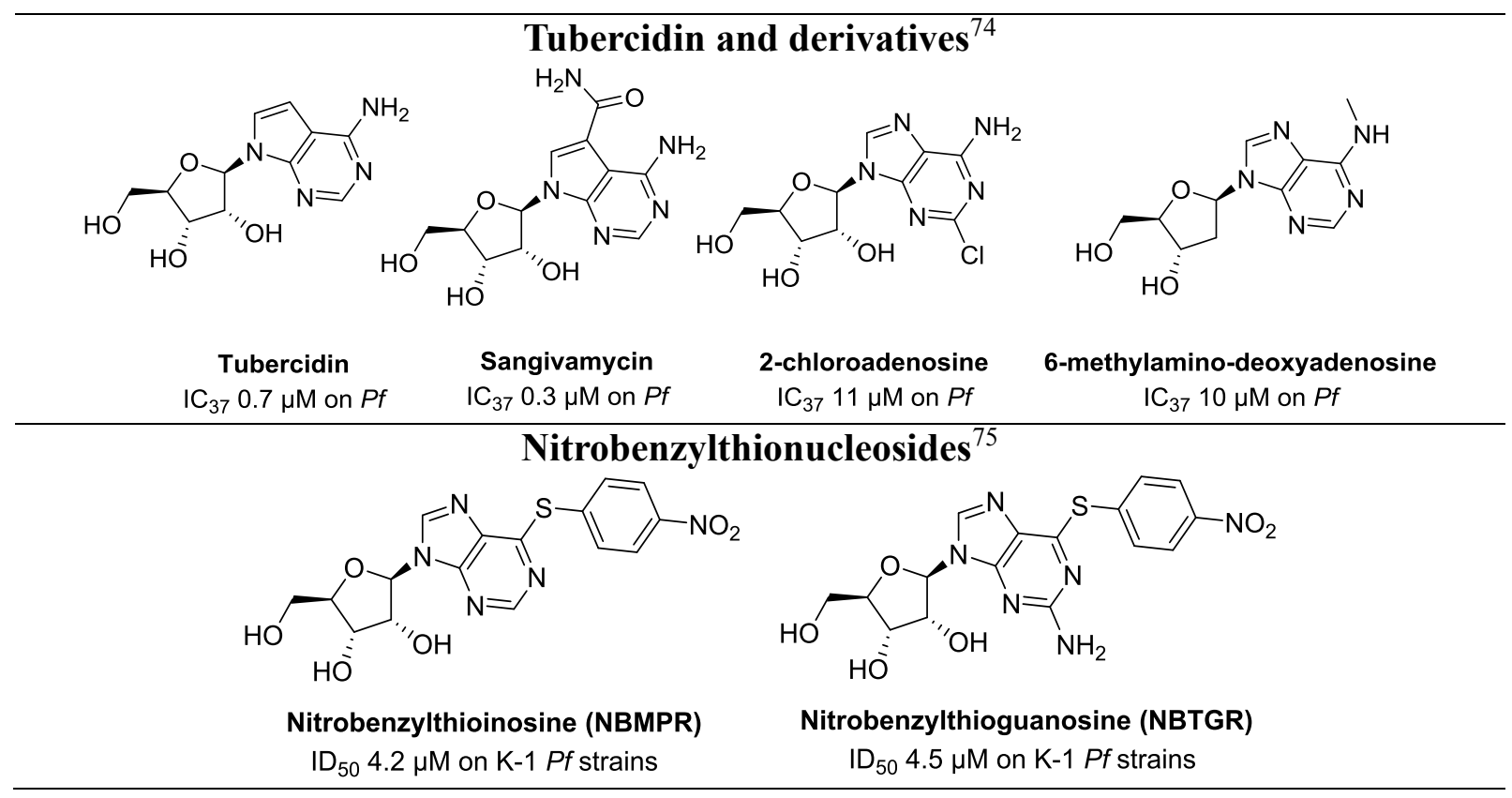

c. Psicofuranine and decoyinine

As psicofuranine and decoyinine (Table 1) were reported to inhibit hGMPS (with 17.3 and $46.5 \mu \mathrm{M}$ $\mathrm{IC}_{50}$ values), ${ }^{76}$ Baht et al. evaluated them on purified $P f$ GMPS. They reported a weak inhibitory effect of psicofuranine $(25 \%$ inhibition at $0.5 \mathrm{mM})$ and no effect of decoynine. ${ }^{62}$ Only psicofuranine had an $\mathrm{IC}_{50}$ of $0.3 \mathrm{mM}$ when tested against $P f$ cultures (3D7 strain). ${ }^{77}$

d. PNBPs - Pyrrolidine nucleoside bisphosphonates

Initially synthesized and tested for their ability to inhibit $E$. coli, 6-oxopurine phosphoribosyltransferases, ${ }^{78}$ pyrrolidine nucleoside phosphonates (Table 1) were subsequently assessed as potential inhibitors of $P v$ HGPRT and PfHGXPRT. The design of such compounds was based on a central 5-membered ring skeleton, bearing three substituents anchored through free rotation bonds, thus allowing to adopt the best conformation at the active site of the enzyme. ${ }^{73}$

In comparison with compound $\mathbf{3}$, the addition of a second phosphonate tail to the pyrrolidine ring markedly decreased the $\mathrm{K}_{\mathrm{i}}$ values (from millimolar to nanomolar range) for all three enzymes but to the detriment of selectivity. It should be noted that: (i) the nature of the nucleobase did not seem to have a real impact 
on the activity, (ii) the addition of the hydroxyl group on the second phosphonate tail enhanced the inhibitory activity of these derivatives and the stereochemistry had an influence on the affinity of the studied enzyme. For instance, the $(R)$-isomer of compound 1 exhibited a 7.5 -fold higher $\mathrm{K}_{\mathrm{i}}$ value than that of its $(S)$-isomer on $P v$ HGPRT. Studies of the crystal structures of the $P v$ HGPRT-compound 1 complex revealed that the oxygen-linked phosphonate tail located within the 5'-phosphate binding pocket could explain the difference in $\mathrm{K}_{\mathrm{i}}$ observed between the two stereoisomers. Additional interactions also occurred between water molecules, the hydroxyl group and the active site for the $(S)$-isomer of compound 1. Structural data regarding the $P f$ protein are currently not available.

\section{e. Tubercidins}

The successful use of adenosine analogues in cancer chemotherapy led Coomber et al. to test some of them against Plasmodium falciparum. In vitro, the most efficient ones were the 7-deaza-adenosine derivatives tubercidin and sangivamycin (Table 1), with $\mathrm{IC}_{37}$ of 0.7 and $0.3 \mu \mathrm{M}$ ( $\mathrm{IC}_{37}$ values are quite unusual compared to $\mathrm{IC}_{50}$, but it was used by the authors to compare their results with previously reported ones). Their mechanism of action was suggested to be related to purine metabolism, especially with a decrease of IMP content in treated $P f$-infected erythrocytes. ${ }^{74}$ In addition, 5 -iodotubercidin (a known human adenosine kinase inhibitor) has been shown to inhibit Pf growth in vitro ( $\mathrm{IC}_{50}$ of $\left.2 \mu \mathrm{M}\right)^{22}$ and several tubercidin derivatives appeared to be PfENT1 substrates. ${ }^{31}$ However, no further studies have been recently reported in the literature concerning this family of compounds.

\section{f. $\quad$ NBMPR - nitrobenzylthioinosine}

Nitrobenzylthioinosine (NBMPR) and its guanine analogue (NBTGR) were first assayed as antimalarial drugs in 1989 (Table 1). ${ }^{75}$ In addition to their micromolar $\mathrm{IC}_{50}$ values in $P f$-K1 strains (multi-

drug resistant)-infected erythrocytes, they were successfully used in an original approach based on the alteration of infected erythrocyte membrane permeability. Briefly, the two derivatives were used to 
facilitate the uptake of cytotoxic nucleosides (presumably through permeability pathways induced by the parasite) into infected erythrocytes, while their ability to selectively inhibit the human transporters $(\mathrm{hENT} 1)^{79}$ prevented the uptake and further toxic effects in uninfected cells. Later on, it was also proven that $P f$ ENT1 and $P f$ ENT4 were insensitive to NBMPR. ${ }^{80}$

\section{Transition state analogues as Pf purine metabolism inhibitors}

In theory, a perfect and chemically stable transition state analogue will bind tighter to the enzyme active site than the substrate. The protein will enclose the compound with a more thermodynamically stable and static conformation, thus preventing natural substrate binding until release of the transition state analogue. Moreover, an ideal transition state analogue will be highly selective of the targeted enzyme, avoiding toxicity and unwanted side-effects.

Natural transition state species have a very short longevity and consequently are not directly observable, but they can be predicted, or hypothesized, by studying the reaction process mechanisms and determining the intrinsic kinetic effects of isotopic compounds. A chemical structure could then be proposed on the basis of in silico calculations. Transition state analogues of three parasite enzymes have thus been reported to date, i.e. $P f \mathrm{ADA}, P f \mathrm{PNP}$ and $P f \mathrm{HGXPRT}^{81}$

\section{a. PfADA inhibition}

- Coformycin and derivatives

Coformycin and 2'-deoxycoformycin (namely pentostatin) were both known as mammalian ADA inhibitors. In 2007, Tyler et al. studied the affinity of these derivatives toward human, bovine and $P f$ ADAs

(Table 2) and inhibition constants in the low nanomolar range were observed, but with no specific

selectivity. ${ }^{82}$ On the basis of previous results showing that 5 'methylthioadenosine or inosine ${ }^{54}$ were $P f$ ADA substrates, 5'-alkylthio and 5'-phenylthio analogues of coformycin and 2'-deoxycoformycin were 
synthesized. ${ }^{82}$ Among them, $5^{\prime}$-methylthio derivatives appeared to be highly selective of the parasite enzyme, with $\mathrm{K}_{\mathrm{i}}$ of less than $1 \mathrm{nM}$ (Table 2), especially 5'-methylthiocoformycin, which showed >20,000fold selectivity for $P f$ versus $H s$ ADA. However, no further studies have been reported.

- L-nucleoside analogues

In 1995, Upston et al. showed that L-adenosine was significantly transported (via a unique parasiteinduced pathway) and selectively metabolized (through ADA activity) within parasites infectederythrocytes. ${ }^{83}$ These preliminary results led the same team to investigate series of L-nucleoside analogues

(Table 2). ${ }^{84,85}$ Among them, L-coformycin and L-isocoformycin were shown to specifically inhibit $P f$ ADA activity in the picomolar range (contrary to their D-isomer, especially 2'-deoxycoformycin, which interacted with both human and parasite enzymes). ${ }^{85} \mathrm{~L}$-coformycin, L-isocoformycin and L-sangivamycin inhibited the in vitro growth of $P f$ with an $\mathrm{ID}_{50}$ in the micromolar range. ${ }^{84}$

Table 2. Nucleoside analogues as $P f$ ADA inhibitors

\section{Coformycin and derivatives as inhibitors of human and plasmodic adenosine deaminases ${ }^{82}$}<smiles>OCC1OC(N2C=NC3C(O)CN=CNC32)[C@H](O)[C@@H]1O</smiles>

Coformycin

$\mathrm{K}_{\mathrm{i}} 13.9 \mathrm{nM} / \mathrm{Ki}^{*} 0.11 \mathrm{nM}$ on Hs ADA $\mathrm{K}_{\mathrm{i}} 0.68 \mathrm{nM} / \mathrm{K}_{\mathrm{i}}^{*} 0.08 \mathrm{nM}$ on Pf ADA<smiles>CSCC1OC(N2C=NC3C(O)CN=CNC32)[C@H](O)[C@@H]1O</smiles>

5'-Methylthiocoformycin $\mathrm{K}_{\mathrm{i}}>10 \mu \mathrm{M} / \mathrm{K}_{\mathrm{i}}^{*} \mathrm{ND}$ on $\mathrm{Hs}$ ADA

$\mathrm{K}_{\mathrm{i}}^{*}$ values correspond to the equilibrium dissociation constant upon completion, after a slow onset, for tight binding inhibition of the enzyme (consequent upon a time-dependent conformational change in the enzyme that improve the binding after a moment, thus $\mathrm{K}_{\mathrm{i}}{ }^{*}$ is lower than $\mathrm{K}_{\mathrm{i}}$ ) reported for transition state-analogues. Compounds with $\mathrm{K}_{\mathrm{i}}^{*}$ values are called slow-onset tight binding inhibitors. $\mathrm{K}_{\mathrm{i}}$ values of $>10,000$ indicate that assays with $10 \mu \mathrm{M}$ concentration of the compound showed no inhibition under the assay conditions 


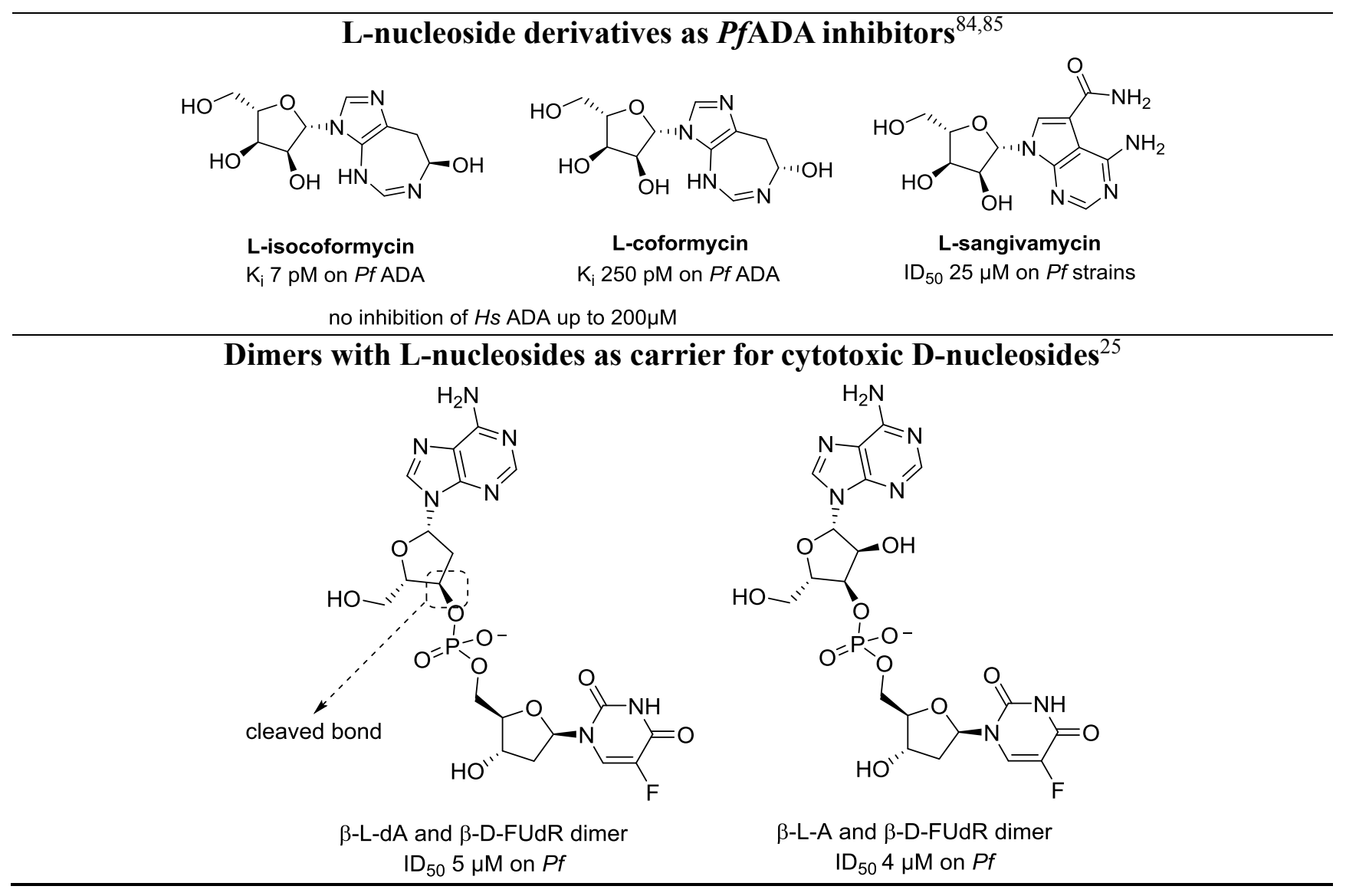

Gero et al. took advantage of the ability of some L-nucleosides to be selectively transported into infected erythrocytes and proposed dinucleoside monophosphate prodrugs (Table 2) that combined a Lnucleoside as carrier and a cytotoxic nucleoside as antimalarial agent. ${ }^{25}$ The release mechanism involved the cleavage of the 3'-5' phosphodiester linkage, delivering the free 3'-OH L-nucleoside and the 5'monophosphate D-nucleoside (the position of the phosphate moiety, 3'- or 5'- inside the targeted cell, was shown to be crucial for the activity. The best results were obtained for dinucleotides containing 5-fluoro2'-D-deoxyuridine (FUdR) as cytotoxic nucleoside and 2'-deoxy-L-adenosine or L-adenosine as carriers, with in vitro antimalarial activities in the low micromolar range. No further information is currently available. 


\section{b. Pf PNP Inhibition}

- First generation: immucillins

In 1966, Reist et al. first synthesized an adenosine analogue in which the sugar ring oxygen was replaced by a nitrogen. ${ }^{86}$ In 1998, studies on bovine PNP transition states led Miles et al. to design immucillin-H (Imm-H) and immucillin-G (Imm-G), as analogues of the proposed riboxocarbenium ion transition state. ${ }^{87}$ These compounds are iminoribitol $C$-glycoside derivatives incorporating an iminoribitol sugar scaffold and 9-deazapurines. Replacement of the labile glycosidic bond by a C-N link led to a stable analogue with increased $\mathrm{pKa}$ values for the nucleobase $\mathrm{N}^{7}$ atom (Figure 11). Tight binding constants, in the picomolar range, were determined for these two immucillins on bovine and human PNP.

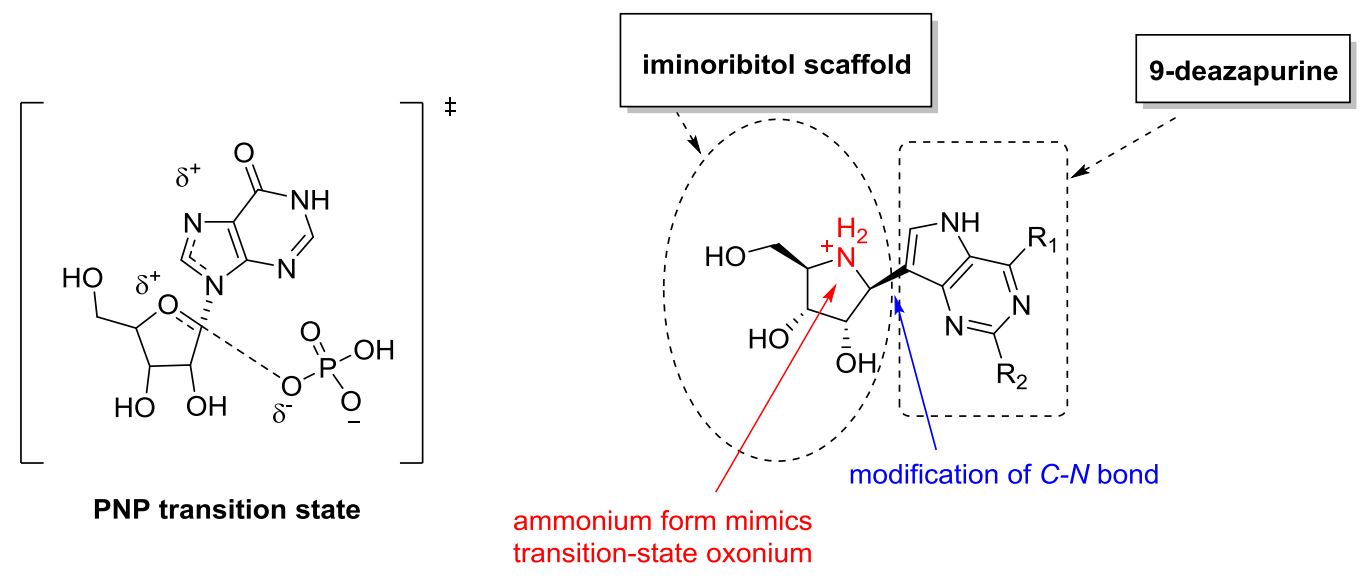

Figure 11: Common structure of first-generation immucillins

In 2002, Imm-H, Imm-G and analogues were evaluated as PfPNP inhibitors (Table 3) ${ }^{48}$ and Imm-H was also shown to be able to kill parasites in culture experiments, with an $\mathrm{IC}_{50}$ of $63 \mathrm{nM}$ (3D7 strain). ${ }^{54}$ But these immucillin derivatives were first designed as substrates of human PNP and exhibited low to modest selectivity for parasite PNPs, which is a crucial point for the development of antimalarial immucillins. As the structures of the Pf PNP-ImmH complex revealed that the enzyme could accept 5'-substitued nucleosides, ${ }^{49}{ }^{5}$ '-methylthioimmucillin (MT-ImmH) was designed to selectively target the parasite 
enzyme. 5'-MT-ImmH inhibited both human and $P f$ PNP in infected erythrocyte cultures and selectively bound to the $P f$ enzyme according to the $\mathrm{K}_{\mathrm{i}}$ values (Table 3). Later, it was also demonstrated that MTImmH was able to kill $P f$ in cultures, with an $\mathrm{IC}_{50}$ of $50 \mathrm{nM}$ (3D7 strain). ${ }^{54}$ Other immucillin analogues (e.g. 2'-deoxy-Imm, 8-aza or fluorinated purine, 6-methoxy or thiopurine, 5'-acid or amide-Imm, ara-Imm, etc.) were reported by Lewandowicz et al., but they all exhibited higher binding affinity for human protein. ${ }^{88}$ Overall, these studies highlighted that the 5 '-methylthiosubstitution resulted in a unique $P f$ PNP substrate specificity, as observed for MT-ImmH.

\section{Table 3. Transition state analogues as $P f P N P$ inhibitors}

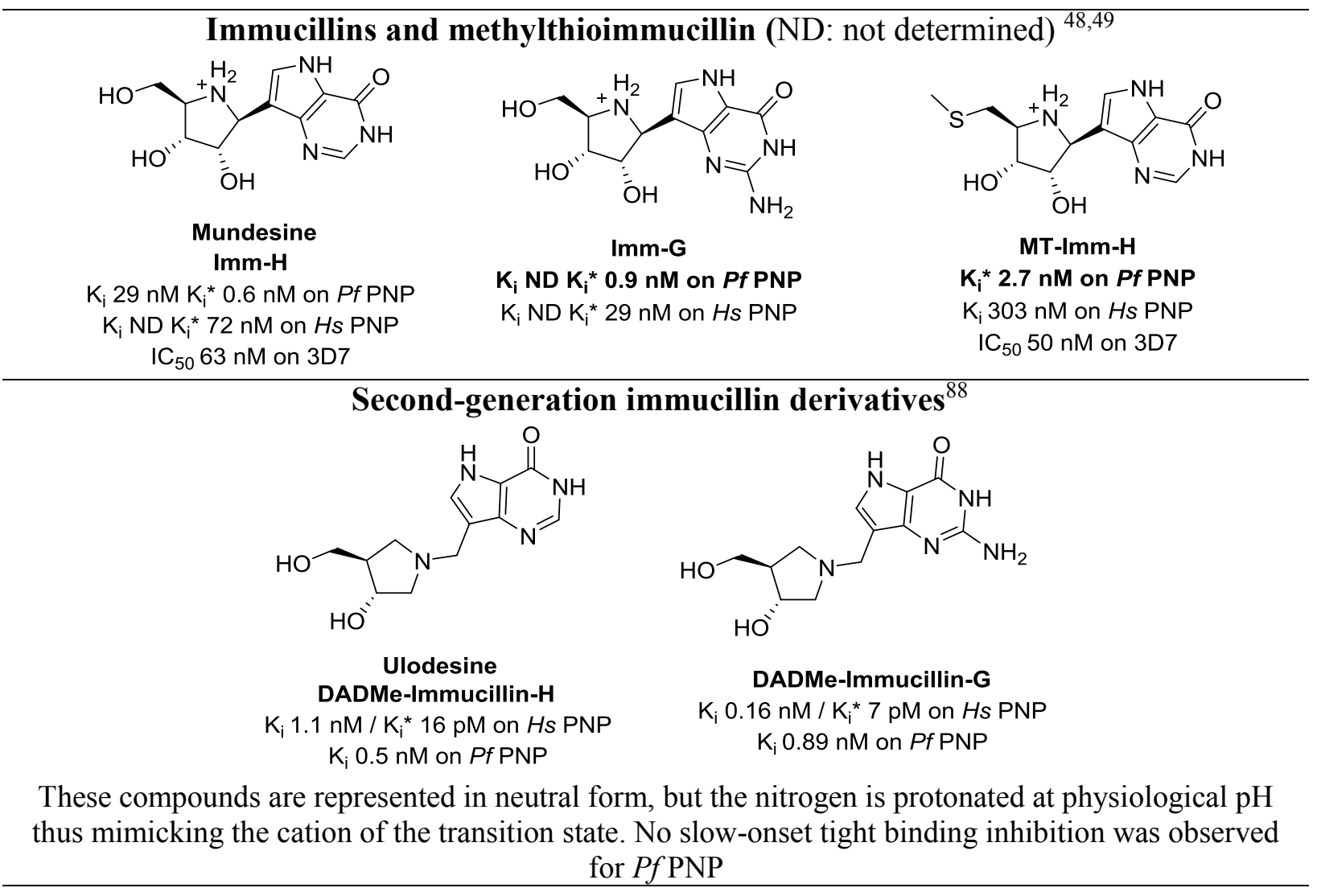




\section{Fluorinated second-generation immucillins ${ }^{89}$}

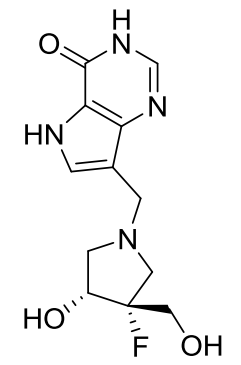

(3R,4R)-F-DADMe-ImmH $\mathrm{K}_{\mathrm{i}} 18 \mathrm{nM} \mathrm{K} \mathrm{K}_{\mathrm{i}}^{*} \mathbf{1 . 8 2} \mathrm{nM}$ on Hs PNP $\mathrm{K}_{\mathrm{i}} 2070 \mathrm{nM} \mathrm{K}_{\mathrm{i}}^{*} 260 \mathrm{nM}$ on Pf PNP

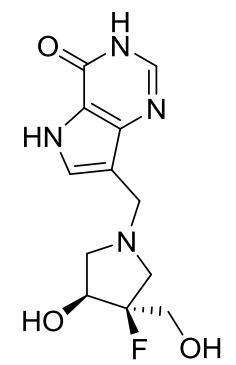

(3S,4S)-F-DADMe-ImmH $\mathrm{K}_{\mathrm{i}} \mathbf{0 . 3 3} \mathrm{nM} \mathrm{K}_{\mathrm{i}}{ }^{*} \mathbf{0 . 0 3 2} \mathrm{nM}$ on Hs PNP $\mathrm{K}_{\mathrm{i}} 19 \mathrm{nM} \mathrm{K}_{\mathrm{i}}^{*} 2.63 \mathrm{nM}$ on Pf PNP

\section{$\mathrm{K}_{\mathrm{i}} \mathbf{0 . 5 0} \mathrm{nM} \mathrm{K}_{\mathrm{i}}^{*} \mathbf{0 . 0 6 6} \mathrm{nM}$ on Hs PNP \\ $\mathrm{K}_{\mathrm{i}} 23.3 \mathrm{nM} \mathrm{K}_{\mathrm{i}}^{*} 3.6 \mathrm{nM}$ on Pf PNP}

\section{Third-generation immucillin derivatives ${ }^{90,1}$}<smiles>O=c1[nH]cnc2c(C3C(O)C(O)C(O)C3CO)c[nH]c12</smiles>

DATMe-Imm-H

$\mathrm{K}_{\mathrm{d}} 8.6 \mathrm{pM}$ on Hs PNP $\mathrm{K}_{\mathrm{d}} 55 \mathrm{nM}$ on Pf PNP

The complete iminoribitol ring shown in red<smiles>C=C(O)C(O)C1NC(CO)C(O)C1c1c[nH]c2c(=O)[nH]cnc12</smiles>

$\mathrm{K}_{\mathrm{d}} \mathbf{0 . 2 1} \mathrm{nM}$ on Hs PNP

$\mathrm{K}_{\mathrm{d}} 297 \mathrm{nM}$ on Pf PNP<smiles>[R2]c1nc([R])c2[nH]cc(C3CC(O)C(CO)N3)c2n1</smiles>

$$
\mathbf{R}_{\mathbf{1}}=\mathbf{O H}, \mathbf{R}_{\mathbf{2}}=\mathbf{H} \text {, SerMe-ImmH }
$$

$\mathrm{K}_{\mathrm{d}} 5.2 \mathrm{pM}$ on $H s$ PNP

$\mathrm{K}_{\mathrm{d}} 2.1 \mathrm{pM}$ on $H s$ PNP

The intact iminoribitol ring is shown in red

\section{L-enantiomers of potent immucillins ${ }^{92}$}<smiles>O=c1[nH]cnc2c(CN3C[C@@H](CO)[C@@H](O)C3)c[nH]c12</smiles>

L-DADMe-ImmH

$\mathrm{K}_{\mathrm{i}} 1.5 \mathrm{nM} / \mathrm{K}_{\mathrm{i}}{ }^{*} \mathbf{0 . 6 8} \mathrm{nM}$ on Hs PNP $\mathrm{K}_{\mathrm{i}} 1700 \mathrm{nM} / \mathrm{K}_{\mathrm{i}}^{*} 80 \mathrm{nM}$ on Pf PNP<smiles>O=c1[nH]cnc2c([C@@H]3N[C@H](CO)[C@@H](O)[C@H]3O)c[nH]c12</smiles>

L-ImmH

$\mathrm{K}_{\mathrm{i}} 18 \mathrm{nM} / \mathrm{K}_{\mathrm{i}}^{*} 0.9 \mathrm{nM}$ on Hs PNP $\mathrm{K}_{\mathrm{i}} 32 \mathrm{nM} / \mathrm{K}_{\mathrm{i}}^{*} 9 \mathrm{nM}$ on Pf PNP

- Second generation immucillins: N1-branched analogues

To overcome the expensive and complex synthesis of these immucillins, the development of a second generation of Imm derivatives was considered while focusing on easier synthetic pathways. The latter initiatives generally involved the displacement nitrogen close to the $\mathrm{C} 1$ ' position on the iminoribitol ring 
to mimic the PNP transition state. This modification nevertheless requires removal of the 2'-hydroxy group to avoid the formation of an unstable hemiaminal scaffold and to eliminate one asymmetric carbon. On the basis of a structural analysis and theoretical calculations, Schramm's group proposed DADMeimmucillin-H (4'-deaza-1'-aza-2'-deoxy-1'-(9-methylene)-immucillin-H, derivatives (Table 3), where the introduction of a methylene bridge between the sugar residue and 9-deazahypoxanthine allows the leaving group to be more distant from the oxacarbenium ion mimic than in Imm-H. ${ }^{52}$

DADMe-immucillin-H (BCX-3408) and DADMe-immucillin-G (4'-deaza-1'-aza-2'-deoxy-1'-(9methylene)-immucillin-G, BCX4945) (Table 3) have been identified as potent human PNP inhibitors (with picomolar $\mathrm{K}_{\mathrm{i}}^{*}$ values) ${ }^{93}$ since 2003 while exhibiting lower affinities for $P f$ PNP. ${ }^{88}$ Despite this, DADMe-immucillin-G has been shown to completely inhibit $P f$ PNP and suppress $P$. falciparum development in Aotus primates, ${ }^{94}$ but no further development has been reported to date.

Many immucillin derivatives have been proposed and studied (fluorinated, $\mathrm{N}$-alkylated, 5' $\mathrm{H}, 5^{\prime}$ thiophenol, 5'-carboxylic acids, etc.) to revert the selectivity of these derivatives toward the $P f$ enzyme, but they preferentially bound to $H s$ PNP rather than $P f$ PNP (Table 3). ${ }^{88,89}$

Second and first generation immucillins and transition state studies on bovine, human and malarial PNPs were reviewed by Schramm in $2005 .^{95}$

In 2010, Cui et al. proposed novel $N$-branched immucillin derivatives where the purine base was replaced by uracil, as uridine was reported to be a PNP substrate, including variations in the linker length between the base and the pyrrolidine ring. ${ }^{96}$ Modest affinities for $P f$ PNP were determined for uracil-based transition state analogues $\left(\mathrm{K}_{\mathrm{i}}\right.$ in the micromolar range), and no significant antiparasitic activity was observed in vitro. 
- Third generation immucillins: Acyclic analogues

As a continuation of their research program on transition state analogues as PNP inhibitors, Schramm's group designed third generation acyclic immucillin derivatives by cleaving the iminoribitol ring, which led to iminoalcohol chains linked to 9 -deazapurine ${ }^{90}$, or by replacing the pyrrolidine ring by a serinol chain. ${ }^{91}$ The flexibility of the acyclic scaffold allowed the chain to rotate freely inside the active site, possibly enhancing the positioning of the compound. In addition, these compounds were easier to synthesized while using cheaper precursors. Only the acyclic iminoalcohol series was assessed against both human and $P f$ PNPs, and all compounds exhibited better selectivity for human protein. The best $\mathrm{K}_{\mathrm{d}}$ value for the human enzyme was reported for the imino-tri-alcohol DATMe-Imm-H (Table 3). Pf PNP thus seemed to be more selective for the ribose ring than its human homologue, and consequently DADMe-immucillins and immucillins are still the best compounds in this series to date.

- L-nucleosides

Several studies carried out on L-enantiomers of known biologically active nucleoside analogues have highlighted the importance of isometry and the potential of L-nucleosides. ${ }^{97-99}$ Based on these observations, Clinch et al. synthesized and compared D-immucillins (Table 3) to their L- enantiomers against human and $P f$ PNPs (Table 3). ${ }^{92}$ All L-analogues were less potent than their D-enantiomers against malarial and human protein, while showing nanomolar range inhibition. No selectivity towards $P f$ enzymes was reported.

\section{c. PfHGXPRT Inhibition}

In 1999, Li et al. hypothesized that known transition state inhibitors of PNPs could also mimic HGPRT (human enzyme) and HGXPRT ribooxocarbenium species after phosphorylation of the 5'hydroxyl of the nucleoside analogue. ${ }^{100}$ The nitrogen atom replacing the intracyclic oxygen of ribose in immucillins can provide a cation which may serve as the ribocation transition state of the enzyme. 5'- 
monophosphate derivatives of immucillinH and immucillinG (Figure 12: Comparative affinities of 5'phosphate immucillin derivatives for Hs HGPRT and Pf HGXPRT) were thus synthesized and evaluated towards $P f$ and human $\mathrm{HG}(\mathrm{X}) \mathrm{PRT}$, and the two compounds were found to exhibit similar affinities to both proteins in the low nanomolar range. Immucillin 5'-monophosphate derivatives were not further investigated due to their susceptibility to phosphates present in biological media.

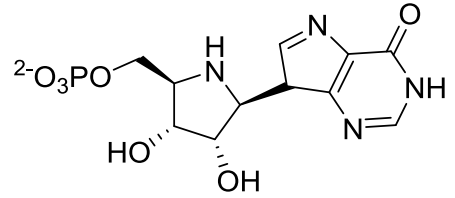

immucillinHP

$\mathrm{K}_{\mathrm{i}} \mathrm{ND} / \mathrm{K}_{\mathrm{i}}^{*} 1 \mathrm{nM}$ on Pf HGXPRT $\mathrm{K}_{\mathrm{i}} 250 \mathrm{nM} / \mathrm{K}_{\mathrm{i}}^{*} 1.8 \mathrm{nM}$ on Hs HGPRT

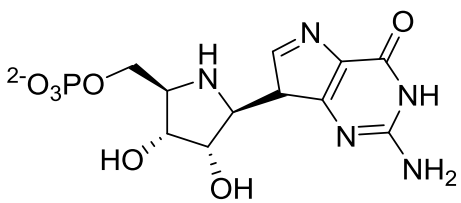

immucillinGP

$\mathrm{K}_{\mathrm{i}} \mathrm{ND} / \mathrm{K}_{\mathrm{i}}^{*} 14 \mathrm{nM}$ on Pf HGXPRT

$\mathrm{K}_{\mathrm{i}} 56 \mathrm{nM} / \mathrm{K}_{\mathrm{i}}^{*} 4.6 \mathrm{nM}$ on Hs HGPRT

Figure 12: Comparative affinities of 5'-phosphate immucillin derivatives for $H s$ HGPRT and $P f$ HGXPRT

In 2012, Hazleton et al. reported the synthesis and biological assessment findings of a second generation of immucillin-5'-monophosphate analogues belonging to the acyclic phosphonate family. In this review, these derivatives are part of the aza-ANPs section. ${ }^{101}$ Briefly, acyclic immucillin phosphonates (AIPs) were the first compounds to show tight binding inhibition of $P f$ (with $\mathrm{K}_{\mathrm{i}}$ in the nanomolar range) and human (with $\mathrm{K}_{\mathrm{i}}$ in the micromolar range) phosphoribosyl transferases, thus good selectivity for the parasite protein was observed.

d. Conclusion on immucillins and transition state analogues

The use of transition state analogues has been successful in inhibiting PNP, ADA and HGXPRT. A wide variety of structures, mainly based on the immucillin skeleton (four generations developed through the years), have been synthesized along with studies on the purified enzymes. One of their limitations is their lack of selectivity regarding human and parasite enzymes, and their entry into the parasite may also 
be problematic due to their high polarity. To our knowledge, the mechanism of their uptake into parasites does not involve $P f$ ENT1 transporters. ${ }^{31}$ In 2012, Frame et al. demonstrated that immucillin and DADMeimmucillins were recognized by $P f$ ENT $4,{ }^{35}$ suggesting the possible role of this transporter in the uptake of these compounds into the parasite

The fourth generation of immucillins designed as human PNP transition state analogues were reviewed by Ho et al. in 2007. ${ }^{102}$ DADMe-immucillin-G was under preclinical development for malaria treatment in $2011,{ }^{94}$ but the data are currently unavailable. Finally, as for all known antimalarial treatments, Plasmodium falciparum has developed genetic drug resistance (gene amplification and drug-binding mutations of $P f$ PNP gene) to PNP inhibition by DADMe-Imm-G, as recently demonstrated by Ducati $e t$ al. ${ }^{103}$

4. Nucleotide analogues: the acyclic nucleoside phosphonate family

a. Introduction to acyclic nucleoside phosphonate derivatives

Since the 1960s, nucleoside analogues have been proposed as antiproliferative agents based on their ability to interfere (as their 5'-triphosphate derivatives) with the last steps of nucleic acid biosynthesis. Extensive modification of the nucleobase and/or sugar moiety was carried out to enhance their efficacy. In 1978, A. Holy and E. De Clercq described the broad spectrum antiviral activity of a new family of nucleoside analogues consisting of a simple aliphatic chain linked to a nucleobase, i.e. (S)-DHPA ( (S)-9(2,3-dihydroxypropyl)adenine, also known as Duviragel ${ }^{\circledR}$, (Figure 13: First acyclic nucleoside and nucleoside phosphonate analogues designed). ${ }^{104} \mathrm{~A}$ few months earlier, G. Elion had reported a new antiherpetic agent, another acyclic nucleoside analogue, ${ }^{105}$ i.e. 9-(2-hydroxyethoxymethyl)guanine, currently known as acyclovir (Figure 13: First acyclic nucleoside and nucleoside phosphonate analogues designed) and in 1988 she shared the Nobel Prize with G. H. Hitchings and Sir J. Black for 
this discovery. Studies on the antiviral potential of phosphonoacetic acid, with the aim of developing isopolar and catabolically stable nucleotide analogues, gave rise to the design of the first acyclic nucleoside phosphonate (ANP) in 1986 by Holy et al, i.e. (S)-HPMPA or ((S)-9-(3-hydroxy-2phosphonomethoxy-propyl)adenine) (Figure 13). The latter was described as a nucleotide analogue resistant to phosphoesterase hydrolysis due to the presence of the phosphonate moiety (P-C bond) and an acyclic chain replacing the sugar ring, and it was found to be active against anti-DNA viruses. ${ }^{106}$ Meanwhile, the antiviral activity of 2-(phosphonomethoxy)ethyl-adenine (PMEA) was also reported. ${ }^{107}$ (S)-HPMPC (cidofovir) was the first ANP marketed (in 1996) for cytomegalovirus retinitis treatment. Over the last three decades, many ANPs have been designed, synthesized and evaluated against viruses (cytomegalovirus, hepatitis B and HIV), and they still represent a promising and efficient family of drugs. ${ }^{108,109}$

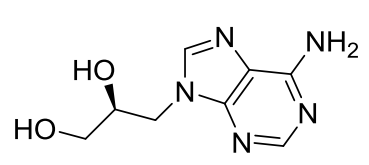

(S)-DHPA Duviragel $^{\circledR}$

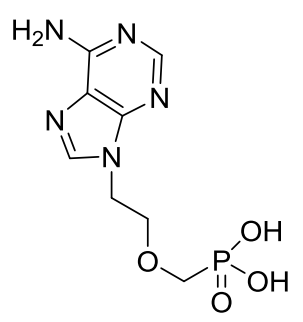

PMEA

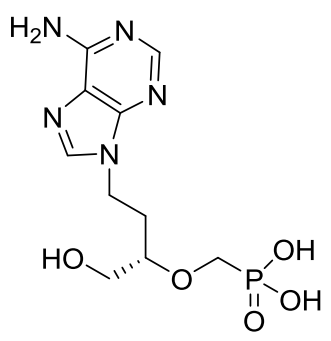

(S)-HPMPA

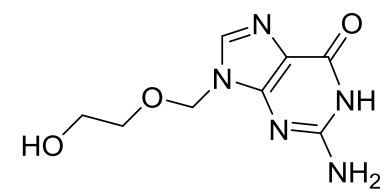

Acyclovir

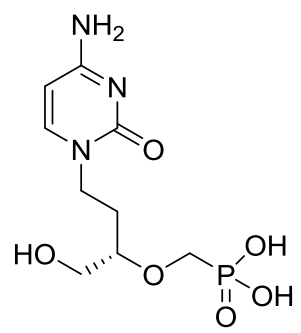

Cidofovir

(S)-HPMPC

Figure 13: First acyclic nucleoside and nucleoside phosphonate analogues designed

Due to their negative charge and relatively small structure, phosphonate derivatives are too polar to easily cross cell membranes, except by endocytosis. Infected erythrocytes, like normal RBCs, are not able to undergo endocytosis. ${ }^{110}$ The drug therefore must reach the intracellular parasite by successively crossing 
erythrocyte, parasitophorous vacuole and parasite membranes. Consequently the use of prodrugs to enhance the lipophilicity of the drug by hiding charges and/or adding long aliphatic tails is essential to increase cell uptake and the overall bioavailability of these derivatives. ${ }^{111,112}$ These temporary phosphonate moiety protecting groups, once within the parasite or RBC, are cleaved to release the parent drug and eventually limit possible side-effects before delivery.

Prodrug approaches have been successfully applied to ANPs in antiviral chemotherapy, including adefovir dipivoxil (Hepsera ${ }^{\circledR}$, approved in 2002 for chronic HBV infection treatment) and tenofovir disoproxil fumarate (Viread® , approved in 2001 for HIV infection treatment). ${ }^{113,114}$

\section{b. Standard acyclic nucleoside phosphonates}

Based on the success of ANPs in chemotherapeutic treatment of DNA virus infections, several groups have assessed their potential for treating other diseases, namely in protozoan infections like malaria. In this respect, $(S)$-HPMPA, $(S)$-3-deaza HPMPA and $(S)$-HPMPADAP (2,6-diaminopurine) were first tested in 1991 against $P f$ and $P$. berghei infected RBCs (Figure 14). S-HPMPA is active in vitro against $P f$ at nanomolar concentration, which is more than 1,000-fold less than the cytotoxic dose for human cells.

${ }^{115}$ When evaluated in P. berghei infected mice, four injections of $20 \mathrm{mg} / \mathrm{kg}$ HPMPA at 3-day intervals decreases parasitemia to low detectable levels but does not lead to a complete cure. ${ }^{115}$ Using extracted plasmodial DNA polymerases, the inhibitory activity of these compounds was also observed and interference with the replication process was hypothesized. Unfortunately, the effects of $(S)$-HPMPA in $P f$ infected mice were hampered by nephrotoxicity and hepatotoxicity as well as the limited half-life in plasma. ${ }^{116}$

In 1999, Smeijsters et al. conducted an in vitro study of 48 ANPs belonging to five main structural groups with the aim of inhibiting plasmodial DNA polymerase activity (Figure 14). ${ }^{117}$ All HPMPA derivatives (except (S)-HPMPA and (S)-3-deaza-HPMPA) exhibited antiplasmodial activity in the micromolar range. 
(S)-HPMPA was found to be less potent $(0.18 \mu \mathrm{M})$ than reported by de Vries et al. due to the use of a different $\mathrm{IC}_{50}$ determination method. One of the most interesting results was the difference in $\mathrm{IC}_{50}$ between the two isomers of HPMPA and 3-deaza-HPMPA. Indeed, $(R)$-enantiomers of both compounds were less potent than the $(S)$-enantiomers. This was attributed to the fact that kinases may not be able to recognize $(R)$-enantiomers of phosphorylated substrates.

Conversely, PMEA derivatives had no significant activity, presumably due to the lack of the hydroxyl group present in the HPMPA derivatives. Studies on hydrogenated and fluorinated ((S)-FPMPA) derivatives revealed no inhibition, thus confirming the previous hypothesis. However, the difference in antimalarial activity observed between PMEA $\left(\mathrm{IC}_{50}>250 \mu \mathrm{M}\right)$ and its prodrugs bis( $\left.\mathrm{POM}\right) \mathrm{PMEA}\left(\mathrm{IC}_{50}=\right.$ $37.3 \mu \mathrm{M}$ ) was significant. As the prodrug is more lipophilic and neutral than PMEA, the improved activity could be explained by the efficient prodrug uptake through the host cell and parasite membranes.

Modification of the nucleobase counterpart with similar phosphonate tail was then envisaged. (S)-HPMPG exhibited a similar antimalarial activity of about $4 \mu \mathrm{M}$, as well as 2-chloroadenine, 2,6-diaminopurine, 7deazaadenine HPMP compounds, whereas 2-aminomethyladenine, 2-aminomethylhypoxanthine or 2methylthioadenine derivatives did not exhibit any activity at $100 \mu \mathrm{M} .{ }^{117}$ The nature of the nucleobase and the presence of the phosphonate moiety thus seemed to be crucial as non-phosphorylated compounds (acyclic nucleoside) were inactive. For the latter, either the lack of appropriate kinases in Plasmodium limits their transformation into active form and/or their polarity prevents their passive passage through the membranes. 


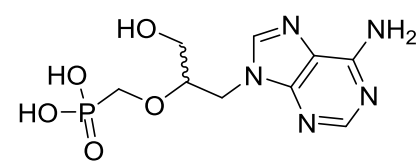

(S)-HPMPA IC $\mathrm{C}_{50} 0.18 \mu \mathrm{M}$ (R)-HPMPA IC ${ }_{50} 6 \mu \mathrm{M}$

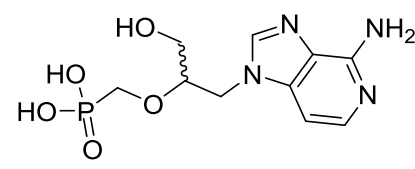

(S)-3-deaza-HPMPA IC $\mathrm{I}_{50} 0.29 \mu \mathrm{M}$ (R)-3-deaza-HPMPA IC $50100 \mu \mathrm{M}$

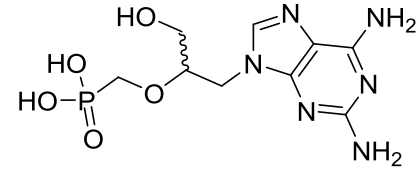

(S)-HPMPDAP IC $502.1 \mu \mathrm{M}$ (R)-HPMPDAP IC $_{50} 15 \mu \mathrm{M}$

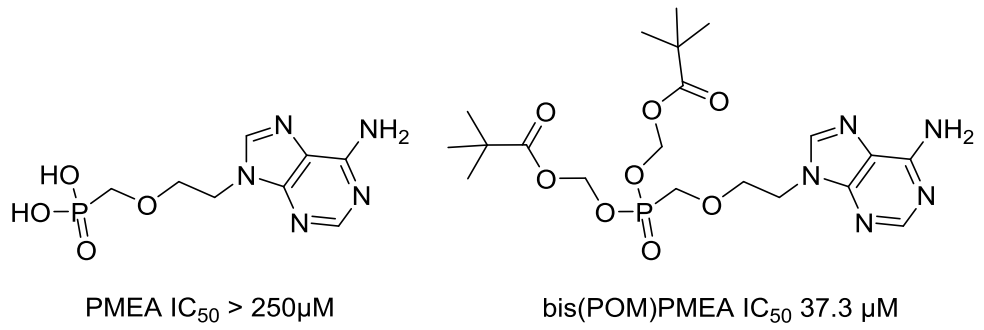

Figure 14: IC50 of several ether ANPs in Pf-infected RBCs (from Smeijsters et al.)

Obviously these compounds could target any enzymes involved in nucleic acid metabolism pathways, but Smeijsters et al. focused on the potency of ANPs to inhibit DNA replication (because $(S)$-HPMPA has been described as a viral DNA polymerase inhibitor) but did not envisage any other possibilities. Note also that pyrimidine-containing ANPs, such as (S)-HPMPU, (S)-HPMPT and (S)-HPMPC, did not show any parasite growth inhibition. ${ }^{117}$

In conclusion, this pioneer work highlighted the antimalarial potency of ANPs and the importance of the nature of the nucleobase and the stereochemistry for in vitro antiplasmodial activity, as well as the possible passive uptake of these drugs when the corresponding prodrugs were used.

In 2009, Keough et al. reported, for the first time, novel series of ANPs to target Pf HGXPRT. ${ }^{118}$ These authors performed an SAR study to compare the length and position of the oxygen atom within the phosphonate tail (e.g. cyclic-3-hydroxy-2-(phosphonomethoxy)-propyl (cyclic-HPMP), 2(phosphonoethoxy)ethyl (PEE), 2-(phosphonomethoxy)ethyl (PME), 3-fluoro-2-(phosphonomethoxy)propyl (FPMP), 2-(phosphonomethoxy)propyl (PMP), etc., (Figure 15: Inhibition constants of two series (C4 and C5) of ether ANPs on parasite and human 6-oxopurine PRTs) and the nature of the nucleobase on the affinity for $P f$ and human enzymes, and selectivity toward the parasite protein. A comparison of several PME analogues revealed that the nature of the nucleobase had a crucial effect on 
binding to the human HGPR catalytic site. The best tradeoff in terms of affinity $\left(\mathrm{K}_{\mathrm{i}}\right.$ in the low micromolar range) and selectivity was found to be the combination of a PEE tail and a 8-substituted guanine as nucleobase (i.e. 8-azaguanine, etc.). Selected derivatives were tested in vitro and were found to be able to inhibit the $P f$ growth, with $\mathrm{IC}_{50}$ values in the micromolar range (Figure 15). ${ }^{118}$

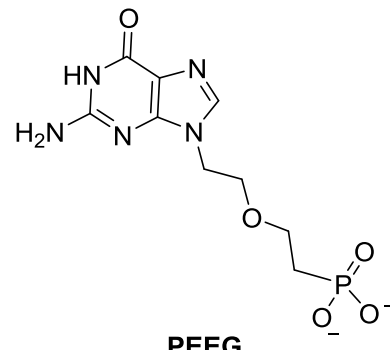

$\mathrm{K}_{\mathrm{i}} 0.1 \mu \mathrm{M}$ on Pf HGXPRT

$\mathrm{K}_{\mathrm{i}} 1 \mu \mathrm{M}$ on $\mathrm{Hs}$ HGPRT

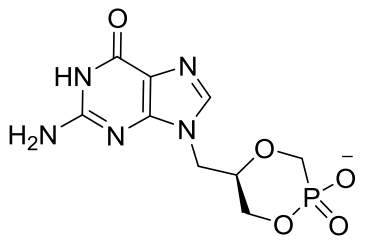

Guanine cyclic-(R)-HPMP $\mathrm{K}_{\mathrm{i}} 1 \mu \mathrm{M}$ on Pf HGXPRT $\mathrm{K}_{\mathrm{i}} 19 \mu \mathrm{M}$ on Hs HGPRT $\mathrm{IC}_{50} 46 \mu \mathrm{M}(P f)$ $\mathrm{IC}_{50}>1 \mathrm{mM}$ (human A549 cells)

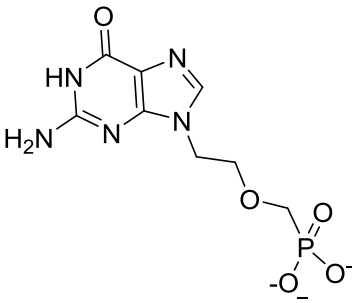

Guanine-PME $\mathrm{K}_{\mathrm{i}} 1.6 \mu \mathrm{M}$ on Pf HGXPRT $\mathrm{K}_{\mathrm{i}} 29 \mu \mathrm{M}$ on Hs HGPRT $\mathrm{IC}_{50} 14 \mu \mathrm{M}(P f)$

$\mathrm{IC}_{50} 17 \mu \mathrm{M}$ (human A549 cells)

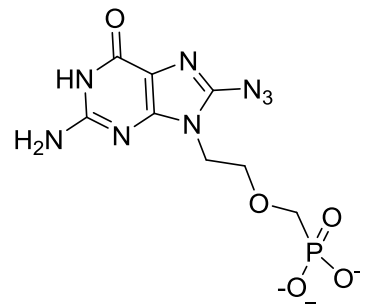

8-AzaGuanine-PME

$\mathrm{K}_{\mathrm{i}} 3 \mu \mathrm{M}$ on Pf HGXPRT $\mathrm{K}_{\mathrm{i}} 175 \mu \mathrm{M}$ on Hs HGPRT

\section{Figure 15: Inhibition constants of two series (C4 and C5) of ether ANPs on parasite and human 6-}

\section{oxopurine PRTs}

In the absence of any crystallized $P f$ HGXPRT with the studied ANPs, human HGPRT complexes were used as models in structural studies and highlighted that the loop hosting the phosphonate or phosphate group seemed to be identical for both enzymes. ${ }^{118}$ The three oxygen atoms of the phosphonate group makes hydrogen bonds with the protein, whereas the natural substrate (GMP) has fewer hydrogen bonds, indicating that the phosphonate group is essential for tight binding at the active site while not being involved in any selectivity contribution. According to docking studies, the purine ring of ANPs binds at the nucleobase binding site of the enzyme. These results pave the way for the development of ANPs targeting HGXPRT, based on the fact that the potency of this family was found to inhibit $P f$ growth in vitro and on findings regarding their interaction within the active site of the enzyme. 
Meanwhile, these authors also reported the synthesis of $43 \alpha$ - and $\beta$-substituted PEE derivatives bearing guanine and hypoxanthine (Figure 16: Structure of $\alpha$ - and $\beta$ - branched 2-(phosphonoethoxy)ethyl ANPs) and their inhibitory activity against $P f$ and human $\mathrm{HG}(\mathrm{X}) \mathrm{PRT}$ was determined. ${ }^{119}$ Overall, $\alpha-$ substituted $\left(\mathrm{R}_{1}=\right.$ methyl or ethyl) phosphonate derivatives were either non-active or weakly active against both enzymes and it was suggested that these results were due to steric hindrance.
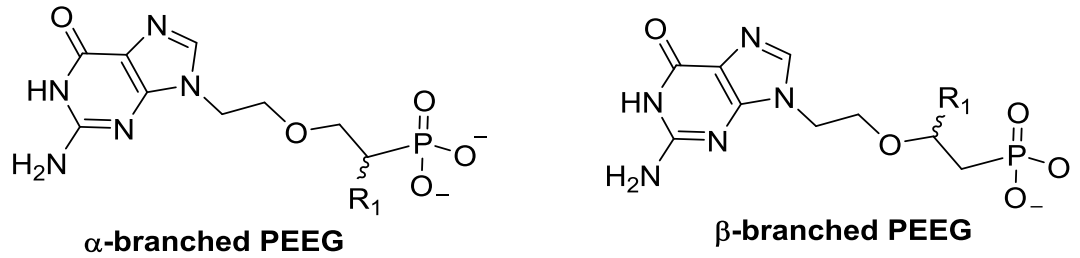

Figure 16: Structure of $\alpha$ - and $\beta$ - branched 2-(phosphonoethoxy)ethyl ANPs

The study of $\beta$-branched ANPs revealed inhibition of both enzymes (Figure 17: Inhibitory activities of $\beta$ - branched PEE ANPs on human HGPRT and Pf HGXPRT) in the micromolar range, but with low to reverse selectivity, with the natural nucleobases being preferred. The smallest substituents better accommodated the active site, and the absence of binding of a $\beta$-benzyl-substituted ANP was confirmed. It was hypothesized that the presence of substituents hampers proper closure of the loop in Pf HGXPRT.<smiles>CC(CP(=O)(O)O)OCCn1cnc2c(=O)[nH]c(N)nc21</smiles>

$\mathrm{K}_{\mathrm{i}} 1 \mu \mathrm{M}$ on Pf HGXPRT $\mathrm{K}_{\mathrm{i}} 0.1 \mu \mathrm{M}$ on Hs HGPRT

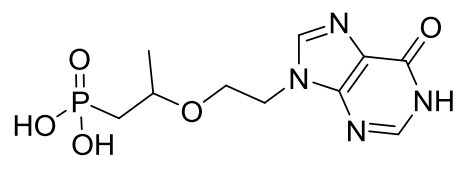

$\mathrm{K}_{\mathrm{i}} 10 \mu \mathrm{M}$ on Pf HGXPRT $\mathrm{K}_{\mathrm{i}} 2 \mu \mathrm{M}$ on Hs HGPRT

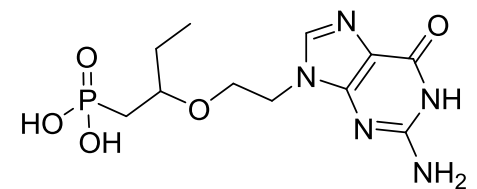

$\mathrm{K}_{\mathrm{i}} 5 \mu \mathrm{M}$ on Pf HGXPRT $\mathrm{K}_{\mathrm{i}} 0.3 \mu \mathrm{M}$ on Hs HGPRT

Figure 17: Inhibitory activities of $\beta$ - branched PEE ANPs on human HGPRT and Pf HGXPRT

Similarly, Cesnek et al. synthesized series of 9-phosphonoalkyl and 9-phosphonoalkoxyalkyl purines and tested them on human and $P v$ HGPRT, and on $P f$ HGXPRT (Figure 18: Studies of the impact of the chain length of ANPs on their inhibitory activities against Pf, Pv and human 6-oxopurinePRT). ${ }^{120}$ 
The optimal number of atoms within the linker thus seemed to be four or five, compounds with six atoms or more being highly selective for human HGPRT. This latter enzyme appears to be able to host longer derivatives than the parasite enzyme. The presence of an oxygen atom within the four-atom linker was mandatory for interfering with parasite proteins, indicating that the oxygen in the ribose ring may be responsible for important binding site interactions. As previously observed, guanine is apparently the preferred nucleobase and all modified nucleobases (2-amino-6-chloropurine, 6-bromopurine, etc.) lead to derivatives with weaker inhibitory activities $\left(\mathrm{K}_{\mathrm{i}}\right.$ values above $\left.100 \mu \mathrm{M}\right)$. This indicates that efficient binding of both the phosphonate group and the nucleobase is essential at the catalytic site to obtain optimal $\mathrm{K}_{\mathrm{i}}$ values. In conclusion, at least a four carbon atom chain length and a guanine as nucleobase were required for significant inhibition of these proteins, but with low or no selectivity towards parasite proteins, while the presence of an oxygen atom in the linker was somewhat favorable. 


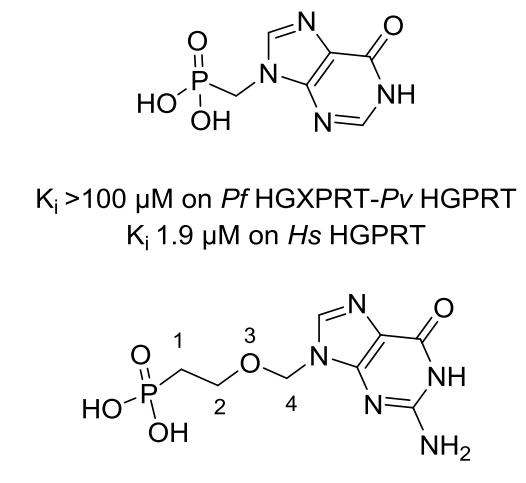

$\mathrm{K}_{\mathrm{i}}$ 5-24 $\mu \mathrm{M}$ on Pf HGXPRT-Pv HGPRT $\mathrm{K}_{\mathrm{i}} 31 \mu \mathrm{M}$ on Hs HGPRT

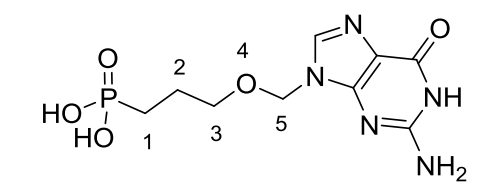

$$
\mathrm{K}_{\mathrm{i}} \text { 6.7-1 } \mu \mathrm{M} \text { on Pf HGXPRT-Pv HGPRT }
$$
$\mathrm{K}_{\mathrm{i}} 3 \mu \mathrm{M}$ on Hs HGPRT

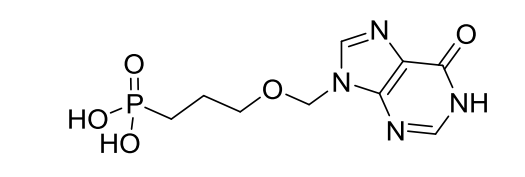

$\mathrm{K}_{\mathrm{i}} 47$ on Pf HGXPRT, $>100 \mu \mathrm{M}$ Pv HGPRT $\mathrm{K}_{\mathrm{i}}>100 \mu \mathrm{M}$ on Hs HGPRT

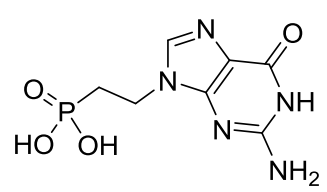

$\mathrm{K}_{\mathrm{i}}>100 \mu \mathrm{M}$ on Pf HGXPRT-P $v$ HGPRT $\mathrm{K}_{\mathrm{i}}>100 \mu \mathrm{M}$ on Hs HGPRT<smiles>Nc1nc2c(ncn2CCCCP(=O)(O)O)c(=O)[nH]1</smiles>

$\mathrm{K}_{\mathrm{i}}>100 \mu \mathrm{M}$ on Pf HGXPRT-P $v$ HGPRT $\mathrm{K}_{\mathrm{i}} 21 \mu \mathrm{M}$ on Hs HGPRT<smiles>Nc1nc2c(ncn2CCCCCP(=O)(O)O)c(=O)[nH]1</smiles>

$\mathrm{K}_{\mathrm{i}}$ 2-6 $\mu \mathrm{M}$ on Pf HGXPRT-Pv HGPRT $\mathrm{K}_{\mathrm{i}} 0.5 \mu \mathrm{M}$ on Hs HGPRT

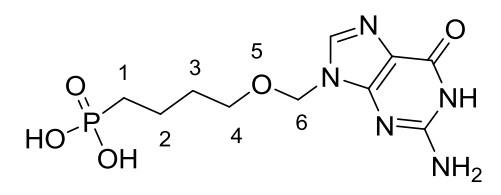

$\mathrm{K}_{\mathrm{i}}>100 \mu \mathrm{M}$ on Pf HGXPRT-Pv HGPRT

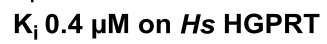

Figure 18: Studies of the impact of the chain length of ANPs on their inhibitory activities against

\section{$P f, P v$ and human 6-oxopurinePRTs}

Based on results on PEE derivatives, Krecmerova et al. proposed to study the effect of the insertion into the phosphonomethoxypropyl chain of a polar group (an hydroxyl or a carboxyl) at the $\beta$-position related to the nucleobase (Figure 19). ${ }^{121}$ These new derivatives, which incorporated a small polar or anionic side chain, were less efficient but presented some selectivity for $P f$ and $P v$ enzymes. These derivatives were all tested as racemic mixtures, so the impacts of stereoisomery could not be determined. 


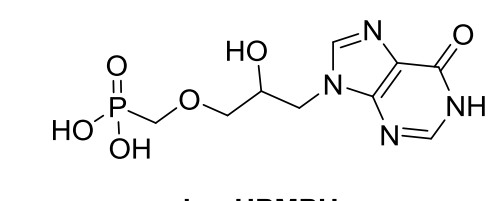

$$
\begin{gathered}
\text { iso-HPMPHx } \\
\mathrm{K}_{\mathrm{i}} 2-5 \mu \mathrm{M} \text { on Pf HGXPRT-P } v \text { HGPRT }
\end{gathered}
$$$$
\mathrm{K}_{\mathrm{i}} \mathrm{NI}^{\mathrm{a}} \text { on Hs HGPRT }
$$

${ }^{a}$ No inhibition at $<30 \mu \mathrm{M}$ concentration

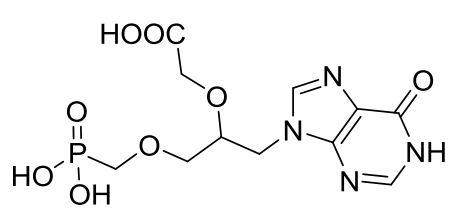

$\mathrm{K}_{\mathrm{i}} \mathrm{NI}^{\mathrm{b}}$ on $P f \mathrm{HGXPRT}-P v$ HGPRT

$\mathrm{K}_{\mathrm{i}} \mathrm{NI}^{\mathrm{b}}$ on $\mathrm{Hs}$ HGPRT

${ }^{b}$ No inhibition at $<100 \mu \mathrm{M}$ concentration

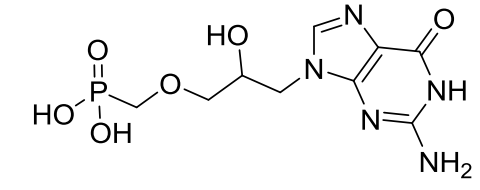

iso-HPMPG

$\mathrm{K}_{\mathrm{i}}$ 1.4-10 $\mu \mathrm{M}$ on Pf HGXPRT-Pv HGPRT

$\mathrm{K}_{\mathrm{i}} 4 \mu \mathrm{M}$ on $\mathrm{Hs}$ HGPRT

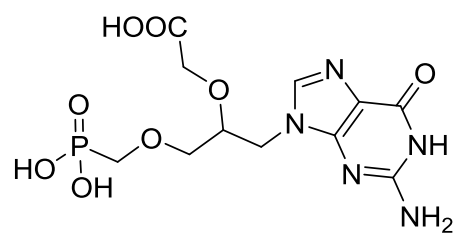

$\mathrm{K}_{\mathrm{i}}$ 5-27 on Pf HGXPRT-Pv HGPRT

$\mathrm{K}_{\mathrm{i}} 5 \mu \mathrm{M}$ on Hs HGPRT

Figure 19: Representatives of PMP ANPs

In 2015, on the basis of the results obtained for the HPMP series (Figure 14) and computational studies, novel analogues bearing side chains in the $\beta$-position related to the nucleobase were designed (Figure 20), including (S)-2-(phosphonoethoxy)propanoic acid (CPEE), (S)-3-hydroxy-2(phosphonoethoxy)propyl (HPEP) and (S)-2-(phosphonomethoxy)propanoic acid (CPME). ${ }^{122}$ Biological studies on $P f$ and human PRT enzymes revealed that CPME analogues were inactive, in agreement with the fact that a five-atom chain is optimal for tight interactions at the active site. ${ }^{123,124}$ Concerning HPEP derivatives, again the nature of the nucleobase was found to be crucial as only the 8-bromoguanine, guanine and hypoxanthine analogues showed some affinity (with $\mathrm{K}_{\mathrm{i}}$ in the low micromolar range), but only the guanine HPEP ANP presented a 6-fold better selectivity for the parasite enzyme. CPEE derivatives exhibited similar activities against both enzymes, and in this case only the hypoxanthine derivatives appeared to be more selective for Pf HGXPRT than for human HGPRT. Finally, the presence of an acidic, ester or hydroxyl group as side chain did not lead to a significant difference between these three series of compounds. The crystal structures of HPEPG and HPEPHx revealed that residues located 
in the vicinity of the active site were flexible and mobile, and the activity enhancement was hypothesized to be associated with the 'locking' of these residues (tighter binding).<smiles>Nc1nc2c(ncn2C[C@H](CO)COCCP(=O)(O)O)c(=O)[nH]1</smiles>

HPEP

$\mathrm{K}_{\mathrm{i}} 0.1 \mu \mathrm{M}$ on Pf HGXPRT $\mathrm{K}_{\mathrm{i}} 0.6 \mu \mathrm{M}$ on $\mathrm{Hs}$ HGPRT<smiles>Nc1nc2c(nc(Br)n2CC(CO)COCCP(=O)(O)O)c(=O)[nH]1</smiles>

HPEP

$\mathrm{K}_{\mathrm{i}}>30 \mu \mathrm{M}$ on Pf HGXPRT $\mathrm{K}_{\mathrm{i}} 13 \mu \mathrm{M}$ on Hs HGPRT<smiles>COC(=O)C(COCCP(=O)(O)O)Cn1cnc2c(=O)[nH]cnc21</smiles>

CPEE

$\mathrm{K}_{\mathrm{i}} 1 \mu \mathrm{M}$ on Pf HGXPRT

$\mathrm{K}_{\mathrm{i}} 6 \mu \mathrm{M}$ on $H s$ HGPRT

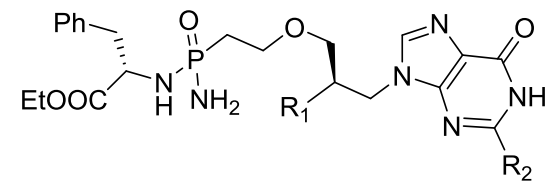

mono-substituted phosphorobisamidate prodrugs $\mathrm{IC}_{50}>250 \mu \mathrm{M}$ in D6 and W2 strains

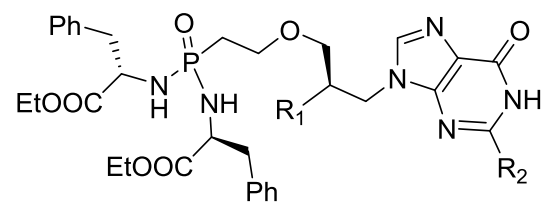

di-substituted phosphorobisamidate prodrugs CPEE Hx or $\mathrm{G}, \mathrm{IC}_{50} \sim 50 \mu \mathrm{M}$ in D6 and W2 strains HPEP G, IC ${ }_{50} 22-70 \mu \mathrm{M}$ in D6 and W2 strains

\section{Figure 20: HPEP and CPEE ANPs and their corresponding prodrugs}

$$
\mathrm{R}_{1} \text {, HPEP or CPEE side-chain; } \mathrm{R}_{2}, \mathrm{H} \text { or } \mathrm{NH}_{2} \text {. }
$$

In order to facilitate cell uptake, phosphorobisamidate prodrugs incorporating L-phenylalanyl moieties

(Figure 20: HPEP and CPEE ANPs and their corresponding prodrugs ) were prepared and assessed in vitro in $P f$ strains W2 and D6. ${ }^{122}$ Mono-substituted phosphorobisamidates did not exhibit significant antimalarial activity, probably due to the fact that the free amino group may not be easily hydrolyzed in cells. $\mathrm{IC}_{50}$ values of di-substituted phosphoramidate prodrugs ranged from 22 to $103 \mu \mathrm{M}$.

\section{c. Bisphosphonates ANPs - ANbPs}

On the basis of an analysis of the crystal structure of human HGPRT complexed with PEEG analogues, new series of ANPs containing a second oxymethylphosphonate group and increased flexibility of the two phosphonate tails were designed (Figure 21). ${ }^{125}$ Most of the compounds had $\mathrm{K}_{\mathrm{i}}$ values in the sub-micromolar range, but little selectivity towards $P f \mathrm{HG}(\mathrm{X}) \mathrm{PRT}$ was observed. Inhibitory activity against the parasite enzyme was noted when the oxygen atom of the phosphonate tail was moved from 
position 4 to 3 . The position of the oxygen atom may thus modify the chain conformation while enhancing its binding at the active site. Studies on the crystal structure of human HGPRT complexed with the first derivative of Figure 21 revealed that the second phosphonate group interacted with amino acid residues via $\mathrm{Mg}^{2+}$ ion, thus highlighting the contribution of this group in comparison to PEEG analogues. Docking studies also revealed that the second phosphonate group was located near the $\mathrm{PP}_{\mathrm{i}}$ binding site but did not share interactions inside this pocket.

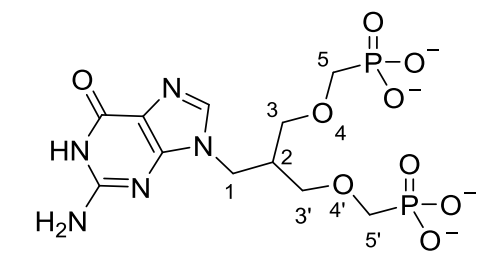

$\mathrm{K}_{\mathrm{i}}$ 0.07-0.6 $\mu \mathrm{M}$ on Pf-Pv HG(X)PRT

$\mathrm{K}_{\mathrm{i}} 0.03 \mu \mathrm{M}$ on Hs HGPRT

Crystal structure obtained in a complex with Hs HGPRT

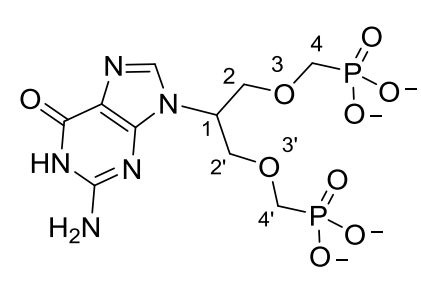

$\mathrm{K}_{\mathrm{i}}$ 2-18 $\mu \mathrm{M}$ on Pf-Pv HG(X)PRT $\mathrm{K}_{\mathrm{i}} 37 \mu \mathrm{M}$ on $H s$ HGPRT

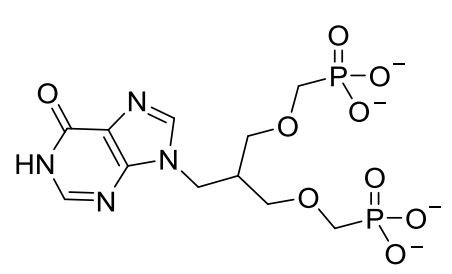

$\mathrm{K}_{\mathrm{i}}$ 5-2 $\mu \mathrm{M}$ on Pf-Pv HG(X)PRT $\mathrm{K}_{\mathrm{i}} 1 \mu \mathrm{M}$ on $\mathrm{Hs}$ HGPRT

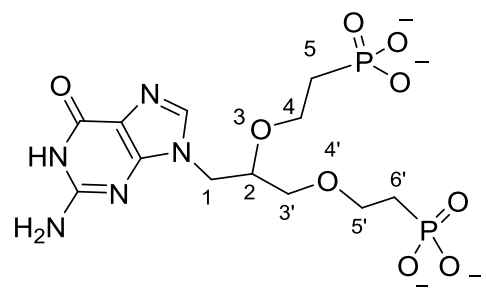

$\mathrm{K}_{\mathrm{i}}$ 0.5-0.7 $\mu \mathrm{M}$ on $P f-P v \mathrm{HG}(\mathrm{X}) \mathrm{PRT}$ $\mathrm{K}_{\mathrm{i}} 0.6 \mu \mathrm{M}$ on Hs HGPRT

Figure 21: Bisphosphonate ANPs tested on human and malarial 6-oxopurinePRTs

Two types of prodrug were proposed to increase the cell permeability of parent ANPs. The negative charges of PEEG (Figure 15) were either masked by one or two lipophilic chains (Figure 22), or as a bis phosphoramidate including an alanine ethyl ester. In comparison to the parent drug (PEEG, $\mathrm{IC}_{50} 242 \mu \mathrm{M}$ on $P f$ strain D6), the presence of two substituents decreased the biological activity $\left(\mathrm{IC}_{50} 56 \mu \mathrm{M}\right)$ and the best result was obtained for the prodrug that included a single hexadecyloxypropyl chain $(7.6 \mu \mathrm{M})^{125}$, a behavior that had already been noted with antiviral compounds. ${ }^{126}$ For ANbPs (Figure 22), ethyl L- 
phenylalanyl (instead of alanyl) moieties were envisaged for phosphorobisamidate prodrugs with the aim of further increasing the lipophilicity of the final compounds. In vitro evaluation of these three prodrugs on $P f$ strains $\mathrm{D} 6$ and $\mathrm{W} 2$ led to similar results, with $\mathrm{IC}_{50}$ values in the low micromolar range. ${ }^{125}$ Note that some cytotoxicity on mammalian cells was observed for the lipophilic monoester PEEG prodrug ( $\sim 36-61$ $\mu \mathrm{M} \mathrm{CC} \mathrm{C}_{50}$ on all three human cell lines tested) as well as for bisphosphonate prodrugs $(\sim 41-130 \mu \mathrm{M}$ $\left.\mathrm{CC}_{50}\right)^{125}$
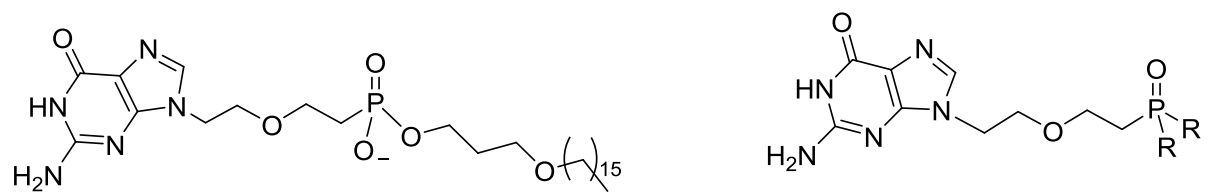

$\mathrm{IC}_{50} 7.6 \mu \mathrm{M}$ on Pf strains D6
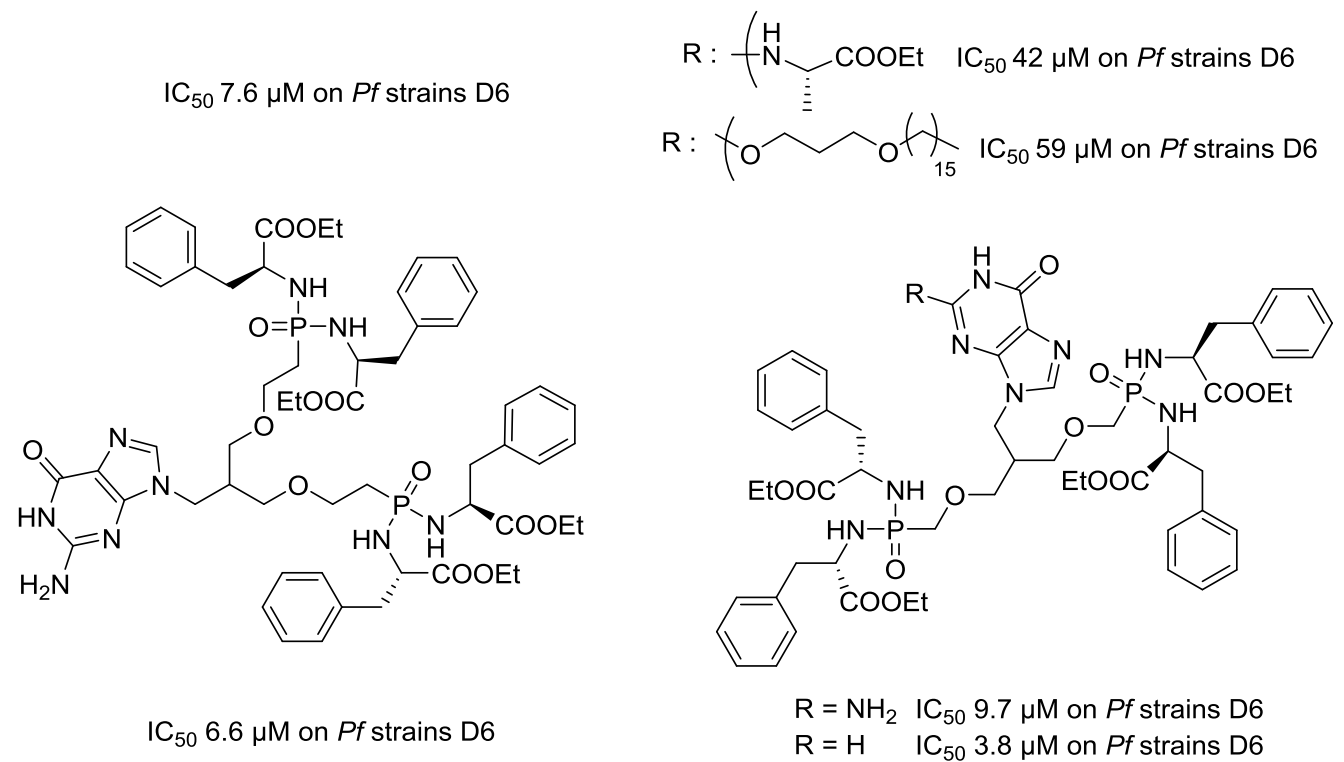

Figure 22: Biological assessment of ANbP prodrugs on $P f$ strains

In 2017, Spacek et al. proposed novel series of ANbPs derivatives (Figure 23) rationally designed on the basis of the crystal structure of the previous ANbP lead compound (Figure 21) complexed with human HGPRT and based on molecular docking studies, suggesting that increasing the length of the phosphonate tail by one atom could allow its location in the $\mathrm{PP}_{\mathrm{i}}$ binding pocket. ${ }^{127}$ Various nucleobase modifications showed that hypoxanthine (compound 7), 8-bromoguanine (compounds 5 and 8) and 7-deazapurine 
(compound 6) derivatives were equally or less active than the guanine derivative (compound 4, Figure 23). Adding one carbon atom into the phosphonate chain (Figure 23, compound 4) led to a 10-fold decrease in the $\mathrm{K}_{\mathrm{i}}$ values on the human enzyme $(0.006 \mu \mathrm{M}$ to $0.03 \mu \mathrm{M})$ but had no effect on Pf HGXPRT $\left(\mathrm{K}_{\mathrm{i}}=0.07 \mu \mathrm{M}\right)$. For this latter derivative, a crystal structure was obtained in a complex with human HGPRT and the affinity gain was associated with the location of the second phosphonate chain within the $\mathrm{PP}_{\mathrm{i}}$ binding site, whereas the phosphonate tail of the previous derivative was too short to reach this site and share interactions. They also showed that this new compound bonded strongly in the active site through a network of hydrogen bonds between protein residues, phosphonyl oxygen atoms and magnesium ions. Finally, phenylalanine phosphoramidate prodrugs were synthesized and their antimalarial and cytotoxicity activities were determined. Most of them exhibited $\mathrm{IC}_{50}$ values in the micromolar range against D6 and W2 $P f$ strains, and prodrugs of the best ANbPs in this series exhibited low cytotoxicity compared to the others $\left(\mathrm{CC}_{50} 212 \mu \mathrm{M}\right.$ on human lung carcinoma cells).

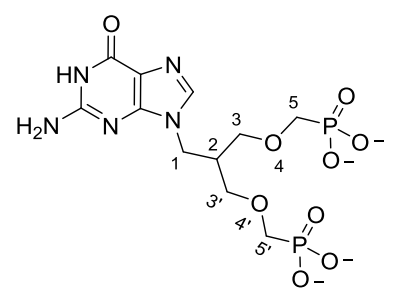

ANbP previously identified $\mathrm{K}_{\mathrm{i}}$ 0.07-0.6 $\mu \mathrm{M}$ on Pf-Pv HGXPRT $\mathrm{K}_{\mathrm{i}} \mathbf{0 . 0 3} \mu \mathrm{M}$ on Hs HGPRT Crystal structure obtained in a complex with Hs HGPRT

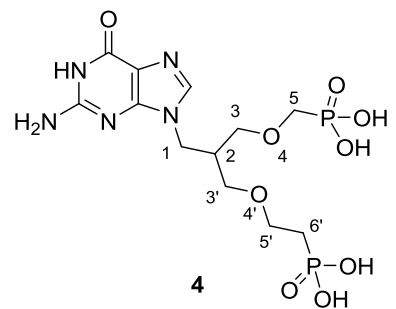

$\mathrm{K}_{\mathrm{i}} 0.07 \mu \mathrm{M}$ on Pf HGXPRT $\mathrm{K}_{\mathrm{i}} \mathbf{0 . 0 0 6} \boldsymbol{\mu M}$ on Hs HGPRT Crystal structure obtained in a

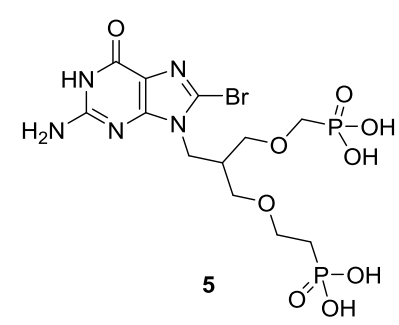

$\mathrm{K}_{\mathrm{i}} 2 \mu \mathrm{M}$ on Pf HGXPRT $\mathrm{K}_{\mathrm{i}} 0.1 \mu \mathrm{M}$ on Hs HGPRT

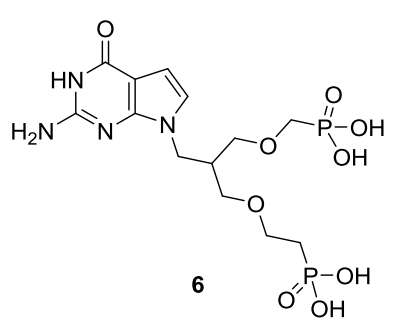

$\mathrm{K}_{\mathrm{i}} 4 \mu \mathrm{M}$ on Pf HGXPRT $\mathrm{K}_{\mathrm{i}} 0.1 \mu \mathrm{M}$ on Hs HGPRT

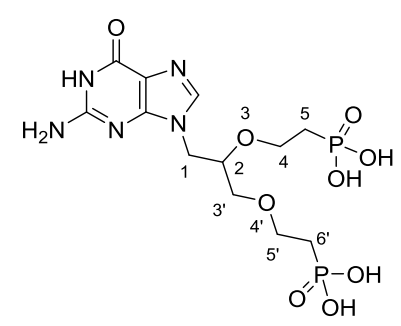

ANbP previously identified $\mathrm{K}_{\mathrm{i}}$ 0.5-0.7 $\mu \mathrm{M}$ on Pf - Pv HGXPRT $\mathrm{K}_{\mathrm{i}} 0.6 \mu \mathrm{M}$ on $\mathrm{Hs}$ HGPRT

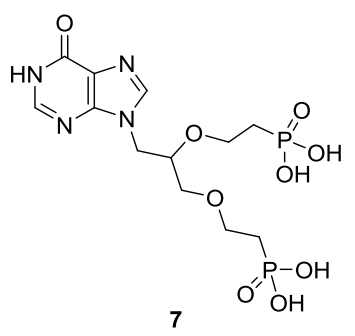

$\mathrm{K}_{\mathrm{i}} \mathrm{NI}$ on Pf HGXPRT $\mathrm{K}_{\mathrm{i}} 0.7 \mu \mathrm{M}$ on Hs HGPRT

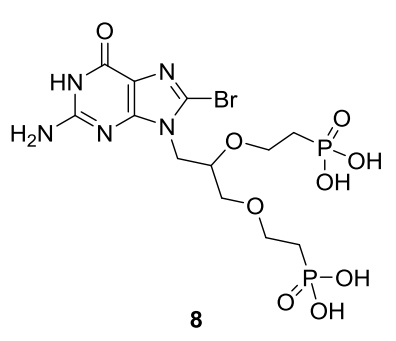

$\mathrm{K}_{\mathrm{i}} 0.9 \mu \mathrm{M}$ on Pf HGXPRT $\mathrm{K}_{\mathrm{i}} 0.4 \mu \mathrm{M}$ on $\mathrm{Hs}$ HGPRT

Figure 23: Novel ANbPs designed by Spacek et al. to study the impact of the phosphonate chain and nucleobase modifications on PRTase inhibition 


\section{d. Fluorinated ANPs}

In addition to the previously reported ANPs, ${ }^{149,119}$ a fluoromethyl group was incorporated as substituent at the beta-position related to the nucleobase on the basis of the PEE and PME scaffolds, giving rise to 3-fluoro-(2-phosphonoethoxy)propyl (FPEP) and 3-fluoro-(2-phosphonomethoxy) propyl (FPMP) derivatives, which were obtained as pure isomers (Figure 24). ${ }^{124}$

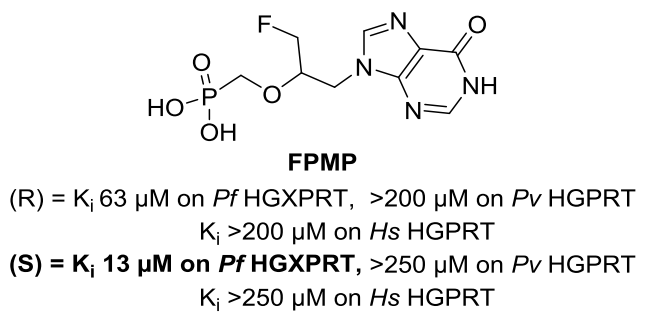

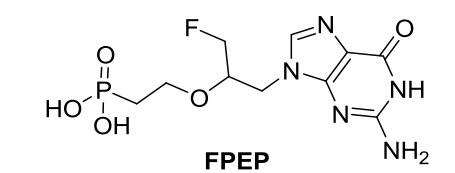

$(\mathrm{R})=\mathrm{K}_{\mathrm{i}} 1-29 \mu \mathrm{M}$ on Pf HGXPRT-P $v$ HGPRT $\mathrm{K}_{\mathrm{i}} 4.7 \mu \mathrm{M}$ on Hs HGPRT

$(\mathrm{S})=\mathrm{K}_{\mathrm{i}}$ 1.2-34 $\mu \mathrm{M}$ on Pf HGXPRT-Pv HGPRT

$\mathrm{K}_{\mathrm{i}} 0.1 \mu \mathrm{M}$ on Hs HGPRT

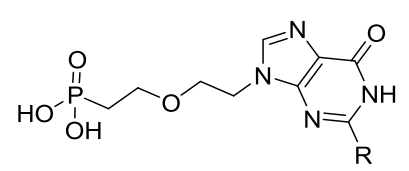

PEEHX, R = H, $\mathrm{K}_{\mathrm{i}} \mathbf{0 . 3} \boldsymbol{\mu} \mathrm{M}$ on Pf HGXPRT $\mathrm{K}_{\mathrm{i}} 3.6 \mu \mathrm{M}$ on Hs HGPRT PEEG, $\mathrm{R}=\mathrm{NH}_{2}, \mathrm{~K}_{\mathrm{i}} 0.1 \mu \mathrm{M}$ on Pf HGXPRT $\mathrm{K}_{\mathrm{i}} 1 \mu \mathrm{M}$ on Hs HGPRT

Figure 24: Fluorinated ANPs and their biological activities

Briefly, FPMP derivatives were found to be very weak inhibitors $\left(K_{i}>50 \mu \mathrm{M}\right)$ of the three enzymes, except for the (S)-isomer incorporating hypoxanthine which exhibited a $\mathrm{K}_{\mathrm{i}}$ of $13 \mu \mathrm{M}$ toward $P f$ HGXPRT. Among the FPEP series, the guanine analogues exhibited inhibition constants in the low micromolar range for the three enzymes, with no significant selectivity for the parasite enzymes (Figure 24). No FPEP and FPMP derivatives were more active than PEEHx and PEEG ANPs.

Molecular docking demonstrated that the fluoromethyl group was too small to interact significantly with protein residues at the active site, thus not really reflecting any effect of the fluorinated group on the activity. One interesting finding was the effect of stereoisomery, $(S)$ - and $(R)$-isomers providing different profiles, as previously noted by other authors. Docking studies revealed different positioning of the nucleobase for each isomer, with one being closest to the aromatic ring of residue F186. The stereochemistry also influenced the position of the phosphonate group within the 5'-phosphate group loop, thus affecting the activity. Indeed, the binding of this group is one of the most crucial for the affinity. ${ }^{124}$ 


\section{e. Acyclic immucillin phosphonates (AIP)}

In 2012, Schramm and co-workers concluded from their preliminary studies on immucillin 5'monophosphate derivatives that they were unable to act efficiently as antimalarials in vitro due to hydrolysis of the 5'-phosphate group by cellular phosphatases. ${ }^{101}$ As an alternative and inspired by the work done on ANPs, they designed acyclic immucillin phosphonate derivatives (AIPs, Figure 25), by cleaving the sugar moiety of immucillin derivatives and replacing the 5'-phosphate group by a hydrolysisresistant phosphonate bond and investigated them as potential PRTase inhibitors. ${ }^{101,123}$

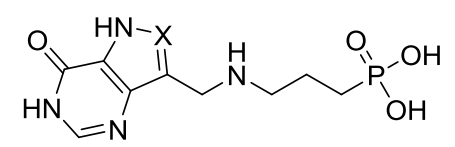

9, $\mathrm{X}=\mathrm{CH} \quad \mathrm{K}_{\mathrm{i}}$ 10.6 nM Pf HGXPRT $\mathrm{K}_{\mathrm{i}} 4,940 \mathrm{nM}$ Hs HGPRT

10, $X=N \quad K_{i} 27.6$ nM Pf HGXPRT $\mathrm{K}_{\mathrm{i}}>10,000 \mathrm{nM}$ on $\mathrm{Hs}$ HGPRT

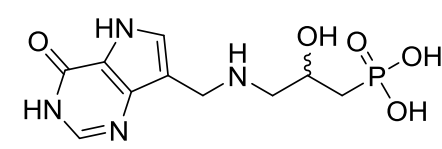

11

$\mathrm{K}_{\mathrm{i}} 9.1 \mathrm{nM}$ Pf HGXPRT $\mathrm{K}_{\mathrm{i}}>10,000 \mathrm{nM}$ Hs HGPRT

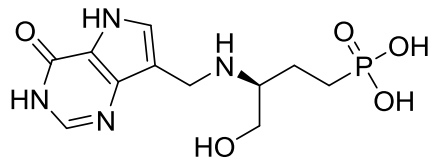

12

$\mathrm{K}_{\mathrm{i}} \mathbf{0 . 6 5} \mathrm{nM}$ Pf HGXPRT $\mathrm{K}_{\mathrm{i}} 380 \mathrm{nM}$ Hs HGPRT

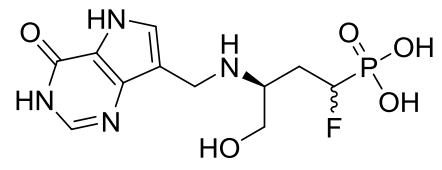

13

$\mathrm{K}_{\mathrm{i}} 1.2 \mathrm{nM}$ Pf HGXPRT

$\mathrm{K}_{\mathrm{i}} 420 \mathrm{nM}$ Hs HGPRT

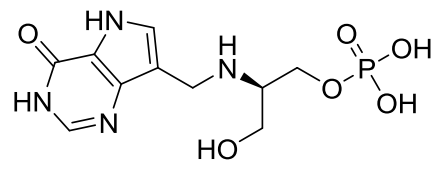

14

$\mathrm{K}_{\mathrm{i}} 2.4 \mathrm{nM}$ Pf HGXPRT $\mathrm{K}_{\mathrm{i}}>10,000 \mathrm{nM}$ Hs HGPRT

\section{Figure 25: First AIPs tested to inhibit Pf HGXPRT and Hs HGPRT activities}

Pf enzymes were found to be remarkably selective for all derivatives (SI >350). The most potent compounds included a hydroxymethyl group as side chain, with sub-nanomolar $\mathrm{K}_{\mathrm{i}}$ values (Figure 25, compounds 12-14). The most surprising result was the increased selectivity observed when a phosphate

group linked to a serinol-like chain replaced the phosphonate tail (compound 14). The introduction of fluorine atom(s) in the $\alpha$-position related to the phosphorus atom (compound 13) was envisaged so that phosphonate would mimic the pKa of a phosphate group, but this modification did not improve $\mathrm{K}_{\mathrm{i}}$ values towards $P f$ and human PRTases. ${ }^{123}$ 


\section{f. Aza-ANPs}

In 2012, novel ANP analogues, where a nitrogen atom replaced the oxygen atom within the parent PEE scaffold, were compared for their ability to inhibit PfHGXPRT, with the aim of introducing a novel class of nitrogen-containing ANPs (Figure 26) ${ }^{128}$ This modification led to less active derivatives and increased the affinity for the human enzyme (reversed selectivity). These negative effects on the activity and selectivity may be attributed to the ability of the secondary amino group to protonate at physiological $\mathrm{pH}$, thus modifying the chain conformation (confirmed by docking studies). ${ }^{128}$

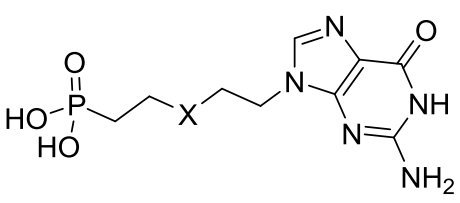

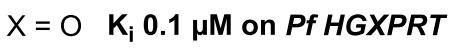

$\mathrm{K}_{\mathrm{i}} 1 \mu \mathrm{M}$ on $H s$ HGPRT

$\mathrm{X}=\mathrm{NH} \quad \mathrm{K}_{\mathrm{i}} 16 \mu \mathrm{M}$ on $P f \mathrm{HGXPRT}$

$\mathrm{K}_{\mathrm{i}} 3 \mu \mathrm{M}$ on Hs HGPRT

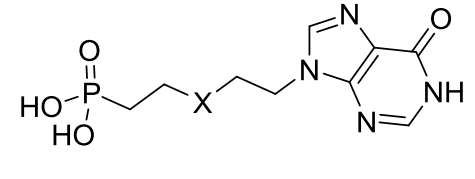

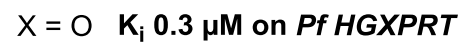

$K_{i} 3.6 \mu \mathrm{M}$ on $H s$ HGPRT

$\mathrm{X}=\mathrm{NH} \quad \mathrm{K}_{\mathrm{i}}>200 \mu \mathrm{M}$ on Pf HGXPRT

$\mathrm{K}_{\mathrm{i}} 40 \mu \mathrm{M}$ on Hs HGPRT

Figure 26: Comparison the inhibitory activity of oxygen- and nitrogen-containing ANPs

derivatives

Then, $N$-branched ANPs including a second chain linked to the nitrogen atom were synthesized, thus leading to a tertiary amine at the core of the compounds (Figure 27: Evaluation of N-branched ANP potent inhibitors of malarial and human 6-oxopurinePRTs). ${ }^{128}$ The side chains were found to have various functionalities such as cyano- (compounds 15-16), hydroxy- (compound 17), methyl ester(compounds 18-19) and carboxylic acids (compounds 20-21), as shown in Figure 27. In all cases, guanosine derivatives exhibited better affinity for the human enzyme than for the parasite enzyme, whereas some hypoxanthine derivatives exhibited sub-micromolar affinity and significant selectivity for the $P f$ protein. Cyano- and hydroxy-substituted aza-ANPs showed better affinity for the human enzyme. All compounds showed weak potency towards parasite enzymes. Finally, promising results were obtained 
when the second tail had a length of three carbon atoms and included a carboxylic acid or a methyl ester group (compounds 19-20).

Docking studies on these compounds were also performed with human HGPRT to support the biological results. The functional group is supposed to be located in a hydrophobic pocket differing from the $\mathrm{PP}_{\mathrm{i}}$ binding site. In the case of the hydroxyl compound, the -OH group is supposedly bound through hydrogen bonds to the internal phosphonate, thus hampering it from occupying the 5 '-phosphate bonding pocket. The nature of the linker has a marked impact on the location of the second group within the active site, e.g. in the case of the two cyano compounds $\mathbf{1 5}$ and 16, thus lowering the affinity.

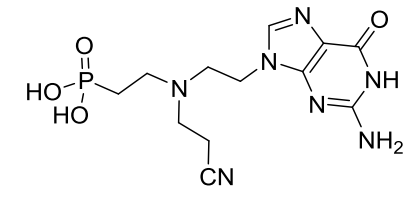

15

$\mathrm{K}_{\mathrm{i}}$ 0.2-0.3 $\mu \mathrm{M}$ on Pf-Pv HGXPRT

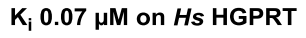

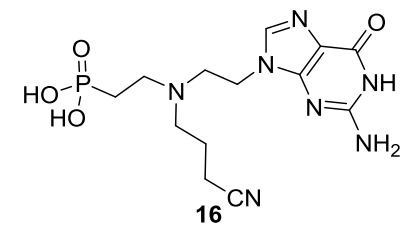

$\mathrm{K}_{\mathrm{i}} 4-8 \mu \mathrm{M}$ on Pf-Pv HGXPRT $\mathrm{K}_{\mathrm{i}} 0.6 \mu \mathrm{M}$ on Hs HGPRT

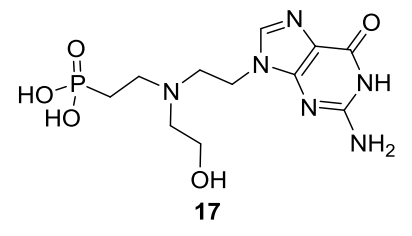

$\mathrm{K}_{\mathrm{i}}$ 0.2-1.4 $\mu \mathrm{M}$ on Pf-Pv HGXPRT $\mathrm{K}_{\mathrm{i}} 0.07 \mu \mathrm{M}$ on Hs HGPRT<smiles>COC(C)=O</smiles>

18

$\mathrm{K}_{\mathrm{i}}$ 0.1-4 $\mu \mathrm{M}$ on Pf-Pv HGXPRT $\mathrm{K}_{\mathrm{i}} 0.5 \mu \mathrm{M}$ on Hs HGPRT

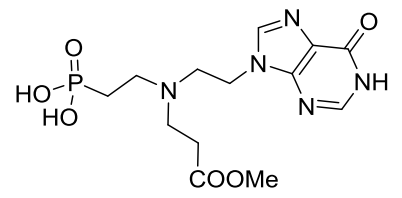

19

$\mathrm{K}_{\mathrm{i}}$ 0.1-21 $\mu \mathrm{M}$ on Pf-Pv HGXPRT $\mathrm{K}_{\mathrm{i}}>200 \mu \mathrm{M}$ on Hs HGPRT

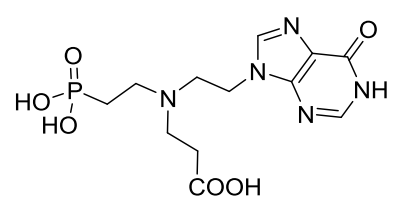

20

$\mathrm{K}_{\mathrm{i}}$ 0.4-41 $\mu \mathrm{M}$ on Pf-Pv HGXPRT $\quad \mathrm{K}_{\mathrm{i}}>210 \mu \mathrm{M}$ on Pf, $1.6 \mu \mathrm{M}$ Pv HGXPRT $\mathrm{K}_{\mathrm{i}}>240 \mu \mathrm{M}$ on Hs HGPRT

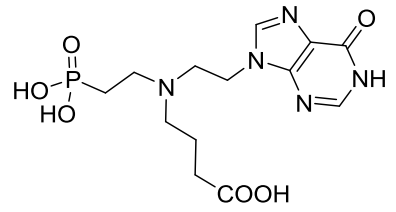

21

$K_{\mathrm{i}} 5.4 \mu \mathrm{M}$ on Hs HGPRT

Figure 27: Evaluation of N-branched ANP potent inhibitors of malarial and human 6oxopurinePRTs

Prodrugs (Figure 28) of the previously described aza-cyano ANPs were subsequently synthesized in order to perform cell culture experiments against $P f$ strains. ${ }^{129}$ As expected, the use of bisamidate and diester prodrugs led to a potency gain in comparison to the parent compounds. However, some cytotoxicity was observed for the guanine derivatives, presumably due to the higher affinity of this ANP for the human protein, contrary to the hypoxanthine-containing prodrug. 


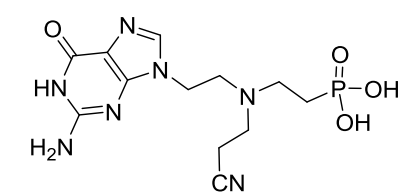

$\mathrm{K}_{\mathrm{i}} 0.2 \mu \mathrm{M}$ on Pf HGXPRT $\mathrm{K}_{\mathbf{i}} \mathbf{0 . 0 7} \boldsymbol{\mu M}$ on human HGPRT $\mathrm{IC}_{50} 145->300 \mu \mathrm{M}$ on PfD6 and PfW2

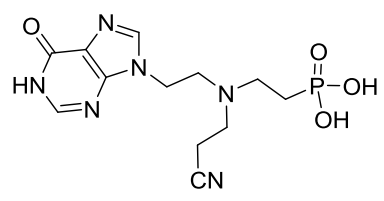

$\mathrm{K}_{\mathrm{i}} \mathbf{0 . 2} \boldsymbol{\mu \mathrm { M }}$ on Pf HGXPRT $\mathrm{K}_{\mathrm{i}} 2.4 \mu \mathrm{M}$ on human HGPRT $I_{50} 75->300 \mu \mathrm{M}$ on Pf D6 and Pf W2

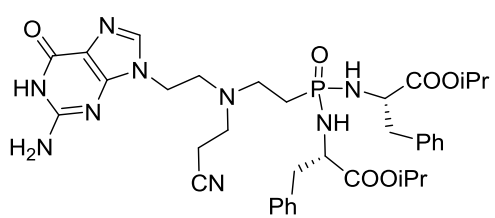

$\mathrm{IC}_{50} 6.4->10.4 \mu \mathrm{M}$ on PfD6 and Pf W2 $\mathrm{CC}_{50} 16 \mu \mathrm{M}$ on human A549 cells

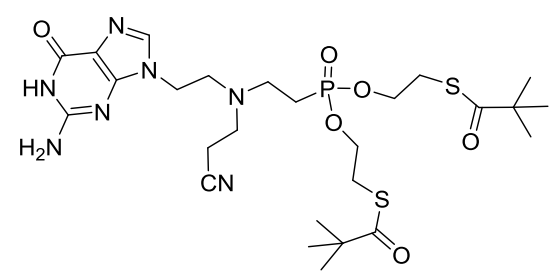

$\mathrm{IC}_{50} 24-45 \mu \mathrm{M}$ on Pf D6 and Pf W2 Not tested on human A549 cells

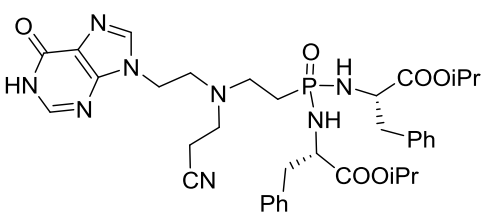

$\mathrm{IC}_{50} 12.5-19.5 \mu \mathrm{M}$ on PfD6 and Pf W2 $\mathrm{CC}_{50}>300 \mu \mathrm{M}$ on human A549 cells

\section{Figure 28: Cyano-aza-ANPs and prodrugs against Pf HGXPRT and human HGPRT}

\section{g. Bisphosphonate aza-ANPs}

By merging the scaffold of $N$-branched ANPs (AIP and aza-ANPs) and bisphosphonate ANPs (ANbPs) described previously, Hockova et al. proposed bisphosphonate aza-acyclic nucleosides (Figure 29: ). ${ }^{128}$ In theory, these compounds should form a tight drug-enzyme complex. Indeed, the presence of the nitrogen atom allows triple anchoring of the compound through the nucleobase and the formation of two phosphonate chains of different lengths. One phosphonate tail was designed to fill the Pf HGXPRT pyrophosphate binding site and the other one the phosphate binding pocket. The main chain included five atoms, which was found to be the optimum length for this target. Studies on their affinity towards human, Pf and $P v$ PRTases showed that the addition of a second phosphonate group seemed to create new interactions at the active site with the human enzyme, which may have been responsible for the improvement in all $\mathrm{K}_{\mathrm{i}}$ values compared to their monophosphonate analogues (Figure 29). These compounds however remained poorly selective for the parasite enzymes. 

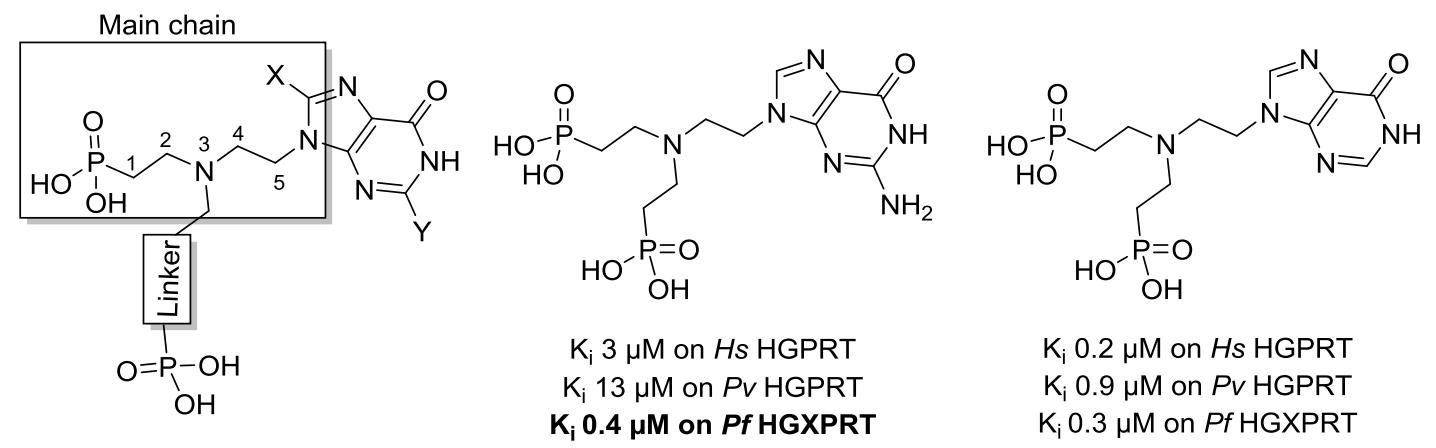

$\mathrm{K}_{\mathrm{i}} 0.2 \mu \mathrm{M}$ on $H s$ HGPRT $\mathrm{K}_{\mathrm{i}} 0.9 \mu \mathrm{M}$ on $P v$ HGPRT $\mathrm{K}_{\mathrm{i}} 0.3 \mu \mathrm{M}$ on Pf HGXPRT

\section{Figure 29: Generic structure of the aza-ANPs bisphosphonates and first derivatives studied}

Modification of the length of the side chain and incorporation of an oxygen atom were then envisaged

(Figure 30). ${ }^{129}$ Regardless of the nature of the second phosphonate tail, guanine derivatives showed similar or better affinity for human HGPRT, with $\mathrm{K}_{\mathrm{i}}$ values in the sub-micromolar range. The increased length of the side chain to eight atoms and the presence of oxygen atoms led in all cases to more potent inhibitors for all three enzymes. In this case, selectivity was in favor of the parasite enzymes for hypoxanthine and 8-bromoguanine derivatives.

Due to the polyanionic nature of the parent compounds, only the corresponding phosphoramidate prodrugs were tested in cell experiments (Pf D6 and W2 strains), and cytotoxicity was assessed on human lung carcinoma A549 cells. The prodrugs exhibited similar $\mathrm{IC}_{50}$ values, in the micromolar range, against both $P f \mathrm{~W} 2$ and D6 strains, with weak cytotoxicity against mammalian cells (SI for prodrugs $\geq 15$ ).

Extensive structural studies revealed that the main phosphonate chain was located in the 5'phosphate binding pocket, whereas the other chain was hosted by the $\mathrm{PP}_{\mathrm{i}}$ binding site. The importance of coordination of the magnesium ion with the second phosphonate moiety through a water molecule for tight binding was highlighted. It was also found that 8-bromoguanine induced inversion of the common positioning of the two phosphonate chains and led to occupation of the 5'-phosphate binding site by the second phosphonate group, not by the main one. The longer chain can enter deeply into the binding site, 
and forming strong interactions. Finally, the hydrogen bond interactions of amino acid residues in the active site with the purine ring have been described and the most important ones were identified (hydrogen bond between V187 and the $\mathrm{N}^{1}$ of the purine ring is present in every case). The authors also observed a hydrogen bond between the $\mathrm{N}^{3}$ of the purine ring and water. ${ }^{129}$

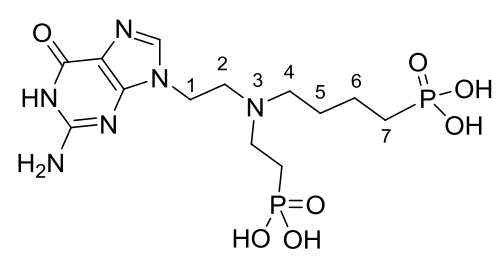

$\mathrm{K}_{\mathrm{i}} 1.5-2 \mu \mathrm{M}$ on Pf-PV HGXPRT

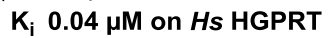

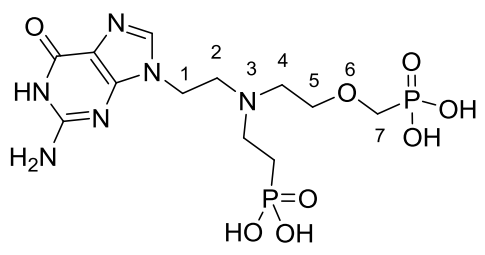

$\mathrm{K}_{\mathrm{i}}$ 0.5-0.13 $\mu \mathrm{M}$ on Pf-Pv HGXPRT

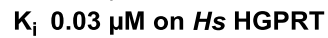

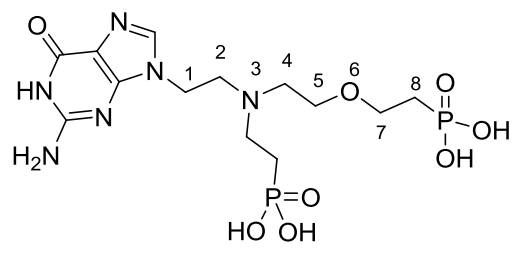

$\mathrm{K}_{\mathrm{i}}$ 0.19-0.03 $\mu \mathrm{M}$ on Pf-Pv HGXPRT $\mathrm{K}_{\mathrm{i}} 0.08 \mu \mathrm{M}$ on Hs HGPRT

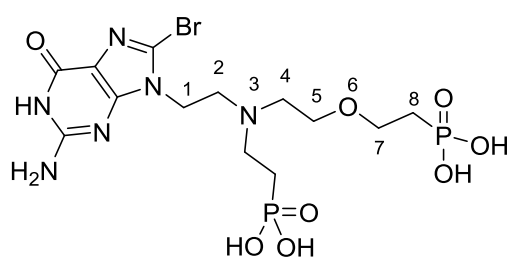

$\mathrm{K}_{\mathrm{i}}$ 0.08-0.01 $\mu \mathrm{M}$ on Pf-Pv HGXPRT $\mathrm{K}_{\mathrm{i}} 0.04 \mu \mathrm{M}$ on Hs HGPRT

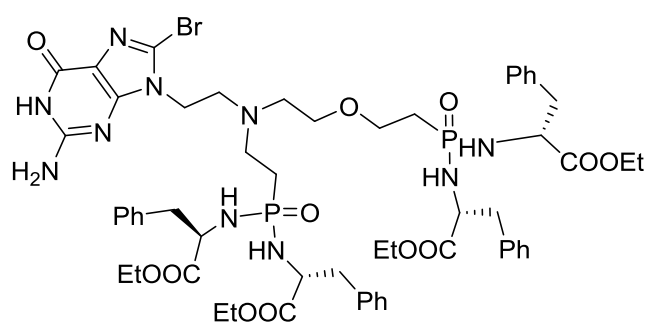

$\mathrm{IC}_{50} \quad 4.1-2.7 \mu \mathrm{M}$ on $P f \mathrm{D} 6$ and $P f \mathrm{~W} 2$ strains $\mathrm{CC}_{50} 59 \mu \mathrm{M}$ on human A549 cells

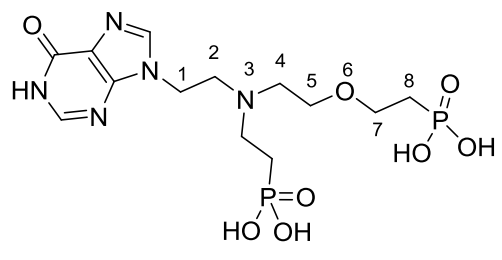

$\mathrm{K}_{\mathrm{i}}$ 0.2-0.04 $\mu \mathrm{M}$ on Pf-Pv HGXPRT $\mathrm{K}_{\mathrm{i}} 1 \mu \mathrm{M}$ on Hs HGPRT

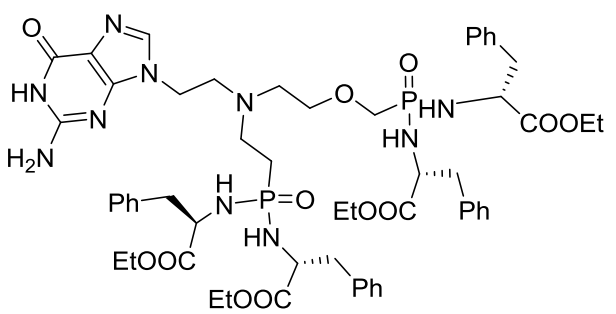

$\mathrm{IC}_{50} \quad$ 6.0-2.6 $\mu \mathrm{M}$ on Pf D6 and Pf W2 strains $\mathrm{CC}_{50} 210 \mu \mathrm{M}$ on human 549 cells

Figure 30: Biological activities of asymmetric aza-bisphosphonate-ANPs and their prodrugs

\section{h. Triazolo-ANPs}

Recently, ANPs containing a triazole ring instead of a ribose ring and a phosphonic acid group at position 4 were reported (Figure 31). ${ }^{130}$ Both guanine enantiomers exhibited the same $\mathrm{K}_{\mathrm{i}}$ on purified $P f$ and human $\mathrm{HG}(\mathrm{X}) \mathrm{PRT}$, which surprisingly indicated that stereoisomery had no effect on affinity. Also surprisingly, the xanthine compound showed the best selectivity for $P f$ enzymes among others (SI $>250)$. 
Hypoxanthine compounds were found to be modest inhibitors of $\mathrm{P} f$ and human $\operatorname{HG}(\mathrm{X}) \mathrm{PRT}((\mathrm{R})$-isomer $\mathrm{K}_{\mathrm{i}}$ values of 3 and $8 \mu \mathrm{M}$ were observed, respectively) and poorly active against $P v$ HGXPRT $\left(\mathrm{K}_{\mathrm{i}}>100\right.$ $\mu \mathrm{M})$.

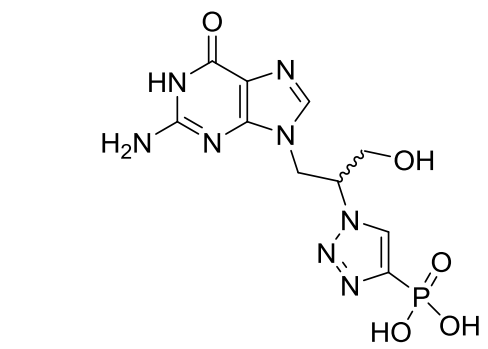

$\mathrm{K}_{\mathrm{i}}(\mathrm{R}) 1-6 \mu \mathrm{M}$, (S) $2 \mu \mathrm{M}$ on Pf-Pv HG(X)PRT

$\mathrm{K}_{\mathrm{i}}$ (R) 0.1 , (S) $0.4 \mu \mathrm{M}$ on Hs HGPRT

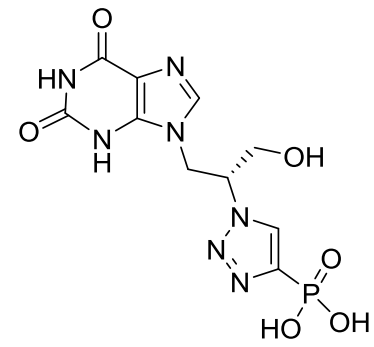

$\mathrm{K}_{\mathrm{i}}$ (R) $2 \mu \mathrm{M}$ on Pf HGXPRT $\mathrm{K}_{\mathrm{i}}(\mathrm{R})>500 \mu \mathrm{M}$ on $H s$ HGPRT

\section{Figure 31: Triazolo-ANPs as potent inhibitor of $P f$ HGXPRT and $H s$ HGPRT}

\section{CONCLUSION}

As the resistance of Plasmodium species to all antimalarial medicines is spreading in Asia and Africa, the search for new treatments is crucial. The main recommendations of WHO to address the drugresistance problem include the use of a single-dose treatment to cure uncomplicated malaria, safety for vulnerable persons such as pregnant women and young children, combining drugs with different targets, activity against several stages of the parasite life cycle and low cost $(\sim$ US\$1 per adult and US\$0.60 for an average child's treatment). Consequently, the scientific community, especially medicinal chemists, biochemists and biologists working in the field of parasitology, is still facing a challenge to discover original drugs and identify novel targets.

Here we have discussed nucleos(t)ide analogues as a class of potential antimalarials and the related metabolic pathway, i.e. enzymes belonging to the purine salvage pathway which have been investigated for chemotherapy. Indeed, Plasmodium parasites behave as purine auxotrophs and inhibition of the corresponding enzymes would lead to death of the parasites through purine starvation. Among the possible 
targets, $P f$ PNP and $P f$ HGXPRT inhibition has been intensively investigated, along with $P f$ ADA and $P f$ IMPDH to a lesser extent. Molecular modelling approaches have been used to improve potential inhibitors. However, the weak (or the lack) of specificity of many compounds towards human and $P f$ species has somewhat limited their development as drug candidates. The antimalarial activity of immucillin derivatives and analogues has been demonstrated in vitro and in vivo. Within this class, DADMeimmucillin-G (BCX4945) was identified as one of the most potent $P f$ PNP inhibitors (with subnanomolar affinity) while acting as a transition state analogue. This compound reached the preclinical phase in 2012, but no further information has been reported since then. The use of ANPs as inhibitors of the plasmodial purine metabolism was proposed in the late 1990s, and investigations are still ongoing. It could represent one of the most promising families of derivatives. Various series of ANPs have been reported to inhibit $P f$ HGXPRT and $P v$ HGPRT, leading to studies on the impact of the nucleobase nature, linker length, the presence of side-chains and their functionalities on the activity and selectivity. Docking studies were also performed to enhance their affinity and/or selectivity. However, the unknown structure of $P f$ HGXPRT is a major limitation which could hamper rational design of these derivatives based on docking studies. All computational studies have been performed with human and/or $P v$ HGPRT, which is not entirely comparable to the $P f$ HGPRT. In addition, the use of prodrug approaches is mandatory for such compounds since phosphonic acids do not readily cross biological membranes - an aspect that could complicate matters (i.e. synthesis and cost).

The overall findings of all of these studies show us that nucleos(t)ide analogues are far from revealing their full potential. Two decades have been enough to develop a broad range of compounds effectively and selectively targeting different enzymatic steps of the Plasmodium purine salvage pathway, and it is hoped that the future of this class of compounds will meet with the success it deserves. 


\section{ABBREVIATION USED}

6-oxoPRTases or 6-oxopurinePRTs, 6-oxopurinephosphoribosyltransferases; A, adenine; ABC, ATPbinding cassette; ABS, asexual blood stage; ACTs, artemisinin combination therapies; ADA, adenosine deaminase; ADC, aminodeoxychorismate; ADCL, aminodeoxychorismate lyase; ADCS, aminodeoxychorismate synthase; ADP, adenosine 5'-diphosphate; AdSL, adenylosuccinate lyase; AdSS, adenylosuccinate synthase; AIP, acyclic immucillin phosphonate; AMPDA, adenosine-5'-monophosphate deaminase; ANbPs, acyclic nucleoside bisphosphonates; ANPs, acyclic nucleoside phosphonate; ATC, aspartate transcarbamoylase; ATP, adenosine 5'-triphosphate; ATPPase, adenosine 5'-triphosphate pyrophosphatase; BCX-1777, immucillin-H; BT1 family, high affinity folate-biopterin transporters C; cytosine $\mathrm{CA}$, carbonic anhydrase; $\mathrm{CC}_{50}, 50 \%$ cytotoxic concentration; $\mathrm{CH}_{2}$.THF, 5,10-methylenetetrahydrofolate; CH.THF, 5,10-methenyltetrahydrofolate; CoQ, co-enzyme; QCPEE, $(S)$-2(phosphonoethoxy)propanoic acid; CPME, $(S)$-2-(phosphonomethoxy)propanoic acid; CPSII, carbamoyl phosphate synthetase; IICS, chorismate synthase; CTP, cytidine-5'-triphosphate; CTPS, cytosine 5'triphosphate synthetase; CVPS, 5-O-(1-carboxyvinyl)-3-phosphoshikimatecyclic; HPMP, cyclic-3hydroxy-2-(phosphonomethoxy)-propyl; DADMe, 4'-deaza-1'-aza-2'-deoxy-1'-(9-methylene); DAP, 2,6-diaminopurine; DATMe : , 4'-deaza-1'-aza-triol-1'-(9-methylene); dCTP, 2'-deoxycytidine-5'triphosphated; GMP, 2'-deoxyguanosine-5'-monophosphate; DHF, 7,8-dihydrofolate; DHFR, dihydrofolate reductase; DHNTP, 7,8-dihydroneopterin triphosphate; DHO, dihydroorotase; DHODH, dihydroorotate dehydrogenase; DHP, 7,8-dihydropteroate; DHPA, 9-(2,3-dihydroxypropyl)adenine; DNA, desoxyribonucleic acid; DON, 6-diazo-5-oxo-norleucine; DOXP, 1'-deoxy-D-xylulose-5'-phosphate 
pathway / non-mevalonate pathway; dTMP, 2'-deoxythymidine-5'-monophosphate; dTTP, 2'deoxythymidine-5'-triphosphate; dUDP, 2'-deoxyuridine-5'-diphosphate; dUMP, 2'-deoxyuridine-5'monophosphate; dUTP, 2'-deoxyuridine-5'-triphosphate; dUTPase, deoxyuridine 5'-triphosphate nucleotidohydrolase; $\mathrm{EC}_{50}, 50 \%$ effective concentration; EMP1, erythrocyte membrane protein 1; ENT1/2/3/4, equilibrative nucleoside transporter 1/2/3/4; EPSPS, 5-enolpyruvylshikimate-3-phosphate synthase ; FUdR, 5-fluoro-D-2'-deoxyuridine ; FMet-tRNA, formylmethionyl-tRNA ; FPEP, 3-fluoro-(2phosphonoethoxy)propyl ; FPGS, folylpolyglutamate synthase ; FPMP, 3-fluoro-(2-phosphonomethoxy)propyl; FOCM, folate-mediated one-carbon metabolism; FT1/2, folate/biopterin transporter 1/2; G, guanine; GAT, domain of GMPS responsible of glutamine hydrolyzation; GMP, guanosine monophosphate; GMPs, guanosine monophosphate synthetase; GTP, guanosine 5'-triphosphate; GTPC, GTP cyclohydrolase I; bis(POM)PMEA, bis(pivaloyloxymethyl)-9-[2-(phosphonomethoxy)ethyl]adenine, brand name Adefovir; dipivoxil HBV, hepatitis B virus; HGPRT, hypoxanthine-guanine phosphoribosyltransferase (human); HGXPRT, hypoxanthine-guanine-xanthine phosphoribosyltransferase (malarial); HG(X)PRT, both human HGPRT and malarial HGXPRT; Hs, Homo sapiens; HIV, human immunodefiency virus; HMDP, 6-hydroxymethyl-7,8-dihydropterin; HMDP-PP, 6hydroxymethyl-7,8-dihydropterin pyrophosphate; HomoCys, homocysteine; HPEP, (S)-3-hydroxy-2(phosphonoethoxy)propyl; HPMP, 9-(3-hydroxy-2-phosphonomethoxypropyl); $\mathrm{IC}_{37}$, molar concentration of an antagonist that inhibits $37 \%$ of the activity of a targeted function in vitro; $\mathrm{IC}_{50}, 50 \%$ inhibitory concentration; $\mathrm{ID}_{50}, 50 \%$ infectious dose; Imm, immucillin ; IMP, inosine monophosphate ; IMPDH, inosine monophosphate dehydrogenase ; $\mathrm{K}_{\mathrm{d}}$, dissociation constant, measure of the propensity of a complex (such as the substrate-enzyme complex) to separate into each of its components; $\mathrm{K}_{\mathrm{i}}$, dissociation constant for the enzyme-drug complex, measured from initial rates; $\mathrm{K}_{\mathrm{i}}{ }^{*}$, equilibrium dissociation constant; Me.THF, 5-methyltetrahydrofolate; Met-tRNA, methionyl-tRNA; MTA, 5'-methylthioadenosine; MTHFD, 
methylenehydrofolate dehydrogenase; MTHFR, methylenetetrahydrofolate reductase; MTI, 5'methylthioinosine; MT-Imm, 5'-methylthioimucillin; NAD+, oxidized nicotinamide adenine dinucleotide (coenzyme); NADH, reduced nicotinamide adenine dinucleotide (coenzyme); NBMPR, nitrobenzylthioinosine; NDP, nucleoside diphosphate; NMPK, nucleoside monophosphate kinase; NPP, new permeability pathway; NTP, nucleoside triphosphate; ODC, orotidine 5'-monophosphate decarboxylase; OPRTase, orotate phosphoribosyltransferase; pABA, para-aminobenzoic acid; $P b$, Plasmodium berguei; PDB, protein data bank; PEE, 2-(phosphonoethoxy)ethyl; Pf, Plasmodium falciparum; Pf3D7, Plasmodium falciparum strain used in lab assays; $P f$ crt, $P f$ chloroquine-resistant transporter gene; PfCRT, Plasmodium falciparum digestive vacuole chloroquine-resistant transmembrane transporter; PfMDR, Plasmodium falciparum multidrug resistance protein; Pfmdr1, gene of Plasmodium falciparum multidrug resistance protein; Pk, Plasmodium knowlesi; $\mathrm{pKa}$, logarithm of acid dissociation constant Ka; PlasmoDB, the online plasmodic genomic resources http://PlasmoDB.orgPm: Plasmodium malariae; PME, 2-(phosphonomethoxy)ethyl; PMP, 2-(phosphonomethoxy)propyl; PNP, purine nucleoside phosphorylase; Po, Plasmodium ovale; $\mathrm{PP}_{\mathrm{i}}$ : inorganic pyrophosphate; PRib-PP, phosphoribosyl pyrophosphate; PSAC, plasmodial surface anion channel; PTPS, 6-pyruvoyltetrahydropterin synthase III; Pv, Plasmodium vivax; PVM, parasitophorous vacuole membrane; RBC, red blood cell; RNA, ribonucleic acid; RNR, ribonucleotide reductase; ROS, reactive oxygen species; SHMT, serine hydroxymethyltransferase; SK, shikimate kinase; T, thymine; THF, 5,6,7,8-tetrahydrofolate; TK, thymidine kinase; TMP, thymidine-5'-monophosphate; TMPK, thymidylate monophosphate kinase; tRNA, transfer ARN; TS, thymidylate synthase; UDP, uridine-5'-diphosphate; UK, uridine kinase; UPRT, uracile phosphoribosyltransferase; UTP, uridine-5'-triphosphate; WHO, world health organization; XMP, xanthosine monophosphate. 


\section{AUTHOR INFORMATION}

Corresponding author: suzanne.peyrottes@umontpellier.fr

ORCID: 0000-0003-1705-0576

\section{Biographies}

Thomas Cheviet holds an MSc degree from the University of Montpellier. He started his Ph.D. studies in 2016 under the supervision of Dr. S. Peyrottes, at the Institut des Biomolecules Max Mousseron (IBMM). His research focuses on the synthesis and study of bioactive molecules on the $P f$ metabolism of purines. Isabelle Lefevbre-Tournier studied organic and analytical chemistry at the University of Montpellier. She joined the laboratory of Pr J.L. Imbach (Montpellier, France) in 1991 and obtained her Ph.D. in analytical chemistry in 1994 under the direction of Dr A. Pompon. In 1995, she was a postdoctoral fellow in the laboratory of Pr. J.P. Sommadossi (University of Alabama, USA), working on cellular pharmacology. In 1996, she joined the laboratory of Dr G. Gosselin (Montpellier, France) focusing on study of drugs in biological media by liquid chromatography. Nowadays, she occupies a position of Professor (University of Montpellier, France), working on identification and quantification of therapeutic agents in biological media. She has co-authored about 60 publications.

Sharon Wein studied biochemistry at the University of Toulouse. In 2001, she became engineer at the CNRS and in the laboratory of Dr H. Vial (Montpellier, France), while working on the development of antimalarial compounds. After a MSc degree in Parasitology at the University of Montpellier, she obtained her Ph.D. in 2012 under the supervision of Dr H. Vial, while working on the mechanism of action of a choline analog with potent antimalarial activity. This choline analog (T3/albitiazolium) was develop in the 
lab and reach clinical phase 2 in collaboration with Sanofi. Since 2016, she also worked with Prof. R. Cerdan on the study of the phospholipid metabolism of Plasmodium falciparum in particular by lipidomics. She has co-authored 36 publications and 2 patents.

Suzanne Peyrottes studied organic chemistry at the University of Montpellier. In 1995, she obtained her $\mathrm{PhD}$; in the laboratory of Prof. J.L. Imbach (Montpellier, France), while working on the synthesis and study of modified oligonucleotides. Then, she was a postdoctoral fellow in the laboratory of Dr M.J. Gait at MRC (Cambridge, UK) where she worked on the solid-phase synthesis of oligonucleotide-peptide conjugates. In 1998, she joined the laboratory of Dr G. Gosselin (Montpellier, France) and focused on the synthesis of antitumoral mononucleotide prodrugs, and became a Senior Scientist at CNRS (France). She is currently Research Director at CNRS, working on designing potential therapeutic agents, while

developing new synthetic methodologies related to nucleic acid components. She has co-authored about 70 publications and 6 patents.

\section{ACKNOWLEDGMENTS}

CNRS (Centre National de la Recherche Scientifique) and University of Montpellier are gratefully acknowledged for their support.

\section{REFERENCES}

(1) WHO | World malaria report 2018 https://www.who.int/malaria/publications/world-malariareport-2018/en/ (accessed March 19, 2019).

(2) Sutherland, C. J.; Tanomsing, N.; Nold Pinto, J.; Mivhon, P.; er, D.; Oguike, M.; Jennison, C.; Pukrittayakamee, S.; Dolecek, C.; Hien, T. T.; Rosário, D.; E, V.; Arez, A. P.; Escalante, A. A.; Nosten, F.; Burke, M.; Lee, R.; Blaze, M.; Dan Otto, T.; Barnwell, J. W.; Pain, A.; Williams, J.; White, N. J.; 
Day, N. P. J.; Snounou, G.; Lockhart, P. J.; Chiodini, P. L.; Imwong, M.; Polley, S. D. Two Nonrecombining Sympatric Forms of the Human Malaria Parasite Plasmodium Ovale Occur Globally. J. Infect. Dis. 2010, 201 (10), 1544-1550. https://doi.org/10.1086/652240.

(3) Calderaro, A.; Piccolo, G.; Gorrini, C.; Rossi, S.; Montecchini, S.; Dell’Anna, M. L.; De Conto, F.; Medici, M. C.; Chezzi, C.; Arcangeletti, M. C. Accurate Identification of the Six Human Plasmodium Spp. Causing Imported Malaria, Including Plasmodium Ovale Wallikeri and Plasmodium Knowlesi. Malar. J. 2013, 12, 321. https://doi.org/10.1186/1475-2875-12-321.

(4) Coelho, C. H.; Doritchamou, J. Y. A.; Zaidi, I.; Duffy, P. E. Advances in Malaria Vaccine Development: Report from the 2017 Malaria Vaccine Symposium. NPJ Vaccines 2017, 2. https://doi.org/10.1038/s41541-017-0035-3.

(5) Matuschewski, K. Vaccines against Malaria_Still a Long Way to Go. FEBS J. 2017, 284 (16), 2560-2568. https://doi.org/10.1111/febs.14107.

(6) Llanos-Cuentas, A.; Casapia, M.; Chuquiyauri, R.; Hinojosa, J.-C.; Kerr, N.; Rosario, M.; Toovey, S.; Arch, R. H.; Phillips, M. A.; Rozenberg, F. D.; Bath, J.; Ng, C. L.; Cowell, A. N.; Winzeler, E. A.; Fidock, D. A.; Baker, M.; Möhrle, J. J.; van Huijsduijnen, R. H.; Gobeau, N.; Araeipour, N.; Andenmatten, N.; Rückle, T.; Duparc, S. Antimalarial Activity of Single-Dose DSM265, a Novel Plasmodium Dihydroorotate Dehydrogenase Inhibitor, in Patients with Uncomplicated Plasmodium Falciparum or Plasmodium Vivax Malaria Infection: A Proof-of-Concept, Open-Label, Phase 2a Study. Lancet Infect. Dis. 2018, 18 (8), 874-883. https://doi.org/10.1016/S1473-3099(18)30309-8.

(7) Cassera, M. B.; Zhang, Y.; Hazleton, K. Z.; Schramm, V. L. Purine and Pyrimidine Pathways as Targets in Plasmodium Falciparum. Curr. Top. Med. Chem. 2011, 11 (16), 2103-2115.

(8) El Kouni, M. H. Potential Chemotherapeutic Targets in the Purine Metabolism of Parasites. Pharmacol. Ther. 2003, 99 (3), 283-309. 
(9) Hyde, J. E. Targeting Purine and Pyrimidine Metabolism in Human Apicomplexan Parasites. Curr. Drug Targets 2007, 8 (1), 31-47.

(10) Krungkrai, S. R.; Wutipraditkul, N.; Krungkrai, J. Dihydroorotase of Human Malarial Parasite Plasmodium Falciparum Differs from Host Enzyme. Biochem. Biophys. Res. Commun. 2008, 366 (3), 821-826. https://doi.org/10.1016/j.bbrc.2007.12.025.

(11) Phillips, M. A.; Rathod, P. K. Plasmodium Dihydroorotate Dehydrogenase: A Promising Target for Novel Anti-Malarial Chemotherapy. Infect. Disord. Drug Targets 2010, 10 (3), 226-239.

(12) Singh, A.; Maqbool, M.; Mobashir, M.; Hoda, N. Dihydroorotate Dehydrogenase: A Drug Target for the Development of Antimalarials. Eur. J. Med. Chem. 2017, 125, 640-651. https://doi.org/10.1016/j.ejmech.2016.09.085.

(13) Krungkrai, S. R.; Krungkrai, J. Insights into the Pyrimidine Biosynthetic Pathway of Human Malaria Parasite Plasmodium Falciparum as Chemotherapeutic Target. Asian Pac. J. Trop. Med. 2016, 9 (6), 525-534. https://doi.org/10.1016/j.apjtm.2016.04.012.

(14) Quashie, N. B.; Ranford-Cartwright, L. C.; de Koning, H. P. Uptake of Purines in Plasmodium Falciparum-Infected Human Erythrocytes Is Mostly Mediated by the Human Equilibrative Nucleoside Transporter and the Human Facilitative Nucleobase Transporter. Malar. J. 2010, 9, 36. https://doi.org/10.1186/1475-2875-9-36.

(15) Quashie, N.; Dorin-Semblat, D.; G Bray, P.; Biagini, G.; Doerig, C.; Ranford-Cartwright, L.; De Koning, H. A Comprehensive Model of Purine Uptake by the Malaria Parasite Plasmodium Falciparum: Identification of Four Purine Transport Activities in Intraerythrocytic Parasites. Biochem. J. 2008, 411, 287-295. https://doi.org/10.1042/BJ20071460. 
(16) Frame, I. J.; Deniskin, R.; Arora, A.; Akabas, M. H. Purine Import into Malaria Parasites as a Target for Antimalarial Drug Development. Ann. N. Y. Acad. Sci. 2015, 1342, 19-28. https://doi.org/10.1111/nyas. 12568.

(17) De Koning, H.; Diallinas, G. Nucleobase Transporters (Review). Mol. Membr. Biol. 2000, 17 (2), $75-94$.

(18) Boswell-Casteel, R. C.; Hays, F. A. Equilibrative Nucleoside Transporters-A Review. Nucleosides Nucleotides Nucleic Acids 2017, 36 (1), 7-30. https://doi.org/10.1080/15257770.2016.1210805.

(19) Das, A.; Sharma, M.; Gupta, B.; Dash, A. P. Plasmodium Falciparum and Plasmodium Vivax: So Similar, yet Very Different. Parasitol. Res. 2009, 105 (4), 1169-1171. https://doi.org/10.1007/s00436009-1521-y.

(20) Ivanov, A. A.; Matsumura, I. The Adenosine Deaminases of Plasmodium Vivax and Plasmodium Falciparum Exhibit Surprising Differences in Ligand Specificity. J. Mol. Graph. Model. 2012, 35, 4348. https://doi.org/10.1016/j.jmgm.2012.02.004.

(21) Ward, P.; Equinet, L.; Packer, J.; Doerig, C. Protein Kinases of the Human Malaria Parasite Plasmodium Falciparum: The Kinome of a Divergent Eukaryote. BMC Genomics 2004, 5, 79. https://doi.org/10.1186/1471-2164-5-79.

(22) Cassera, M. B.; Hazleton, K. Z.; Riegelhaupt, P. M.; Merino, E. F.; Luo, M.; Akabas, M. H.; Schramm, V. L. Erythrocytic Adenosine Monophosphate as an Alternative Purine Source in Plasmodium Falciparum. J. Biol. Chem. 2008, $283 \quad$ (47), 32889-32899. https://doi.org/10.1074/jbc.M804497200.

(23) Ginsburg, H.; Krugliak, M.; Eidelman, O.; Cabantchik, Z. I. New Permeability Pathways Induced in Membranes of Plasmodium Falciparum Infected Erythrocytes. Mol. Biochem. Parasitol. 1983, 8 (2), $177-190$. 
(24) Liu, J.; Istvan, E. S.; Gluzman, I. Y.; Gross, J.; Goldberg, D. E. Plasmodium Falciparum Ensures Its Amino Acid Supply with Multiple Acquisition Pathways and Redundant Proteolytic Enzyme Systems. Proc. Natl. Acad. Sci. U. S. A. 2006, 103 (23), 8840-8845. https://doi.org/10.1073/pnas.0601876103.

(25) Gero, A. M.; Dunn, C. G.; Brown, D. M.; Pulenthiran, K.; Gorovits, E. L.; Bakos, T.; Weis, A. L. New Malaria Chemotherapy Developed by Utilization of a Unique Parasite Transport System. Curr. Pharm. Des. 2003, 9 (11), 867-877. https://doi.org/10.2174/1381612033455233.

(26) Kirk, K.; Lehane, A. M. Membrane Transport in the Malaria Parasite and Its Host Erythrocyte. Biochem. J. 2014, 457 (1), 1-18. https://doi.org/10.1042/BJ20131007.

(27) Kirk, K.; Howitt, S. M.; Bröer, S.; Saliba, K. J.; Downie, M. J. Purine Uptake in Plasmodium: Transport versus Metabolism. Trends Parasitol. 2009, $25 \quad$ (6), 246-249. https://doi.org/10.1016/j.pt.2009.03.006.

(28) Rager, N.; Mamoun, C. B.; Carter, N. S.; Goldberg, D. E.; Ullman, B. Localization of the Plasmodium Falciparum PfNT1 Nucleoside Transporter to the Parasite Plasma Membrane. J. Biol. Chem. 2001, 276 (44), 41095-41099. https://doi.org/10.1074/jbc.M107037200.

(29) Downie, M. J.; Kirk, K.; Mamoun, C. B. Purine Salvage Pathways in the Intraerythrocytic Malaria Parasite Plasmodium Falciparum. Eukaryot. Cell 2008, 7 (8), 1231-1237. https://doi.org/10.1128/EC.00159-08.

(30) Hyde, R. J.; Cass, C. E.; Young, J. D.; Baldwin, S. A. The ENT Family of Eukaryote Nucleoside and Nucleobase Transporters: Recent Advances in the Investigation of Structure/Function Relationships and the Identification of Novel Isoforms. Mol. Membr. Biol. 2001, 18 (1), 53-63.

(31) Riegelhaupt, P. M.; Cassera, M. B.; Fröhlich, R. F. G.; Hazleton, K. Z.; Hefter, J. J.; Schramm, V. L.; Akabas, M. H. Transport of Purines and Purine Salvage Pathway Inhibitors by the Plasmodium 
Falciparum Equilibrative Nucleoside Transporter PfENT1. Mol. Biochem. Parasitol. 2010, 169 (1), 40-49. https://doi.org/10.1016/j.molbiopara.2009.10.001.

(32) Sundaram, M.; Yao, S. Y. M.; Ingram, J. C.; Berry, Z. A.; Abidi, F.; Cass, C. E.; Baldwin, S. A.;

Young, J. D. Topology of a Human Equilibrative, Nitrobenzylthioinosine (NBMPR)-Sensitive Nucleoside Transporter (HENT1) Implicated in the Cellular Uptake of Adenosine and Anti-Cancer Drugs. J. Biol. Chem. 2001, 276 (48), 45270-45275. https://doi.org/10.1074/jbc.M107169200.

(33) Jiang, L.; Lee, P. C.; White, J.; Rathod, P. K. Potent and Selective Activity of a Combination of Thymidine and 1843U89, a Folate-Based Thymidylate Synthase Inhibitor, against Plasmodium Falciparum. Antimicrob. Agents Chemother. 2000, 44 (4), 1047-1050.

(34) Downie, M. J.; El Bissati, K.; Bobenchik, A. M.; Nic Lochlainn, L.; Amerik, A.; Zufferey, R.; Kirk, K.; Ben Mamoun, C. PfNT2, a Permease of the Equilibrative Nucleoside Transporter Family in the Endoplasmic Reticulum of Plasmodium Falciparum. J. Biol. Chem. 2010, 285 (27), 20827-20833. https://doi.org/10.1074/jbc.M110.118489.

(35) Frame, I. J.; Merino, E. F.; Schramm, V. L.; Cassera, M. B.; Akabas, M. H. Malaria Parasite Type 4 Equilibrative Nucleoside Transporters (ENT4) Are Purine Transporters with Distinct Substrate Specificity. Biochem. J. 2012, 446 (2), 179-190. https://doi.org/10.1042/BJ20112220.

(36) Deniskin, R.; Frame, I. J.; Sosa, Y.; Akabas, M. H. Targeting the Plasmodium Vivax Equilibrative Nucleoside Transporter 1 (PvENT1) for Antimalarial Drug Development. Int. J. Parasitol. Drugs Drug Resist. 2015, 6 (1), 1-11. https://doi.org/10.1016/j.ijpddr.2015.11.003.

(37) Arora, A.; Deniskin, R.; Sosa, Y.; Nishtala, S. N.; Henrich, P. P.; Kumar, T. R. S.; Fidock, D. A.; Akabas, M. H. Substrate and Inhibitor Specificity of the Plasmodium Berghei Equilibrative Nucleoside Transporter Type 1. Mol. Pharmacol. 2016, 89 (6), 678-685. https://doi.org/10.1124/mol.115.101386. 
(38) Keough, D.; Hockova, D.; Krecmerova, M.; Cesnek, M.; Holý, A.; Lieve, N.; Brereton, I.; J Winzor, D.; de Jersey, J.; Guddat, L. Plasmodium Vivax Hypoxanthine-Guanine Phosphoribosyltransferase: A Target for Anti-Malarial Chemotherapy. Mol. Biochem. Parasitol. 2010, 173, 165-169. https://doi.org/10.1016/j.molbiopara.2010.05.018.

(39) Reyes, P.; Rathod, P. K.; Sanchez, D. J.; Mrema, J. E.; Rieckmann, K. H.; Heidrich, H. G. Enzymes of Purine and Pyrimidine Metabolism from the Human Malaria Parasite, Plasmodium Falciparum. Mol. Biochem. Parasitol. 1982, 5 (5), 275-290.

(40) Keough, D. T.; Ng, A. L.; Winzor, D. J.; Emmerson, B. T.; de Jersey, J. Purification and Characterization of Plasmodium Falciparum Hypoxanthine-Guanine-Xanthine Phosphoribosyltransferase and Comparison with the Human Enzyme. Mol. Biochem. Parasitol. 1999, $98(1), 29-41$.

(41) Raman, J.; Ashok, C. S.; Subbayya, S. I. N.; Anand, R. P.; Selvi, S. T.; Balaram, H. Plasmodium Falciparum Hypoxanthine Guanine Phosphoribosyltransferase. FEBS J. 272 (8), 1900-1911. https://doi.org/10.1111/j.1742-4658.2005.04620.x.

(42) Xu, Y.; Eads, J.; Sacchettini, J. C.; Grubmeyer, C. Kinetic Mechanism of Human Hypoxanthine-Guanine Phosphoribosyltransferase: Rapid Phosphoribosyl Transfer Chemistry. Biochemistry 1997, 36 (12), 3700-3712. https://doi.org/10.1021/bi9616007.

(43) Sarkar, D.; Ghosh, I.; Datta, S. Biochemical Characterization of Plasmodium Falciparum Hypoxanthine-Guanine-Xanthine Phosphorybosyltransferase: Role of Histidine Residue in Substrate Selectivity. Mol. Biochem. Parasitol. 2004, $137 \quad$ (2), $267-276$. https://doi.org/10.1016/j.molbiopara.2004.05.014.

(44) Shi, W.; Li, C. M.; Tyler, P. C.; Furneaux, R. H.; Cahill, S. M.; Girvin, M. E.; Grubmeyer, C.; Schramm, V. L.; Almo, S. C. The 2.0 A Structure of Malarial Purine Phosphoribosyltransferase in 
Complex with a Transition State Analogue Inhibitor. Biochemistry 1999, 38 (31), 9872-9880. https://doi.org/10.1021/bi990664p.

(45) Roy, S.; Nagappa, L. K.; Prahladarao, V. S.; Balaram, H. Kinetic Mechanism of Plasmodium Falciparum Hypoxanthine-Guanine-Xanthine Phosphoribosyltransferase. Mol. Biochem. Parasitol. 2015, 204 (2), 111-120. https://doi.org/10.1016/j.molbiopara.2016.02.006.

(46) Madrid, D. C.; Ting, L.-M.; Waller, K. L.; Schramm, V. L.; Kim, K. Plasmodium Falciparum Purine Nucleoside Phosphorylase Is Critical for Viability of Malaria Parasites. J. Biol. Chem. 2008, 283 (51), 35899-35907. https://doi.org/10.1074/jbc.M807218200.

(47) Kicska, G. A.; Tyler, P. C.; Evans, G. B.; Furneaux, R. H.; Schramm, V. L.; Kim, K. Purine-Less Death in Plasmodium Falciparum Induced by Immucillin-H, a Transition State Analogue of Purine Nucleoside Phosphorylase. J. Biol. Chem. 2002, $277 \quad$ (5), 3226-3231. https://doi.org/10.1074/jbc.M105906200.

(48) Kicska, G. A.; Tyler, P. C.; Evans, G. B.; Furneaux, R. H.; Kim, K.; Schramm, V. L. Transition State Analogue Inhibitors of Purine Nucleoside Phosphorylase from Plasmodium Falciparum. J. Biol. Chem. 2002, 277 (5), 3219-3225. https://doi.org/10.1074/jbc.M105905200.

(49) Shi, W.; Ting, L.-M.; Kicska, G. A.; Lewandowicz, A.; Tyler, P. C.; Evans, G. B.; Furneaux, R. H.; Kim, K.; Almo, S. C.; Schramm, V. L. Plasmodium Falciparum Purine Nucleoside Phosphorylase: Crystal Structures, Immucillin Inhibitors, and Dual Catalytic Function. J. Biol. Chem. 2004, 279 (18), 18103-18106. https://doi.org/10.1074/jbc.C400068200.

(50) Schnick, C.; Robien, M. A.; Brzozowski, A. M.; Dodson, E. J.; Murshudov, G. N.; Anderson, L.; Luft, J. R.; Mehlin, C.; Hol, W. G. J.; Brannigan, J. A.; Wilkinson, A. J. Structures of Plasmodium Falciparum Purine Nucleoside Phosphorylase Complexed with Sulfate and Its Natural Substrate 
Inosine. Acta Crystallogr. D Biol. Crystallogr. 2005, $61 \quad$ (9), $1245-1254$. https://doi.org/10.1107/S0907444905020251.

(51) Kline, P. C.; Schramm, V. L. Pre-Steady-State Transition State Analysis of the Hydrolytic Reaction Catalyzed by Purine Nucleoside Phosphorylase. Biochemistry 1995, 34 (4), 1153-1162. https://doi.org/10.1021/bi00004a008.

(52) Lewandowicz, A.; Schramm, V. L. Transition State Analysis for Human and Plasmodium Falciparum Purine Nucleoside Phosphorylases. Biochemistry 2004, 43 (6), 1458-1468. https://doi.org/10.1021/bi0359123.

(53) Luo, M.; Singh, V.; Taylor, E. A.; Schramm, V. L. Transition state Variation in Human, Bovine, and Plasmodium Falciparum Adenosine Deaminases. J. Am. Chem. Soc. 2007, 129 (25), 8008-8017. https://doi.org/10.1021/ja072122y.

(54) Ting, L.-M.; Shi, W.; Lewandowicz, A.; Singh, V.; Mwakingwe, A.; Birck, M. R.; Ringia, E. A. T.; Bench, G.; Madrid, D. C.; Tyler, P. C.; Evans, G. B.; Furneaux, R. H.; Schramm, V. L.; Kim, K. Targeting a Novel Plasmodium Falciparum Purine Recycling Pathway with Specific Immucillins. J. Biol. Chem. 2005, 280 (10), 9547-9554. https://doi.org/10.1074/jbc.M412693200.

(55) Larson, E. T.; Deng, W.; Krumm, B. E.; Napuli, A.; Mueller, N.; Van Voorhis, W. C.; Buckner, F. S.; Fan, E.; Lauricella, A.; DeTitta, G.; Luft, J.; Zucker, F.; Holl, W. G. J.; Verlinde, C. L. M.; Merrit, E. A. Structures of Substrate- and Inhibitor-Bound Adenosine Deaminase from a Human Malaria Parasite Show a Dramatic Conformational Change and Shed Light on Drug Selectivity. J. Mol. Biol. 2008, 381 (4), 975-988. https://doi.org/10.1016/j.jmb.2008.06.048.

(56) Webster, H. K.; Wiesmann, W. P.; Pavia, C. S. Adenosine Deaminase in Malaria Infection: Effect of 2'-Deoxycoformycin in Vivo. Adv. Exp. Med. Biol. 1984, 165 Pt A, 225-229. 
(57) Mogire, R. M.; Akala, H. M.; Macharia, R. W.; Juma, D. W.; Cheruiyot, A. C.; Andagalu, B.;

Brown, M. L.; El-Shemy, H. A.; Nyanjom, S. G. Target-Similarity Search Using Plasmodium

Falciparum Proteome Identifies Approved Drugs with Anti-Malarial Activity and Their Possible

Targets. PLOS ONE 2017, 12 (10), e0186364. https://doi.org/10.1371/journal.pone.0186364.

(58) Hedstrom, L. IMP Dehydrogenase: Structure, Mechanism and Inhibition. Chem. Rev. 2009, 109

(7), 2903-2928. https://doi.org/10.1021/cr900021w.

(59) Fotie, J. Inosine 5'-Monophosphate Dehydrogenase (IMPDH) as a Potential Target for the Development of a New Generation of Antiprotozoan Agents. Mini Rev. Med. Chem. 2018, 18 (8), 656671. https://doi.org/10.2174/1389557516666160620065558.

(60) Raza, M.; Khan, Z.; Ahmad, A.; Raza, S.; Khan, A.; Mohammadzai, I. U.; Zada, S. In Silico 3-D Structure Prediction and Molecular Docking Studies of Inosine Monophosphate Dehydrogenase from Plasmodium Falciparum. Comput. Biol. Chem. 2017, 71, 10-19. https://doi.org/10.1016/j.compbiolchem.2017.09.002.

(61) Cuny, G. D.; Suebsuwong, C.; Ray, S. S. Inosine-5'-Monophosphate Dehydrogenase (IMPDH) Inhibitors: A Patent and Scientific Literature Review (2002-2016). Expert Opin. Ther. Pat. 2017, 27 (6), 677-690. https://doi.org/10.1080/13543776.2017.1280463.

(62) Bhat, J. Y.; Shastri, B. G.; Balaram, H. Kinetic and Biochemical Characterization of Plasmodium Falciparum GMP Synthetase. Biochem. J. 2008, $409 \quad$ (1), 263-273. https://doi.org/10.1042/BJ20070996.

(63) Ballut, L.; Violot, S.; Shivakumaraswamy, S.; Thota, L. P.; Sathya, M.; Kunala, J.; Dijkstra, B. W.; Terreux, R.; Haser, R.; Balaram, H.; Aghajari, N. Active Site Coupling in Plasmodium Falciparum GMP Synthetase Is Triggered by Domain Rotation. Nat. Commun. 2015, 6, 8930. https://doi.org/10.1038/ncomms9930. 
(64) Wang, C. C. Parasite Enzymes as Potential Targets for Antiparasitic Chemotherapy. J. Med. Chem. 1984, 27 (1), 1-9. https://doi.org/10.1021/jm00367a001.

(65) Keough, D. T.; Skinner-Adams, T.; Jones, M. K.; Ng, A.-L.; Brereton, I. M.; Guddat, L. W.; de Jersey, J. Lead Compounds for Antimalarial Chemotherapy: Purine Base Analogs Discriminate between Human and P. Falciparum 6-Oxopurine Phosphoribosyltransferases. J. Med. Chem. 2006, 49 (25), 7479-7486. https://doi.org/10.1021/jm061012j.

(66) Erb, N.; Harms, D. O.; Janka-Schaub, G. Pharmacokinetics and Metabolism of Thiopurines in Children with Acute Lymphoblastic Leukemia Receiving 6-Thioguanine versus 6-Mercaptopurine. Cancer Chemother. Pharmacol. 1998, 42 (4), 266-272. https://doi.org/10.1007/s002800050816.

(67) Trigg, P. I.; Gutteridge, W. E.; Williamson, J. The Effects of Cordycepin on Malaria Parasites. Trans. R. Soc. Trop. Med. Hyg. 1971, 65 (4), 514-520. https://doi.org/10.1016/0035-9203(71)90162-3.

(68) Kawasaki, Y. Mizoribine: A New Approach in the Treatment of Renal Disease. Clin. Dev. Immunol. 2009, 2009, 681482. https://doi.org/10.1155/2009/681482.

(69) Yokota, S. Mizoribine: Mode of Action and Effects in Clinical Use. Pediatr. Int. Off. J. Jpn. Pediatr. Soc. 2002, 44 (2), 196-198.

(70) Webster, H. K.; Whaun, J. M. Antimalarial Properties of Bredinin. Prediction Based on Identification of Differences in Human Host-Parasite Purine Metabolism. J. Clin. Invest. 1982, 70 (2), 461-469.

(71) Streeter, D. G.; Witkowski, J. T.; Khare, G. P.; Sidwell, R. W.; Bauer, R. J.; Robins, R. K.; Simon, L. N. Mechanism of Action of 1- $\beta$-D-Ribofuranosyl-1,2,4-Triazole-3-Carboxamide (Virazole), A New Broad-Spectrum Antiviral Agent. Proc. Natl. Acad. Sci. U. S. A. 1973, 70 (4), 1174-1178. 
(72) Thomas, E.; Ghany, M. G.; Liang, T. J. The Application and Mechanism of Action of Ribavirin in Therapy of Hepatitis C. Antivir. Chem. Chemother. 2012, 23 (1), 1-12. https://doi.org/10.3851/IMP2125.

(73) Keough, D. T.; Rejman, D.; Pohl, R.; Zborníková, E.; Hocková, D.; Croll, T.; Edstein, M. D.; Birrell, G. W.; Chavchich, M.; Naesens, L. M. J.; Pierens, G. K.; Brereton, I. M.; Guddat, L. W. Design of Plasmodium Vivax Hypoxanthine-Guanine Phosphoribosyltransferase Inhibitors as Potential Antimalarial Therapeutics. ACS Chem. Biol. 2018, $13 \quad$ (1), 82-90. https://doi.org/10.1021/acschembio.7b00916.

(74) Coomber, D. W. J.; O’Sullivan, W. J.; Gero, A. M. Adenosine Analogues as Antimetabolites against Plasmodium Falciparum Malaria. Int. J. Parasitol. 1994, $24 \quad$ (3), 357-365. https://doi.org/10.1016/0020-7519(94)90083-3.

(75) Gero, A. M.; Scott, H. V.; O’Sullivan, W. J.; Christopherson, R. I. Antimalarial Action of Nitrobenzylthioinosine in Combination with Purine Nucleoside Antimetabolites. Mol. Biochem. Parasitol. 1989, 34 (1), 87-97.

(76) Nakamura, J.; Lou, L. Biochemical Characterization of Human GMP Synthetase. J. Biol. Chem. 1995, 270 (13), 7347-7353. https://doi.org/10.1074/jbc.270.13.7347.

(77) McConkey, G. A. Plasmodium Falciparum: Isolation and Characterisation of a Gene Encoding Protozoan GMP Synthase. Exp. Parasitol. 2000, 94 (1), 23-32. https://doi.org/10.1006/expr.1999.4467. (78) Keough, D. T.; Hocková, D.; Rejman, D.; Špaček, P.; Vrbková, S.; Krečmerová, M.; Eng, W. S.; Jans, H.; West, N. P.; Naesens, L. M. J.; De Jersey, J.; Guddat, L. W. Inhibition of the Escherichia Coli 6-Oxopurine Phosphoribosyltransferases by Nucleoside Phosphonates: Potential for New Antibacterial Agents. J. Med. Chem. 2013, 56 (17), 6967-6984. https://doi.org/10.1021/jm400779n. 
(79) Young, J. D.; Jarvis, S. M. Nucleoside Transport in Animal Cells. Biosci. Rep. 1983, 3 (4), 309322. https://doi.org/10.1007/BF01122895.

(80) Parker, M. D.; Hyde, R. J.; Yao, S. Y. M.; Mcrobert, L.; Cass, C. E.; Young, J. D.; Mcconkey, G. A.; Baldwin, S. A. Identification of a Nucleoside/Nucleobase Transporter from Plasmodium Falciparum, a Novel Target for Anti-Malarial Chemotherapy. Biochem. J. 2000, 349 (1), 67-75. https://doi.org/10.1042/bj3490067.

(81) Schramm, V. L. Enzymatic Transition State Theory and Transition State Analogue Design. J. Biol. Chem. 2007, 282 (39), 28297-28300. https://doi.org/10.1074/jbc.R700018200.

(82) Tyler, P. C.; Taylor, E. A.; Fröhlich, R. F. G.; Schramm, V. L. Synthesis of 5'-Methylthio Coformycins: Specific Inhibitors for Malarial Adenosine Deaminase. J. Am. Chem. Soc. 2007, 129 (21), 6872-6879. https://doi.org/10.1021/ja0708363.

(83) Upston, J. M.; Gero, A. M. Parasite-Induced Permeation of Nucleosides in Plasmodium Falciparum Malaria. Biochim. Biophys. Acta 1995, 1236 (2), 249-258.

(84) Gero, A. M.; Perrone, G.; Brown, D. M.; Hall, S. T.; Chu, C. K. L-Purine Nucleosides as Selective Antimalarials. Nucleosides Nucleotides 1999, 18 (4-5), 885-889.

(85) Brown, D. M.; Netting, A. G.; Chun, B. K.; Choi, Y.; Chu, C. K.; Gero, A. M. L-Nucleoside Analogues as Potential Antimalarials That Selectively Target Plasmodium Falciparum Adenosine Deaminase. Nucleosides Nucleotides 1999, 18 (11-12), 2521-2532.

(86) Reist, E. J.; Gueffroy, D. E.; Blackford, R. W.; Goodman, L. Pyrrolodine Sugars. Synthesis of 4'Acetamidoadenosine and Other Derivatives of 4-Amino-4-Deoxy-D-Ribose. J. Org. Chem. 1966, 31 (12), 4025-4030. https://doi.org/10.1021/jo0135a033. 
(87) Miles, R. W.; Tyler, P. C.; Furneaux, R. H.; Bagdassarian, C. K.; Schramm, V. L. One-Third-theSites Transition State Inhibitors for Purine Nucleoside Phosphorylase. Biochemistry 1998, 37 (24), 8615-8621. https://doi.org/10.1021/bi980658d.

(88) Lewandowicz, A.; Ringia, E. A. T.; Ting, L.-M.; Kim, K.; Tyler, P. C.; Evans, G. B.; Zubkova, O. V.; Mee, S.; Painter, G. F.; Lenz, D. H.; Furneaux, R. H.; Schramm, V. L. Energetic Mapping of Transition State Analogue Interactions with Human and Plasmodium Falciparum Purine Nucleoside Phosphorylases. J. Biol. Chem. 2005, $280 \quad$ (34), 30320-30328. https://doi.org/10.1074/jbc.M505033200.

(89) Mason, J. M.; Murkin, A. S.; Li, L.; Schramm, V. L.; Gainsford, G. J.; Skelton, B. W. A BetaFluoroamine Inhibitor of Purine Nucleoside Phosphorylase. J. Med. Chem. 2008, 51 (18), 5880-5884. https://doi.org/10.1021/jm800792b.

(90) Taylor, E. A.; Clinch, K.; Kelly, P. M.; Li, L.; Evans, G. B.; Tyler, P. C.; Schramm, V. L. Acyclic Ribooxacarbenium Ion Mimics as Transition State Analogues of Human and Malarial Purine Nucleoside Phosphorylases. J. Am. Chem. Soc. 2007, 129 (22), 6984-6985. https://doi.org/10.1021/ja071087s.

(91) Clinch, K.; Evans, G. B.; Fröhlich, R. F. G.; Furneaux, R. H.; Kelly, P. M.; Legentil, L.; Murkin, A. S.; Li, L.; Schramm, V. L.; Tyler, P. C.; Woolhouse, A. D. Third-Generation Immucillins: Syntheses and Bioactivities of Acyclic Immucillin Inhibitors of Human Purine Nucleoside Phosphorylase. J. Med. Chem. 2009, 52 (4), 1126-1143. https://doi.org/10.1021/jm801421q.

(92) Clinch, K.; Evans, G. B.; Fleet, G. W. J.; Furneaux, R. H.; Johnson, S. W.; Lenz, D. H.; Mee, S. P. H.; Rands, P. R.; Schramm, V. L.; Ringia, E. A. T.; Tyler, P. C. Syntheses and Bio-Activities of the LEnantiomers of Two Potent Transition State Analogue Inhibitors of Purine Nucleoside Phosphorylases. Org. Biomol. Chem. 2006, 4 (6), 1131-1139. https://doi.org/10.1039/B517883E. 
(93) Lewandowicz, A.; Tyler, P. C.; Evans, G. B.; Furneaux, R. H.; Schramm, V. L. Achieving the Ultimate Physiological Goal in Transition State Analogue Inhibitors for Purine Nucleoside Phosphorylase. J. Biol. Chem. 2003, 278 (34), 31465-31468. https://doi.org/10.1074/jbc.C300259200.

(94) Cassera, M. B.; Hazleton, K. Z.; Merino, E. F.; Obaldia, N.; Ho, M.-C.; Murkin, A. S.; DePinto, R.; Gutierrez, J. A.; Almo, S. C.; Evans, G. B.; Babu, Y. S.; Schramm, V. L. Plasmodium Falciparum Parasites Are Killed by a Transition State Analogue of Purine Nucleoside Phosphorylase in a Primate Animal Model. PloS One 2011, 6 (11), e26916. https://doi.org/10.1371/journal.pone.0026916.

(95) Taylor Ringia, E. A.; Schramm, V. L. Transition States and Inhibitors of the Purine Nucleoside Phosphorylase Family. Curr. Top. Med. Chem. 2005, 5 (13), 1237-1258.

(96) Cui, H.; Ruda, G. F.; Carrero-Lérida, J.; Ruiz-Pérez, L. M.; Gilbert, I. H.; González-Pacanowska, D. Exploring New Inhibitors of Plasmodium Falciparum Purine Nucleoside Phosphorylase. Eur. J. Med. Chem. 2010, 45 (11), 5140-5149. https://doi.org/10.1016/j.ejmech.2010.08.026.

(97) Gumina, G.; Chong, Y.; Choo, H.; Song, G.-Y.; Chu, C. K. L-Nucleosides: Antiviral Activity and Molecular Mechanism. Curr. Top. Med. Chem. 2002, 2 (10), 1065-1086.

(98) Gumina, G.; Song, G. Y.; Chu, C. K. L-Nucleosides as Chemotherapeutic Agents. FEMS Microbiol. Lett. 2001, $202(1), 9-15$.

(99) Mathé, C.; Gosselin, G. L-Nucleoside Enantiomers as Antivirals Drugs: A Mini-Review. Antiviral Res. 2006, 71 (2-3), 276-281. https://doi.org/10.1016/j.antiviral.2006.04.017.

(100) Li, C. M.; Tyler, P. C.; Furneaux, R. H.; Kicska, G.; Xu, Y.; Grubmeyer, C.; Girvin, M. E.; Schramm, V. L. Transition state Analogs as Inhibitors of Human and Malarial Hypoxanthine-Guanine Phosphoribosyltransferases. Nat. Struct. Biol. 1999, 6 (6), 582-587. https://doi.org/10.1038/9367.

(101) Hazleton, K. Z.; Ho, M.-C.; Cassera, M. B.; Clinch, K.; Crump, D. R.; Rosario, I.; Merino, E. F.; Almo, S. C.; Tyler, P. C.; Schramm, V. L. Acyclic Immucillin Phosphonates: Second-Generation 
Inhibitors of Plasmodium Falciparum Hypoxanthine-Guanine-Xanthine Phosphoribosyltransferase.

Chem. Biol. 2012, 19 (6), 721-730. https://doi.org/10.1016/j.chembiol.2012.04.012.

(102) Ho, M.-C.; Shi, W.; Rinaldo-Matthis, A.; Tyler, P. C.; Evans, G. B.; Clinch, K.; Almo, S. C.;

Schramm, V. L. Four Generations of Transition State Analogues for Human Purine Nucleoside Phosphorylase. Proc. Natl. Acad. Sci. U.S.A. 2010, 107 (11), 4805-4812. https://doi.org/10.1073/pnas.0913439107.

(103) Ducati, R. G.; Namanja-Magliano, H. A.; Harijan, R. K.; Fajardo, J. E.; Fiser, A.; Daily, J. P.; Schramm, V. L. Genetic Resistance to Purine Nucleoside Phosphorylase Inhibition in Plasmodium Falciparum. Proc. Natl. Acad. Sci. U.S.A. 2018, 115 (9), 2114-2119. https://doi.org/10.1073/pnas.1525670115.

(104) DeClercq, E.; Descamps, J.; Somer, P. D.; Holý, A. (S)-9-(2,3-Dihydroxypropyl)Adenine: An Aliphatic Nucleoside Analog with Broad-Spectrum Antiviral Activity. Science 1978, 200 (4341), 563565. https://doi.org/10.1126/science.200.4341.563.

(105) Elion, G. B.; Furman, P. A.; Fyfe, J. A.; de Miranda, P.; Beauchamp, L.; Schaeffer, H. J. Selectivity of Action of an Antiherpetic Agent, 9-(2-Hydroxyethoxymethyl) Guanine. Proc. Natl. Acad. Sci. U. S. A. 1977, 74 (12), 5716-5720.

(106) De Clercq, E.; Holý, A.; Rosenberg, I.; Sakuma, T.; Balzarini, J.; Maudgal, P. C. A Novel Selective Broad-Spectrum Anti-DNA Virus Agent. Nature 1986, 323 (6087), 464-467. https://doi.org/10.1038/323464a0.

(107) De Clercq, E.; Sakuma, T.; Baba, M.; Pauwels, R.; Balzarini, J.; Rosenberg, I.; Holý, A. Antiviral Activity of Phosphonylmethoxyalkyl Derivatives of Purine and Pyrimidines. Antiviral Res. 1987, 8 (56), 261-272. 
(108) De Clercq, E. The Clinical Potential of the Acyclic (and Cyclic) Nucleoside Phosphonates. The Magic of the Phosphonate Bond. Biochem. Pharmacol. 2011, 82 (2), 99-109. https://doi.org/10.1016/j.bcp.2011.03.027.

(109) Thornton, P. J.; Kadri, H.; Miccoli, A.; Mehellou, Y. Nucleoside Phosphate and Phosphonate Prodrug Clinical Candidates. J. Med. Chem. 2016, 59 (23), 10400-10410. https://doi.org/10.1021/acs.jmedchem.6b00523.

(110) Pouvelle, B.; Gormley, J. A.; Taraschi, T. F. Characterization of Trafficking Pathways and Membrane Genesis in Malaria-Infected Erythrocytes. Mol. Biochem. Parasitol. 1994, 66 (1), 83-96. https://doi.org/10.1016/0166-6851(94)90038-8.

(111) Pradere, U.; Garnier-Amblard, E. C.; Coats, S. J.; Amblard, F.; Schinazi, R. F. Synthesis of Nucleoside Phosphate and Phosphonate Prodrugs. Chem. Rev. 2014, 114 (18), 9154-9218. https://doi.org/10.1021/cr5002035.

(112) Wiemer, A. J.; Wiemer, D. F. Prodrugs of Phosphonates and Phosphates: Crossing the Membrane Barrier. Top. Curr. Chem. 2015, 360, 115-160. https://doi.org/10.1007/128_2014_561.

(113) Hadziyannis, S. J.; Tassopoulos, N. C.; Heathcote, E. J.; Chang, T.-T.; Kitis, G.; Rizzetto, M.; Marcellin, P.; Lim, S. G.; Goodman, Z.; Wulfsohn, M. S.; Xiong, S.; Fry, J.; Brosgart, C. L. Adefovir Dipivoxil for the Treatment of Hepatitis B \& Antigen-Negative Chronic Hepatitis B. N. Engl. J. Med. 2003, 348 (9), 800-807. https://doi.org/10.1056/NEJMoa021812.

(114) Robbins, B. L.; Srinivas, R. V.; Kim, C.; Bischofberger, N.; Fridland, A. Anti-Human Immunodeficiency Virus Activity and Cellular Metabolism of a Potential Prodrug of the Acyclic Nucleoside Phosphonate 9-R-(2-Phosphonomethoxypropyl)Adenine (PMPA), Bis(Isopropyloxymethylcarbonyl)PMPA. Antimicrob. Agents Chemother. 1998, 42 (3), 612-617. 
(115) de Vries, E.; Stam, J. G.; Franssen, F. F. J.; Nieuwenhuijs, H.; Chavalitshewinkoon, P.; de Clercq, E.; Prosper Overdulve, J.; van der Vliet, P. C. Inhibition of the Growth of Plasmodium Falciparum and Plasmodium Berghei by the DNA Polymerase Inhibitor HPMPA. Mol. Biochem. Parasitol. 1991, 47 (1), 43-50. https://doi.org/10.1016/0166-6851(91)90146-W.

(116) Smeijsters, L. J.; Nieuwenhuijs, H.; Hermsen, R. C.; Dorrestein, G. M.; Franssen, F. F.; Overdulve,

J. P. Antimalarial and Toxic Effects of the Acyclic Nucleoside Phosphonate (S)-9-(3-Hydroxy-2Phosphonylmethoxypropyl)Adenine in Plasmodium Berghei-Infected Mice. Antimicrob. Agents Chemother. 1996, 40 (7), 1584-1588.

(117) Smeijsters, L. J.; Franssen, F. F.; Naesens, L.; de Vries, E.; Holý, A.; Balzarini, J.; de Clercq, E.; Overdulve, J. P. Inhibition of the in Vitro Growth of Plasmodium Falciparum by Acyclic Nucleoside Phosphonates. Int. J. Antimicrob. Agents 1999, 12 (1), 53-61.

(118) Keough, D. T.; Hocková, D.; Holý, A.; Naesens, L. M. J.; Skinner-Adams, T. S.; Jersey, J. de; Guddat, L. W. Inhibition of Hypoxanthine-Guanine Phosphoribosyltransferase by Acyclic Nucleoside Phosphonates: A New Class of Antimalarial Therapeutics. J. Med. Chem. 2009, 52 (14), 4391-4399. https://doi.org/10.1021/jm900267n.

(119) Hocková, D.; Holý, A.; Masojídková, M.; Keough, D. T.; de Jersey, J.; Guddat, L. W. Synthesis of Branched 9-[2-(2-Phosphonoethoxy)Ethyl]Purines as a New Class of Acyclic Nucleoside Phosphonates Which Inhibit Plasmodium Falciparum Hypoxanthine-Guanine-Xanthine Phosphoribosyltransferase. Bioorg. Med. Chem. 2009, 17 (17), 6218-6232. https://doi.org/10.1016/j.bmc.2009.07.044.

(120) Česnek, M.; Hocková, D.; Holý, A.; Dračínský, M.; Baszczyňski, O.; Jersey, J. de; Keough, D. T.; Guddat, L. W. Synthesis of 9-Phosphonoalkyl and 9-Phosphonoalkoxyalkyl Purines: Evaluation of Their Ability to Act as Inhibitors of Plasmodium Falciparum, Plasmodium Vivax and Human 
Hypoxanthine-Guanine-(Xanthine) Phosphoribosyltransferases. Bioorg. Med. Chem. 2012, 20 (2), 1076-1089. https://doi.org/10.1016/j.bmc.2011.11.034.

(121) Krečmerová, M.; Dračínský, M.; Hocková, D.; Holý, A.; Keough, D. T.; Guddat, L. W. Synthesis of Purine N9-[2-Hydroxy-3-O-(Phosphonomethoxy)Propyl] Derivatives and Their Side-Chain Modified Analogs as Potential Antimalarial Agents. Bioorg. Med. Chem. 2012, 20 (3), 1222-1230. https://doi.org/10.1016/j.bmc.2011.12.034.

(122) Kaiser, M. M.; Hocková, D.; Wang, T.-H.; Dračínský, M.; Poštová-Slavětínská, L.; Procházková, E.; Edstein, M. D.; Chavchich, M.; Keough, D. T.; Guddat, L. W.; Janeba, Z. Synthesis and Evaluation of Novel Acyclic Nucleoside Phosphonates as Inhibitors of Plasmodium Falciparum and Human 6Oxopurine Phosphoribosyltransferases. ChemMedChem 2015, 10 (10), 1707-1723. https://doi.org/10.1002/cmdc.201500322.

(123) Clinch, K.; Crump, D. R.; Evans, G. B.; Hazleton, K. Z.; Mason, J. M.; Schramm, V. L.; Tyler, P. C. Acyclic Phosph(on)Ate Inhibitors of Plasmodium Falciparum Hypoxanthine-Guanine-Xanthine Phosphoribosyltransferase. Bioorg. Med. Chem. 2013, 21 (17), 5629-5646. https://doi.org/10.1016/j.bmc.2013.02.016.

(124) Baszczyňski, O.; Hocková, D.; Janeba, Z.; Holý, A.; Jansa, P.; Dračínský, M.; Keough, D. T.; Guddat, L. W. The Effect of Novel [3-Fluoro-(2-Phosphonoethoxy)Propyl]Purines on the Inhibition of Plasmodium Falciparum, Plasmodium Vivax and Human Hypoxanthine-Guanine-(Xanthine) Phosphoribosyltransferases. Eur. J. Med. Chem. 2013, 67, 81-89. https://doi.org/10.1016/j.ejmech.2013.06.032.

(125) Keough, D. T.; Špaček, P.; Hocková, D.; Tichý, T.; Vrbková, S.; Slavětínská, L.; Janeba, Z.; Naesens, L.; Edstein, M. D.; Chavchich, M.; Wang, T. H.; De Jersey, J.; Guddat, L. W. Acyclic Nucleoside Phosphonates Containing a Second Phosphonate Group Are Potent Inhibitors of 6- 
Oxopurine Phosphoribosyltransferases and Have Antimalarial Activity. J. Med. Chem. 2013, 56 (6), 2513-2526. https://doi.org/10.1021/jm301893b.

126) Tichý, T.; Andrei, G.; Snoeck, R.; Balzarini, J.; Dračínský, M.; Krečmerová, M. Synthesis and Antiviral Activities of Hexadecyloxypropyl Prodrugs of Acyclic Nucleoside Phosphonates Containing Guanine or Hypoxanthine and a (S)-HPMP or PEE Acyclic Moiety. Eur. J. Med. Chem. 2012, 55, $307-$ 314. https://doi.org/10.1016/j.ejmech.2012.07.027.

(127) Špaček, P.; Keough, D. T.; Chavchich, M.; Dračínský, M.; Janeba, Z.; Naesens, L.; Edstein, M. D.; Guddat, L. W.; Hocková, D. Synthesis and Evaluation of Asymmetric Acyclic Nucleoside Bisphosphonates as Inhibitors of Plasmodium Falciparum and Human Hypoxanthine-Guanine(Xanthine) Phosphoribosyltransferase. $\quad J . \quad$ Med. Chem. 2017, 60 (17), 7539-7554. https://doi.org/10.1021/acs.jmedchem.7b00926.

(128) Hocková, D.; Keough, D. T.; Janeba, Z.; Wang, T.-H.; de Jersey, J.; Guddat, L. W. Synthesis of Novel N-Branched Acyclic Nucleoside Phosphonates as Potent and Selective Inhibitors of Human, Plasmodium Falciparum and Plasmodium Vivax 6-Oxopurine Phosphoribosyltransferases. J. Med. Chem. 2012, 55 (13), 6209-6223. https://doi.org/10.1021/jm300662d.

(129) Keough, D. T.; Hocková, D.; Janeba, Z.; Wang, T.-H.; Naesens, L.; Edstein, M. D.; Chavchich, M.; Guddat, L. W. Aza-Acyclic Nucleoside Phosphonates Containing a Second Phosphonate Group as Inhibitors of the Human, Plasmodium Falciparum and Vivax 6-Oxopurine Phosphoribosyltransferases and Their Prodrugs as Antimalarial Agents. J. Med. Chem. 2015, 58 (2), 827-846. https://doi.org/10.1021/jm501416t.

(130) Lukáč, M.; Hocková, D.; Keough, D. T.; Guddat, L. W.; Janeba, Z. Novel Nucleotide Analogues Bearing (1H-1,2,3-Triazol-4-Yl)Phosphonic Acid Moiety as Inhibitors of Plasmodium and Human 6- 
Oxopurine Phosphoribosyltransferases. Tetrahedron 2017, $73 \quad$ (6), 692-702. https://doi.org/10.1016/j.tet.2016.12.046. 


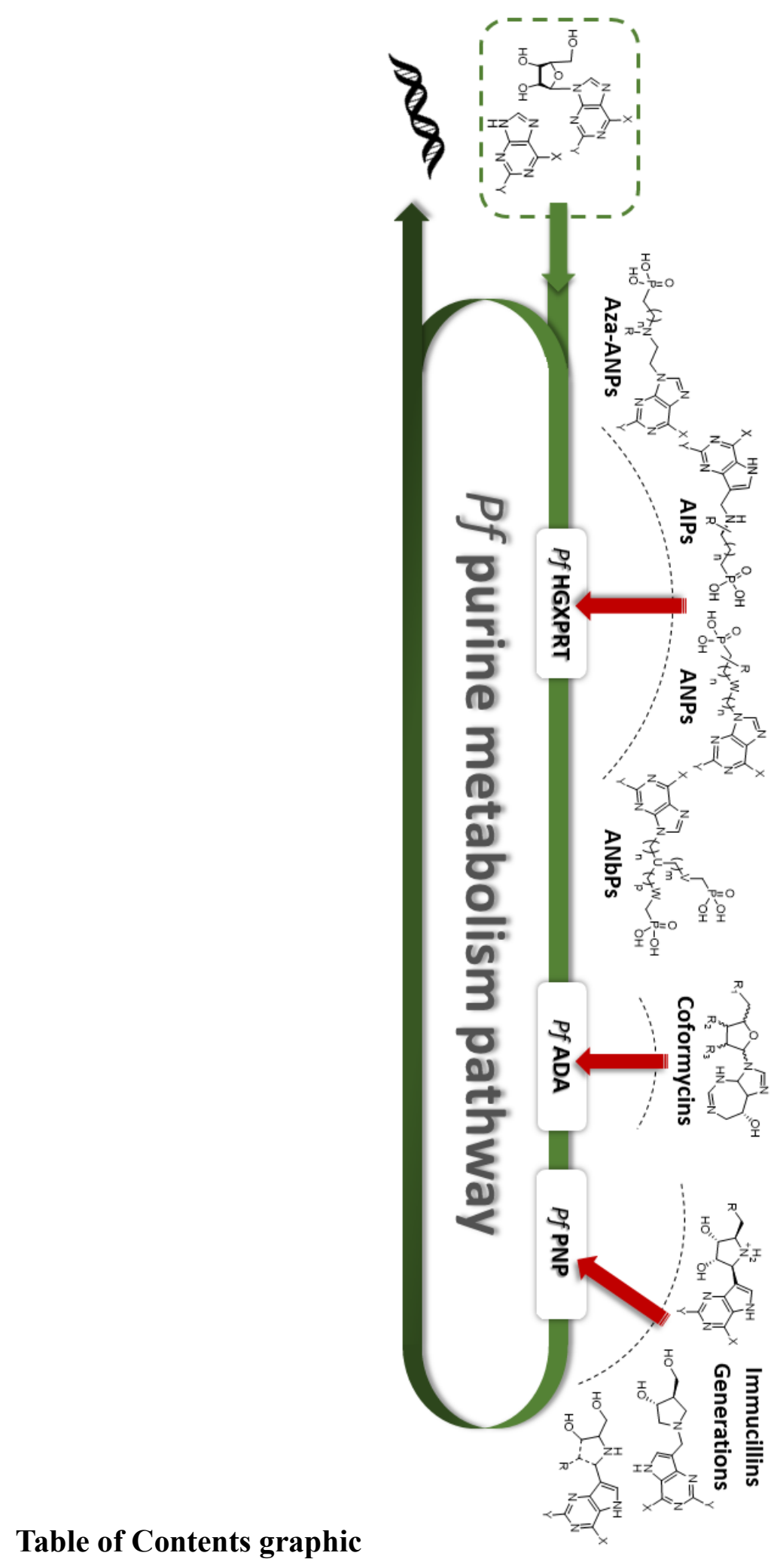

